COAL LIQUEFACTION PROCESS STREAMS

CHARACTERIZATION AND EVALUATION

Solid-State NMR Characterization of Coal Llquefaction Products

Toplcal Report

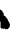

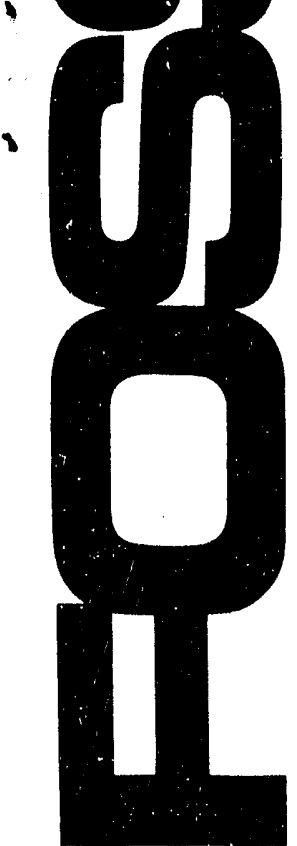

By

Francls P. Miknis

November 1991

Work Performed Under Contract No. AC22-89PC89883

For

U.S. Department of Energy

PIttsburgh Energy Technology Center

Pittsburgh, Pennsylvania

By

Western Research Institute

Laramle, Wyoming 


\section{DISCLAIMER}

This report was prepared as an account of work sponsored by an agency of the United States Government. Neither the United States Government nor any agency thereof, nor any of their employees, makes any warranty, express or implied, or assumes any legal liability or responsibility for the accuracy, completeness, or usefulness of any information, apparatus, product, or process disclosed, or represents that its use would not infringe privately owned rights. Reference herein to any specific commercial product, process, or service by trade name, trademark, manufacturer, or otherwise does not necessarily constitute or imply its endorsement, recommendation, or favoring by the United States Government or any agency thereof. The views and opinions of authors expressed herein do not necessarily state or reflect those of the United States Government or any agency thereof.

This report has been reproduced directly from the best available copy.

Available to DOE and DOE contractors from the Office of Scientific and Technical Information, P.O. Box 62, Oak Ridge, TN 37831; prices available from (615)576-8401, FTS 626-8401.

Available to the public from the National Technical Information Service, U. S. Department of Commerce, 5285 Port Royal Rd., Springfield, VA 22161. 


\title{
COAL LIQUEFACTION PROCESS STREAMS CHARACTERIZATION AND EVALUATION
}

\author{
Solid-State NMR Characterization \\ of Coal Liquefaction Products \\ Topical Report \\ Prepared by:
Western Research Institute
P.0. Box 3395
University Station
Laramie, WY
Francis P. Miknis

Prepared for:

\author{
CONSOLIDATION COAL COMPANY \\ Research \& Development \\ 4000 Brownsville Road \\ Library, PA 15129 \\ F. P. Burke \\ R. A. Winschel \\ S. D. Brandes
}

November 1991

\author{
Under Contract to: \\ United States Department of Energy \\ Contract No. DE-AC22-89PC89883
}

U.S. DOE Patent Clearance was provided by Chicago Operations office on $11 / 13 / 91$ 


\section{PROJECT ASSESSHENT}

\section{Introduction}

Under subcontract to Consolidation Coal Co. (U.S. DOE Contract No. DE-AC22-89P(89883), Western Research Institute examined solid- and liquid-state ${ }^{13} \mathrm{C}$ and ${ }^{1} \mathrm{H}$ nuclear magnetic resonance (NMR) analysis for use in support of coal liquefaction process development. The full report authored by the WRI researchers is presented here. The following assessment briefly highlights the major findings of the project, and provides Consol's evaluation of the potential of the method for application to coal-derived materials. These results will be incorporated by consol into a general overview of the application of novel analytical techniques to coal-derived materials.

\section{Summary}

This study clearly demonstrated the usefulness of liquid-and solid-state ${ }^{13} \mathrm{C}$ - and ${ }^{1} \mathrm{H}-\mathrm{NMR}$ for the examination of process-derived materials from direct coal liquefaction. The techniques can provide data not directly obtainable by other methods to examine the saturation of aromatic rings and to determine the modes of hydrogen utilization during coal liquefaction. In addition, these methods can be used to infer the extent of condensation and retrograde reactions occurring in the direct coal i iquefaction process. Five NMR techniques were employed. Solid-state ${ }^{13} \mathrm{C}$-NMR measurements were made using the Cross Polarization Magic Angle Spinning (CP/MAS) and Single Pulse (SP) techniques. Solid-state ${ }^{1} H$-NMR measurements were made using the technique of Combined Rotation and Multiple-Pulse Spectroscopy (CRAMPS). Conventional liquid-state ${ }^{12} \mathrm{C}$ - and ${ }^{1} H$-NMR techniques were employed as appropriate. Interpretation of the NMR data, once obtained, is relatively straightforward. Combined with other information, such as elemental analyses and process conversion data, the NMR data prove to be a powerful tool for the examination of direct coal liquefaction process-derived material. Further development and more wide-spread application of this analytical method as a process development tool is justified on the basis of these results. 


\section{Program Description}

This report describes the work performed at Western Research Institute under a subcontract to Consolidation Coal Co., Research and Development. Consol's prime contract to the U.S. Department of Energy (Contract No. DE-AC22-89PC89883, "Coal Liquefaction Process Streams Characterization and Evaluation") established a program for the analysis of direct coal liquefaction materials. The program involves a number of participating organizations whose analytical expertise is being applied to these materials. This Participants Program has two main objectives. The broad objective is to improve our understanding of fundamental coal liquefaction chemistry to facilitate process improvement and new process development. The specific approach to achieving this objective is to provide a bridge between direct coal liquefaction process development and analytical chemistry by demonstrating the application of various advanced analytical methods to coal liquefaction materials. The methodologies (or techniques) of interest are those which are novel in their application for the support of coal liquefaction process development and those which have not been fully demonstrated in this application. Consol is providing well-documented samples from different continuous direct coal liquefaction facilities to the program participants. The participants are required to interpret their analytical data in context to the processing conditions under which the samples were generated. The methodology employed is then evaluated for its usefulness in analyzing direct coal liquefaction-derived materials.

\section{Participant's Methodology}

WRI used solid-and liquid-state ${ }^{13} \mathrm{C}$ - and ${ }^{1} \mathrm{H}$-NMR to analyze nineteen samples. The sample set consisted of four coals, six coal liquefaction distillation resids $\left(850^{\circ} \mathrm{F}^{+}\right)$, two coal liquefaction process distillates, and one coal liquefaction ash concentrate. The resids are solid at room temperature and contain THF-soluble and insoluble organics and mineral matter. The samples were produced at two different continuous liquefaction facilities: the Wilsonville pilot plant and the Hydrocarbon Research Inc. (HRI) bench unit. The major processing parameter varied among the Wilsonville runs was feed coal. Samples from Wilsonville were taken from 
five locations around the plant. These samples are expected to represent different extents of coal liquefaction. Some of the Wilsonville samples were composites of samples taken over long periods of single runs; others were samples obtained from a single run day. The samples from HRI also were chosen to represent material which had undergone different degrees of processing and were obtained from different plant locations.

\section{Participant's Major Findings}

The following principal observations for the application of solid-and liquid-state ${ }^{13} \mathrm{C}$ - and ${ }^{1} \mathrm{H}$-NMR to coal liquefaction materials were reported by WRI. An expanded discussion can be found in the attached report, pages 5 through 19.

${ }^{13} \mathrm{C}$ - and ${ }^{9} \mathrm{H}$-NMR measurements were used to obtain the aromatic $\mathrm{H} / \mathrm{C}$ ratio of the feed coals and liquefaction products of Wilsonville Runs 251-II, 257 and 259. This information was used to assess the relative degree of condensation of samples at different stages in the liquefaction process. Little difference in the aromatic $H / C$ ratio was observed in interstage and second stage product samples obtained from the same wilsonville run. Though the interpretation of this observation is not conclusive, it can be inferred that neither condensation reactions nor the reduction of aromatic-ring cluster size are extensive in the second stage.

${ }^{13} \mathrm{C}$-NMR data were collected on a set of samples obtained from different sampling points during a single run period at the wilsonville facility (Run 259G). The NMR data were used along with elemental analyses and mass balance data to examine the progress of aromatic carbon saturation at various stages of 1 iquefaction About $58 \%$ of the aromatic carbon in Pittsburgh coal was saturated through the process, most of it in the second staga. The modes of hydrogen utilization during the same Wilsonville run were determined using the same set of NMR, analytical and mass balance data according to a slightly modified version of the method of Firseth et al. ' It was shown that aromatic ring saturation consumes most of the hydrogen in the two-stage liquefaction process. This is followed by hydrogen consumed by coal matrix cleavage, by the pror $\%$ n 
of heterogases, by the production of hydrocarbon gases $\left(C_{1} \times C_{6}\right)$ through hydrogenolysis, and by that consumed to renlace carbon-heteroatom honds with carbon-hydrogen bonds through hydrogenolysis. Almost all of the hydrogen consumed by matrix cleavage is consumed in the first stage. Additionally, the first stage accounts for about $70 \%$ of the hydrogen consumption for total gas production, i.e., for hydrogenolys is to produce hydrocarbon gases and heterogases and for the hydrogen contained in heterogases. Two-thirds of the hydrogen consumed in the second stage is consumed by saturation of aromatic rings.

The NMR measurements provided quantitation of numerous carbon and hydrogen types that could, in theory, be used as pseudo-components for lumped kinetic modeling in a manner similar to that of Chen and Schindler. ${ }^{2}$

Repeat measurements showed that reproducible aromaticity measurements could be made on a routine basis. SP and CP/MAS measurements agreed we 11 for coal but not as well for the coal liquids.

\section{Consol Evaluation}

Solid-state NMR appears to be the most direct means to obtain the aromaticity value of solids-containing process streams. This useful piece of information, when combined with the mass balances and the elemental analyses of the materials analyzed, provides information on the degree of hydrogenation and modes of hydrogen utilization during coal liquefaction. Additionally, the extent of condensation or retrograde reactions that occur in the various product streams can be inferred from this measurement .

The precision of the techniques examined is high. The aromaticity measurements of the same samples are highly reproducible. The SP and CP/MAS techniques give good agreement for the aromaticity of coals; there is also good agreement with findings of other laboratories for different samples of coal from the same seam. The solid-state ${ }^{13} \mathrm{C}$-NMR techniques can be fairly rapid, requiring about one-half hour per sample for data acquisition to obtain adequate signal-to-noise ratios. The initial 
capital investment for a $100 \mathrm{Mhz}$ instrument with the appropriate equipment for CRAMPS measurements is approximately $\$ 175,000$. The labor costs are relatively low. Sample preparation is minimal, requiring only that the sample be uniformly ground and uniformly packed into the NMR tube. Samples need not be ground smaller than 100 mesh $(150 \mu \mathrm{m})$. Solidstate ${ }^{1} H$-NMR and 1 iquid NMR require only 1-2 minutes data acquisition time. There is, however, some time required to do the set-up for the CRAMPS procedure. Once the initial set-up is done, the sample preparation and examination can be done by a laboratory technician. Computer integration of sample signal provides quantitative information. Visual inspection of CRAMPS spectra can provide qualitative information.

\section{Further Development}

The information obtainable with the solid-state NMR techniques could be used to develop a lumped kinetic model for coal liquefaction. Because of the lower resolution of the solid-state measurements, spectral curvefitting techniques may need to be employed to obtain the necessary structural parameters for input to the kinetic model.

\section{Participant's Statement of Work}

Solid-state nuclear magnetic resonance (NMR) techniques have been applied to various fuel materials such as coals and shales; however, little work has been done to utilize solid-siate NMR for analysis of coal liquefaction process streams. As such, this technique is novel and fits within the scope of the participants program.

Four applications of this technique will be explored in this work.

1. Aromatic hydrogen to aromatic carbon ratios will be determined for a suite of coals and coal liquefaction sample distillation resids via solid state ${ }^{13} \mathrm{C}$ and ${ }^{1} \mathrm{H}$-NMR.

2. A carbon aromaticity balance will be determined to gain a more fundamental understanding of the chemistry associated with each 
stage of the liquefaction process starting with the feed coal for two different processes (Wilsonville and HRI).

3. Each spectrum generated will be deconvoluted to measure pseudocomponent contents of coals and resids to partially evaluate the use of the technique to generate data for an extended lumped kinetic model.

4. A hydrogen balance will be made over the Wilsonville plant based NMR data, and information provided to WRI by Consol, using the method of Finseth et al."

Consol will supply to WRI seventeen well documented samples (four coals, six non-distillable resids, two process distillates, and fiveprocess oils), as designated in the attached list, for solid-state and liquid NMR analyses. Each process $0 i 1$ and resid sample will be supplied to WRI with the following information as appropriate and as available: elemental analysis, ash content, ash elemental analysis, phenolic - $\mathrm{OH}$ concentration, calorific value, hydrogen classes by $1 \mathrm{H}-\mathrm{NMR}$, and the full history of the resid samples ( $p l a n t$, process conditions, age, storage conditions, total hydrogen consumption, and heteroatom and hydrocarbon gas yield data for the associated run). The coal samples will be supplied with a proximate and ultimate analysis and will be supplied ground to pass 100 mesh $(0.15 \mathrm{~mm})$. The resids are brittle pitch-like materials, and will be supplied as particles which pass approximately 8 mesh $(2.4 \mathrm{~mm})$. All resid and process oil samples may contain ash. Sample size will be at least $5 \mathrm{~g}$. These seventeen samples will form.a basis for an evaluation of the method.

The two process distillates will be analyzed by WRI using conventional liquid NMR techniques. The remaining samples will be analyzed by $W^{r}$ utilizing the following methodology. Carbon aromaticity measurements will be made at a $13 \mathrm{C}$ frequency of $25 \mathrm{MHz}$ on a Chemagnetics CMX-100/200 solids NMR spectrometer. Cross-Polarization Magic-Angle Spinning (CP/MAS) experiments will be employed using a $9.5 \mathrm{~mm}$ zirconia spinner. Carbon aromaticity measurements will be made using currently accepted NMR parameters. Hydrogen aromaticity measurements will be made at a $1 H$ 
frequency of $200 \mathrm{MHz}$ on a Chemagnetics CMX-100/200 solids NMR spectrometer using the technique of combined rotation and multiple pulse spectroscopy (CRAMPS). Replicate analyses will be performed as necessary to assess reproducibility. At least one of the coals, one of the resids and one of the whole process oils will be analyzed by the single-pulse magic angle spinning (SP/MAS) method to provide data for comparison with those generated by the CP/MAS method.

The deconvolution of the spectra to component classes (or psuedocomponents) will be done for each sample. Component classes will include, as a minimum, $H_{a r}, C_{a r}, H_{a r} / C_{a r}, C_{\text {cartionyl }}, H_{a l i p h .}, C_{a l i p h}$ and $H_{a l i p h} / C_{a l i p h}$. Additional component classes will be provided as available. Hydrogen accounting techniques will be applied to the samples designated as Nos. $2,14,15$ and 17 .

\section{References}

1. Finseth, D. H.; Ci110, D. L.; Sprecher, R. F.; Retcofsky, H. L.; Lett, R. G. Fuel 1985, 64, 1718.

2. Chen, J. M.; Schindler, H. D.; Ind. Eng. Chem. Res. 1987, 26, 921. 
$\underset{\text { The University of Wyoming Research Corporation }}{T}$

\section{SOLID-STATE NMR \\ CHARACTERIZATION OF COAL LIQUEFACTION PRODUCTS}

Prepared for

Consolidation Coal Company

Library, PA

August 1991

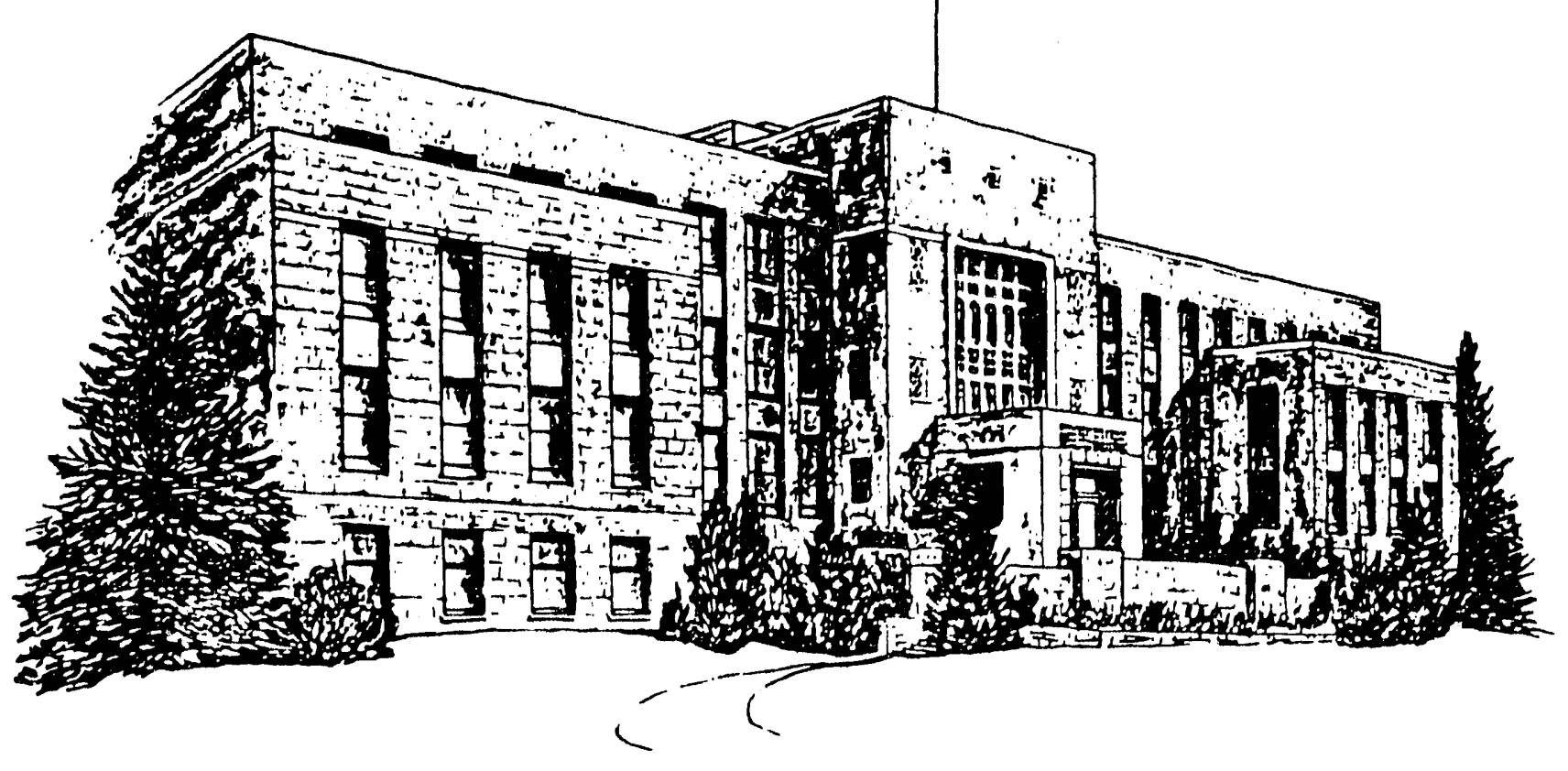


Solid-State NMR Characterization of Coal Liquefaction Products

By

Francis P. Miknis

August 1991

Work Performed Under Subcontract for

DOE Contract DE-AC22-89PC89883

For

Consolidation Coal Company

Library, PA

By

The University of Wyoming Research Corporation

a.k.a. Western Research Institute

Laramie, WY 


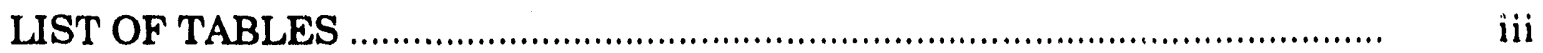

LIST OF FIGURES ……........................................................................ iv

EXECUTIVE SUMMARY ................................................................... v

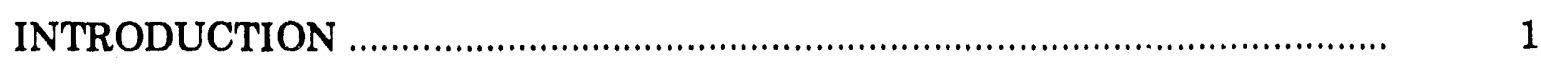

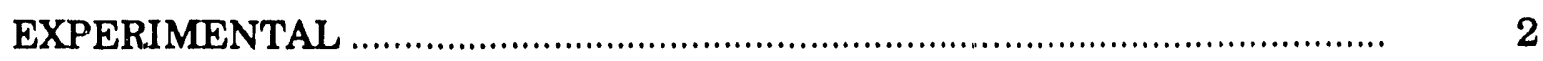

NMR Measurements .................................................................... 2

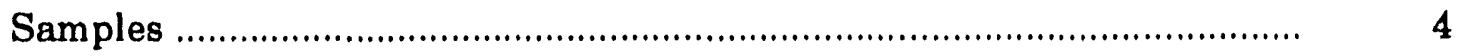

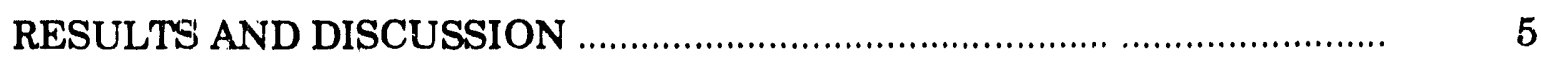

Reproducibility of Results......................................................................

Aromatic Hydrogen-to-Carbon Ratio Measurements .................................

Aromatic Carbon Balances .................................................................... 11

Hydrogen Utilization During Liquefaction ............................................ 12

Spectral Deconvolution............................................................................ 17

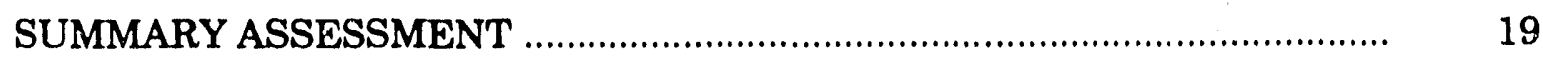

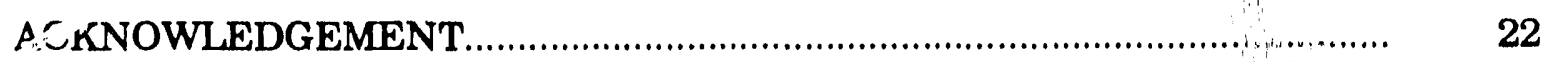

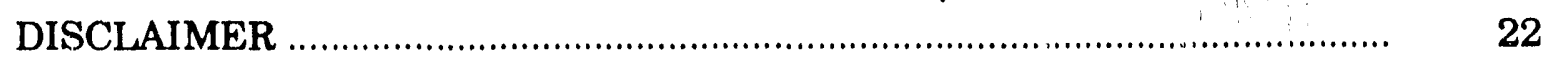

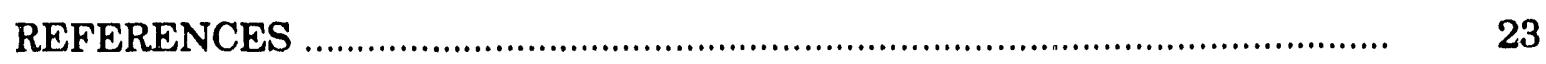

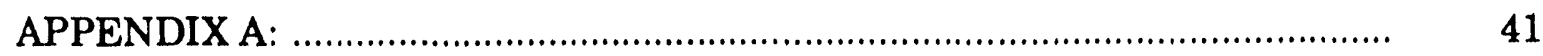

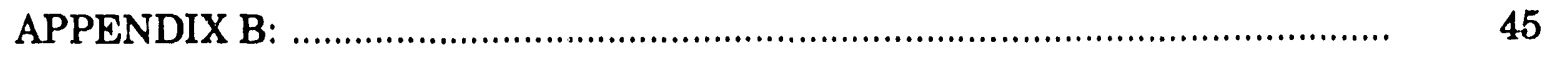

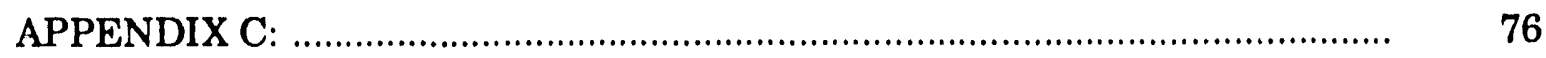




\section{LIST OF TABLES}

Table

Page

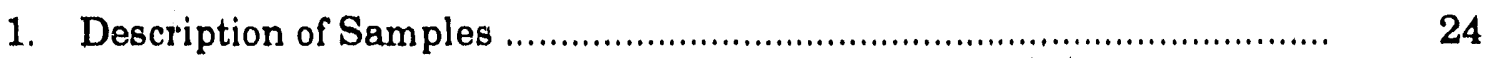

2. Sample Description, Elemental Analysis, and Aromaticities................ . $\quad 25$

3. Summary of Carbon and Hyurogen Aromaticities andHydrogen -to-Carbon Ratios

4. Overall Steady-State Material Balance Two-Stage Liquefaction System and First-Stage Reactor System.

5. Summary of Aromatic Carbon Mass Balance Data

6. Hydrogen Utilization Accounting Calculation, Wilsonville Run 259G, First Stage.

7. Hydrogen Utilization Accounting Calculation, Wilsonville Run 259G, Overall Two-Stage

8. Hydrogen Utilization Accounting Calculations, Wilsonville Run 259G.

9. Hydrogen Utilization Accounting Results, Wilsonville Run 259G.

10. Summary of NMR-Derived Parameters for Consol Samples, maf basis. 


\section{LIST OF FIGURES}

Figure

Page

1. CP/MAS ${ }^{13} \mathrm{C}$. NMR Spectra and Carbon Aromaticities of Resids

From Wilsonville Run 257 on Illinois No. 6 Coal

2. CP/MAS ${ }^{13} \mathrm{C}$ NMR Spectra and Carbon Aromaticities of Resids

From Wilsonville Run 259 on Pittsburgh Seam Coal

3. CP/MAS ${ }^{13} \mathrm{C}$ NMR Spectra and Carbon Aromaticities of Resids

From Wilsonville Run 251-III on Wyodak Coal

4. Plots of (a) Aromaticities and (b) Hydrogen-to-Carbon

Ratios of Resids From Wilsonville Run 257 on Illinois

No. $6 \mathrm{Coal}$

5. Plots of (a) Aromaticities and (b) Hydrogen-to-Carbon Ratios of Resids From Wilsonville Run on 259 on Pittsburgh

Seam Coal

6. Plots of (a) Aromaticities and (b) Hydrogen-to-Carbon

Ratios of Resids From Wilsonville Run 251-III on

Wyodak Coal 


\section{EXECUTIVE SUMMARY}

Solid-State ${ }^{13} \mathrm{C}$ and ${ }^{1} \mathrm{H}$ NMR measurements were made on whole coals, product oil resids, and whole product oils obtained from different stages of coal liquefaction and from different liquefaction processes. Cross polarization (CP) and magic-angle spinning (MAS), and single pulse measurements were made to determine carbon aromaticities; combined rotation and multiple-pulse spectroscopy (CRAMPS) techniques were employed to determine the hydrogen aromaticities in these materials. The objectives of this study were to provide data that are important for closing aromaticity balances, for determining the extent of condensation and retrograde reactions, and for determining the modes of hydrogen utilization during coal liquefaction. Such data are difficult, if not impossible, to acquire by any other means.

The NMR measurements were made on nineteen samples comprising coals and liquefaction products obtained from Wilsonville and Hydrocarbon Research Incorporated (HRI) coal liquefaction experiments on subbituminous and bituminous coals. The coal samples were divided into three sets. One set was used for measuring aromatic hydrogen-to-carbon ratios in raw coals and process oil resids from Wilsonville liquefaction runs on Illinois No. 6, Pittsburgh, and Wyodak coals. A second set of samples was obtained from HRI liquefaction runs on Black Thunder mine subbituminous coal and Wilsonville runs on Ireland mine Pittsburgh seam coal. A third set of samples from Pittsburgh seam coal was used for hydrogen utilization measurements.

${ }^{13} \mathrm{C}$ NMR aromaticity measurements were made in duplicate on several samples to assess the reproducibility of the aromaticity measurements. The results showed that reproducible aromaticity measurements could be obtained on a routine basis. Comparisons between single pulse and cross polarization aromaticity measurements were good for coal but only fair for coal products.

Aromatic hydrogen-to-carbon (H/C) ratios were calculated from elemental analyses and ${ }^{13} \mathrm{C}$ and ${ }^{1} \mathrm{H}$ NMR aromaticity measurements. The aromatic $\mathrm{H} / \mathrm{C}$ ratio 
of the resids remained fairly constant between the first-stage and the second-stage reactors from Wilsonville runs, suggesting that most of the condensation/retrograde reactions take place in the first-stage reactor. The aromatic $\mathrm{H} / \mathrm{C}$ ratios of some of the raw coals had values similar to the resids. However, by comparing their CP/MAS ${ }^{13} \mathrm{C}$ NMR spectra, it was inferred that the raw coal aromatic $\mathrm{H} / \mathrm{C}$ values were influenced mainly by small, highly substituted aromatic rings rather than by large, condensed aromatic ring systems. Some resids had lower carbon aromaticities and higher aliphatic carbon intensities than the starting coal. These observations are consistent with some hydrogenation of aromatic rings taking place during liquefaction.

NMR measurements were combined with elemental analysis and mass balance data to obtain aromatic carbon balances for Wilsonville coal liquefaction run 259G. By measuring the increase or decrease of aromatic carbon in the various liquefaction products, the degree of hydrogenation at various stages of liquefaction and under various corditions can be ascertained. On the basis of the feed coal, about $58 \%$ of the aromatic carbon in Pittsburgh coal was hydrogenated during two-stage liquefaction, and $57 \%$ of the hydrogenation occurred during the second stage.

Liquid-and solid-state NMR measurements, in conjunction with other analytical and conversion data, were employed to determine the modes of hydrogen utilization during liquefaction. In principle, the amount of hydrogen consumed for producing coal liquids, producing hydrocarbon gases, and removing heteroatoms can be obtained from these combined measurements. A net of $54.8 \mathrm{~mol}$ of hydrogen per $100 \mathrm{~mol}$ of coal carbon were consumed during the first stage of Wilsonville run 259G. This amounted to $66.5 \%$ of the total overall two-stage hydrogen consumption. Matrix cleavage and hydrogenation reactions accounted for $40 \%$ and $33 \%$, respectively, of the total first-stage hydrogen consumption. Most (77\%) of the hydrogen consumed during the second stage was used for hydrogenation. Overall, hydrogenation reactions accounted for $48 \%$ of the overall two-stage total hydrogen consumption. These observations are consistent with the notion that the first stage involves a dissolution stage, whereas the second stage is primarily an upgrading stage. 


\section{INTRODUCTION}

The purpose of the Coal Liquefaction Process Streams Characterization and Evaluation Participants Program is to provide a bridge between coal liquefaction process development and analytical chemistry. Well-documented samples from process development units are provided by Consol to subcontractors for testing analytical methods that provide valuable data for understanding and developing processes. Analytical methods of interest are those that are novel but have not been fully demonstrated for applications to coal liquefaction. It is not the intent of he program to completely develop new analytical techniques but to exploit the potential of existing, but currently underutilized, techniques. A further intent of the program is to acquire data that assists with process development efforts rather than just data collection.

Western Research Institute's (WRI's) objective in the program is to use solidstate ${ }^{13} \mathrm{C}$ and ${ }^{1} \mathrm{H}$ NMR techniques to measure changes in the carbon and hydrogen aromaticities in coal and coal-derived products generated during liquefaction. Solidstate NMR measurements are made on whole coals, residues, and insoluble fractions obtained at different stages of liquefaction from different liquefaction processes. The objectives of WRI's subcontract are to provide process developers with data that are important for closing aromaticity balances, for assessing the extent of condensation/retrograde reactions, and for understanding the chemistry of hydrogen utilization during coal liquefaction.

Solid-state NMR techniques have been applied to various fuel materials such as coals and oil shales; however, little work has been done in using these methods for the analysis of coal-liquefaction process streams. As such, the NMR techniques are novel and are within the scope of the participants program. 


\section{EXPERIMENTAL}

\section{NMR Measurements}

Solid-State NMR measurements were made using a Chemagnetics CMX 100/200 solids NMR spectrometer, which consists of two superconducting magnets and an operating console. Carbon aromaticity measurements were made at a ${ }^{13} \mathrm{C}$ frequency of $25 \mathrm{MHz}$ using the technique of cross polarization (CP) with magic-angle spinning (MAS) and high-power decoupling. A 9.5-mm-diameter zirconia bullet spinner was used. Spinning rates were between 3.5 and $4.2 \mathrm{kHz}$. A total of 10,800 transients were collected for each CP/MAS spectrum. This number of acquisitions was chosen more for convenience than for signal-to-noise $(\mathrm{S} / \mathrm{N})$ considerations. Other NMR parameters were a $90^{\circ}$ pulse width of $5 \mu \mathrm{s}$, a contact time of $1 \mathrm{~ms}$, and a pulse delay of $1 \mathrm{~s}$. These parameters are typical for CP/MAS measurements of coals (Miknis et al. 1981; Solum et al. 1989).

Single-pulse (SP) NMR measurements were made using the 9.5-mm-diameter zirconia spinner. For the SP measurements, the pulse width was $5 \mu \mathrm{s}$, and the pulse delay was $30 \mathrm{~s}$. SP measurements were made for comparison with the CP/MAS measurements to assess the reliability of the catbon aromaticity measurements. Because the relaxation mechanisms are different for the two NMR methods, agreement between the two methods lends credibility to the aromaticity values.

Solid-state ${ }^{1} \mathrm{H}$ NMR aromaticity measurements were made using the technique of combined rotation and multiple-pulse spectroscopy (CRAMPS). These mersurements were made at $200 \mathrm{MHz}$ using a BR-24 multiple-pulse sequence. C : timization of instrumental conditions followed that of Bronnimann et al. (1988). Typically, CRAMPS spectra of coals exhibit poor resolution despite the sophistication of the measurement. To obtain the best spectral resolution, a number of experimental parameters must be varied. The CRAMPS spectra in this study were obtained with a pulse width of $1.25 \mu \mathrm{s}$, a multiple-pulse cycle time of $122.4 \mu \mathrm{s}$, and a spinning speed of $1800 \mathrm{~Hz}$. 
Liquid-state ${ }^{1} \mathrm{H}$ and ${ }^{13} \mathrm{C}$ NMR measurements were made on a JEOL GSX-270 NMR spectrometer. The experimental conditions for recording a ${ }^{1} \mathrm{H}$ spectrum were 8 scans, a pulse width of $5.4 \mu \mathrm{s}\left(45^{\circ}\right)$, an acquisition time of $1.5 \mathrm{~s}$, a pulse delay of 20 $s$, and $16 \mathrm{~K}$ time-domain data points. Th. conditions for recording a ${ }^{13} \mathrm{C} \mathrm{NMR}$ spectrum were 1800 scans, $7 \mu$ s pulse width $\left(68^{\circ}\right), 0.8$ s acquisition time, a pulse delay of $20 \mathrm{~s}, 32 \mathrm{~K}$ time-domain data points, and gated de zoupling with the decoupler on during data acquisition.

All NMR spectra were phased manually and integrated using, in part, the instrument's computer software. For the CP/MAS ${ }^{13} \mathrm{C}$ aromaticity measurements, the integrations covered the range from 360 to $-160 \mathrm{ppm}$. This large range was required to include contributions form spinning sidebands to the aromatic carbon integrals. For all the samples, the region between 340 and 90 ppm was considered the aromatic carbon region. This region included contributions from carbonyl carbons in the region $165-210$ ppm, which were only important for the low-rank raw coal spectra. The region between 90 and -20 ppm was considered the aliphatic carbon region, and the integrated sideband intensity between -20 and -80 ppm was added to the aromatic carbon integral.

For the ${ }^{1} \mathrm{H}$ aromaticity measurements, the region $>5 \mathrm{ppm}$ was considered the aromatic hydrogen region, and the region $<5 \mathrm{ppm}$ was considered the aliphatic hydrogen region. This division is consistent with that used by Consol for liquidstate ${ }^{1}$ H NMR measurements (Winschel et al. 1986). Because of the lack of resolution of the CRAMPS spectra no further discrimination of hydrogen types was attempted.

The chernical shift ranges that were used for integrating the liquid-state NMR spectra are listed in Table A-1 of Appendix A. Because the liquid-state NMR measurements provide greater spectral resolution than the solid-state NMR measurements additional structural parameters were calculated from the liquidstate ${ }^{1} \mathrm{H}$ and ${ }^{13} \mathrm{C}$ NMR spectra. These are listed in Table A-2 of Appendix A. ${ }^{13} \mathrm{C}$ spectra are included in Appendix $\mathrm{B} ;{ }^{1} \mathrm{H}$ spectra are included in Appendix $\mathrm{C}$. 


\section{Sampleg}

Nineteen, well-documented samples were supplied by Consol (Table 1). The suite of samples consisted of four raw coals, six nondistillable resids, two process distillates, six process oils, and one ash concentrate. Solid-state ${ }^{13} \mathrm{C}$ NMR measurements were made on sixteen of the samples; CRAMPS spectra were obtained for fifteen of the samples; and liquid-state NMR measurements were obtained for three of the samples. The samples were arranged in three sets to assess the merits of NMR measurements for characterizing different aspects of coal liquefaction. The elemental compositions supplied by Consol and the NMR aromaticity measurements are summarized in Table 2.

The first set of nine samples consisted of a raw coal, the interstage product oil resid, and the second-stage product oil resid from liquefaction runs on Illinois No. 6 , Pittsburgh seam, and Wyodak coals conducted at the Wilsonville facility. NMR aromaticity measurements on these materials in conjunction with elemental carbon and hydrogen analyses were used to calculate an aromatic $\mathrm{H} / \mathrm{C}$ ratio for these materials. The objective of this study was to assess the use of this parameter for monitoring condensation/retrograde reactions.

A second set of samples was obtained from coal liquefaction runs on Black Thunder mine subbituminous coal conducted by Hydrocarbon Research Incorporated and from Wilsonville liquefaction runs on Ireland mine Pittsburgh seam bituminous coal. This set of samples consisted of the starting coal and process oils and distillates from various stages of the liquefaction process. Solid-and liquid-state ${ }^{13} \mathrm{C}$ NMR aromaticity measurements were made on these samples. These measurements and the carbon analysis and mass balance data were used to obtain a carbon aromaticity mass balance for the process. This type of information can be used, for example, to determine where and how much aromatic carbon is formed or destroyed (hydrogenated) at different process steps. 
A third set of samples consisted of six sanples from a catalytic/cataiytic liquefaction run on Pittsburgh seam coal at Wilsonville. This set of samples was obtained for determining hydrogen utilization using the method of Finseth et al. (1985).

The NMR measuremcnts were made on the samples as received from Consol. Samples 15, 16, and 17 were semisolids at room temperature. These samples were heated to $105^{\circ} \mathrm{C}$ for -10 minutes until they became liquids, and then they were poured into the NMR sample spinner. For these samples, it was necessary for the material to return to room temperature before beginning the sample spinning. Otherwise, when the sample was spun at $-250,000 \mathrm{rpm}$, the sample was forced to the sides and up the walls of the spinner. At times, this forced the cap off of the spinner, creating problems in the probe. Two samples (11 and 12) were liquids at room temperature and were poured into the spinner without heating. However, CP/MAS measurements at high spinning speeds were not feasible for these samples and were abandoned in favor of nonspinning, single-pulse measurements. Surprisingly, these measurements gave baseline resolution between the aliphatic and aromatic regions, and the spectra were of high quality.

\section{RESULTS AND DISCUSSION}

\section{Reproducibility of Results}

CP/MAS NMR spectra were recorded in duplicate on several samples to determine the reproducibility of the aromaticity values (Table 2 ). The NMR results in Table 2 represent measurements made at different times and on different aliquots of the same master batch sample. The results for samples 2 and 3 show excellent reproducibility. The results for samples 1,5 , and 7 are better than the precision $( \pm 0.03)$ that night be expected from the CP/MAS technique when used for routine analysis (Miknis et al. 1981). 
NMR aromaticity measurements were also made on a raw coal, a product oil resid, and a second-stage product oil (samples 2, 6, and 15, respectively) using single pulses with high-power decoupling and magic-angle spinning. Because the relaxation mechanisms are different in the single-pulse (SP) method, these measurements should provide an independent check on the aromaticity values determined by CP/MAS. Usually, single-pulse aromaticity values are expected to be slightly greater than those determined by CP/MAS. This is because the SP method does not rely on having protons attached to, or in the vicinity, of the carbons to observe a signal. Therefore, observation of signals from quaternary aromatic carbons in the interior of condensed rings is not so much a problem with SP methods as it sometimes is for CP/MAS. The single-pulse results are also listed in Table 2.

There is good agreement between the SP and CP/MAS aromaticity measurements for the Pittsburgh coal ( 0.706 vs. 0.691). However, the agreement is not good for the aromaticity measurements for the second-stage product oil resid (somple 6) and for the second-stage product oil (sample 15). As mentioned earlier, sample 15 was a very viscous material at room temperature and had to be heated and poured into the NMR sample spinner. Although Sample 15 was "solid" at room temperature, it is conceivable that on a molecular scale there could have been mobile (liquid-like) components in this sample that were not detected by CP/MAS. The reason is that $\mathrm{CP} / \mathrm{MAS}$ relies on static interactions for effective cross polarization. If the liquid-like components contain aliphatic components, the observed CP/MAS aromaticity will be higher because the mobile aliphatic components will not have been measured. The ${ }^{13} \mathrm{C}$ NMR spectra of sample 15 (see Appendix A) provide a clue that this might be the case. The SP spectrum shows much greater resolution of the aliphatic carbons than the CP/MAS spectrum. This is interpreted as being due to components in the sample that have some mobility or possess some liquid-like characteristics on a molecular scale.

It is not clear as to why the agreement between aromaticities is not better for sample 6. As mentioned, SP measurements generally give slightly higher aromaticity values than CP/MAS measurements. One possible explanation is that 
the aromatic carbons in this sample have long spin-lattice relaxation times so that a 30-second pulse delay is not sufficiently long enough to completely measure the full aromatic carbon magnetization. Single-pulse measurements using long delays $(\sim 180$ s) were beyond the scope of this project. On the basis of other data, such as the total carbon values and $\mathrm{H} / \mathrm{C}$ ratios, and by comparing the raw coal and product resid aromaticities, the CP/MAS aromaticity value appears to be the more reasonable of the two.

The single-pulse measurements were also plagued with probe background signals that were not a problem with the CP/MAS spectra. As a result, the SP spectra were difficult to phase, and the background signals may have had an effect on the aromaticities. The background signals are believed to arise from the fluorinated polymeric materials in the rotor bearings and drive tip. During longterm signal averaging these background signals may have been recorded. Presently, we are working to eliminate this problem.

\section{Aromatic Hydrogen-to-Carbon Ratio Measurements}

The aromatic $\mathrm{H} / \mathrm{C}$ ratio in coals and coal liquefaction product materials can be obtained directly using ${ }^{1} \mathrm{H}$ CRAMPS and ${ }^{13} \mathrm{C}$ CP/MAS NMR techniques and elemental analysis:

$$
\mathrm{H}_{\mathrm{a}} / \mathrm{C}_{\mathrm{a}}=\left(\mathrm{f}_{\mathrm{a}}^{\mathrm{H}} / \mathrm{f}_{\mathrm{a}}^{\mathrm{C}}\right)(\% \mathrm{H} / \% \mathrm{C}) \times 12
$$

where $\mathrm{f}_{\mathrm{a}}^{\mathrm{H}}$ is the hydrogen aromaticity determined by CRAMPS; $\mathrm{f}_{a}^{\mathrm{C}}$ is the carbon aromaticity determined by CP/MAS; and \% $\mathrm{H}$ and $\% \mathrm{C}$ are determined by elemental analyses. In principle, changes in the aromatic $\mathrm{H} / \mathrm{C}$ ratio during coal liquefaction may be used to determine the extent of condensation reactions (or their reverse, bond scission reartions). The are illustrated by the following examples of condensation reactions of 1,1,binaphthyl (Scheme 1) and resorcinol (Scheme 2). 


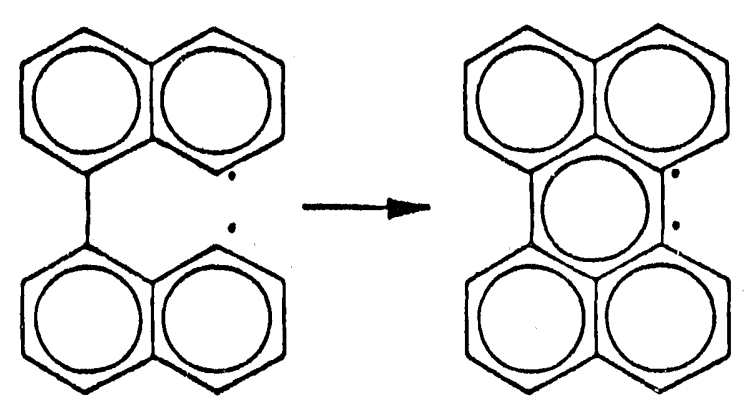

Scheme 1<smiles>C[I+](C)(C)c1cccc(O)c1-c1c(O)cccc1-c1cccc(O)c1</smiles>

Scheme 2

In these examples, the total aromatic carbon remains the same, but the distribution between protonated $\left(\mathrm{H}_{\mathrm{a}} / \mathrm{C}_{\mathrm{a}}\right)$ and nonprotonated aromatic carbon changes as a result of the condensation reactions. For example, in Scheme 2, the aromatic $\mathrm{H} / \mathrm{C}$ ratio decreases from 0.67 to 0.50 as a result of condensation.

Table 3 summarizes carbon and hydrogen aromaticities and calculated aromatic $\mathrm{H} / \mathrm{C}$ ratios for the set of nine samples of coals and resids. CP/MAS spectra of the raw coal, interstage product oil resid, and second-stage product oil resid for 
each of the coals are shown in Figures 1-3; aromaticities and hydrogen-to-carbon ratios are shown in Figures 4-6.

There are a number of observations that can be made about the NMR data and the liquefaction process. The agreement between these carbon aromaticities and those recently reported by Solum et al. (1989) for Argonne Premium coals is quite good. They report carbon aromaticities of 0.72 and 0.71 for two Illinois No. 6 coals; we report a value of 0.717 . Their Wyodak coal aromaticity was 0.55 , excluding carbonyls; our value is 0.538 , excluding carbonyls. The values for the Pittsburgh coal were 0.72 compared with our value of 0.691 .

The aromatic $\mathrm{H} / \mathrm{C}$ ratio for the Illinois No. 6 coal is less than either of the process resids (Figure $4 \mathrm{~b}$ ). This suggests that the starting coal is more highly condensed than the products, based on the preceding arguments. This observation illustrates a possible disadvantage of simply using an aromatic $\mathrm{H} / \mathrm{C}$ as an indicator of condensation reactions, namely small aromatic rings that are highly substituted can give aromatic $\mathrm{H} / \mathrm{C}$ ratios that are similar to those of highly condensed systems (Gerstein et al. 1981). One possible way to discriminate between condensed rings versus highly substituted small rings is to compare the CP/MAS ${ }^{13} \mathrm{C}$ NMR spectru of the coals and the resids (Figures 1-3) in spectral regions characteristic of different types of aromatic carbons.

The aromatic carbon region between 135 and $150 \mathrm{ppm}$ is attributed to alkylated aromatic carbons, and the region between 150 and $165 \mathrm{ppm}$ is attributable to phenolic carbons (Solum et al. 1989). Both types of carbon functionality produce a lower aromatic $\mathrm{H} / \mathrm{C}$ ratio just as would carbons in condensed aromatic rings. However, aromatic carbons arising from condensed ring structures have a narrower aromatic band because of lesser chemical shift dispersion and are centered at a chemical shift $<135 \mathrm{ppm}$.

By comparing the CP/MAS spectra of the raw coals with those of the interstage and second-stage product oil resids, a clear line narrowing in both types of resids is 
seen for all three coals. The Wyodak coal shows line narrowing due to both the loss of phenolic-OH and alkyl-substituted aromatic carbons, as evidenced by the disappearance of those resonances in the resid spectra. Thus, an argument can be made that the resid materials have undergone condensation during coal liquefaction, but the degree of condensation over the starting coal can not be quantified without additional work.

There does not appear to be any significant increase in the condensation reactions between the first-and second-stage reactors because the aromatic $\mathrm{H} / \mathrm{C}$ ratios of the two resids are basically the same. This is true for all the coals. These data are consistent with the observation that most of the liquefaction conversion occurs in the first-stage reactor.

There are some apparent discrepancies between the NMR and elemental analysis data for the Illinois No. 6 coal samples. The total $\mathrm{H} / \mathrm{C}$ ratio of the interstage resid is greater than that of the starting coal (Table 3 and Figure 4), implying that hydrogenation has occurred during the first stage. However, the ${ }^{13} \mathrm{C}$ NMR carbon aromaticities are about the same (Table 3, Figures 1 and 4), implying that little, if any, hydrogenation has occurred. The total $\mathrm{H} / \mathrm{C}$ ratio remains about the same after the second-stage reactor, whereas the CP/MAS spectra clearly show an increase in the aliphatic carbon fraction, implying that hydrogenation has occurred between the first stage and the second stage of the process. However, it must be kept in mind that direct comparisons of the resid materials with the starting coal are not completely valid because the starting coal represents only a portion of the feed material from which the resids are derived.

The data for the Pittsburgh coal appears to be consistent with what is expected during liquefaction. There is a slight drop in the total $\mathrm{H} / \mathrm{C}$ ratio from the starting coal to the resid materials (Figure 5 and Table 3 ). This is accompanied by a slight increase in carbon aromaticity (Figure 5), and there is a decrease of aromatic carbon signal in the region of phenolic and alkylated aromatic carbons (Figure 2). This 
suggests that some condensation reactions have occurred. This is supported by the decrease in the aromatic $\mathrm{H} / \mathrm{C}$ ratio of the resid materials (Figure 5). "Tone of the data suggest that any extensive hydrogenation of the resids has taken place.

The data for the Wyodak coal show that some degree of hydrogenation has taken place, particularly after the second stage of the liquefaction (Figures 3 and 6). Figure 3 shows a noticeable increase in the aliphatic component on the second-stage resid over that of the interstage resid. The CP/MAS spectra also clearly show a loss in straight-chain aliphatic components between the starting coal and the interstage resid. Figure 6 shows the overall decrease in carbon aromaticity and increase in total $\mathrm{H} / \mathrm{C}$ in support of this observation.

\section{Aromatic Carbon Balances}

In principle, the calculation of carbon aromaticity balar.ces is straightforward. All that is necessary is knowledge of the carbon values of all the materials entering and leaving a reactor; knowledge of the aromatic carbon fractions of the same materials; and a mass balance across the reactor so thac the conversion of coal to gas, liquid, and solid products can be obtained. The amount of aromatic carbon, on a mass basis, for a given product is obtained by multiplying the percent carbon by the aromaticity, and this value is multiplied by the percent conversion to that product. The net production (aromatization) or destruction (hydrogenation) of aromatic carbons across a reactor is obtained by difference between the output and input aromatic carbons.

Carbon aromaticity balances were made for Wilsonville coal liquefaction run 259G. The material balance across the first-stage reactor and the overall steadystate material balance across the two-stage liquefaction system are summarized in

Table 4. The carbon aromaticity balances are summarized in Table 5. The carbon aromaticity balance across the first-stage reactor shows a deficit of $14.1 \mathrm{lb}$ of aromatic carbon (output - input). This represents the amount of aromatic carbon that was hydrogenated in the first stage of liquefaction during run 259G. The 
overall carbon aromaticity balance across the first- and second-stage reactors shows a deficit of $32.7 \mathrm{lb}$ of aromatic carbon. On the basis of the feed coal, this means that $58.3 \%$ of the original aromatic carbon in the Pittsburgh coal was hydrogenated during the Wilsonville two-stage liquefaction run 259G. The amount of aromatic carbon hydrogenated during the second stage of liquefaction can be obtained by subtracting the first-stage aromatic carbon deficit from the overall deficit. This gives a value of $18.6 \mathrm{lb}$ of aromatic carbon that was hydrogenated during the second stage of liquefaction.

The aromatic carbon balance data (Table 5) show that 57\% of the hydrogenation of aromatic carbon occurs in the second stage of liquefaction. Presumably, this causes a reduction in molecular weight of the products (thus lighter products). It also contributes to the increase in the $\mathrm{H} / \mathrm{C}$ ratio of the final liquid product ( 1.81 net product oil product versus 1.07 total first-stage liquid product). This is consistent with the notion that the first stage of liquefaction involves coal dissolution and the second stage involves primarily liquids upgrading. Data on the modes of hydrogen utilization, which are discussed in the next section, support these notions.

Carbon aromaticity balances for the Hydrocarbon Research Incorporated run, HRI CC-1, were not successful because the required mass balance and conversion data were not available. Nevertheless, the available data are listed in Table 5. For the HRI CC-1 run, a total of $41.87 \mathrm{lb}$ of aromatic carbon was fed to the first stage reactor, assuming a oil/coal ratio of $1.1 / 1.0$ and a 100-lb total charge to the reactor. It was not possible to develop the aromaticity balance beyond this point because the conversion data for the first- and second-stage samples was not available.

\section{Hydrogen Utilization During Liquefaction}

Hydrogen chemistry and utilization are very important for design of coal liquefaction processes because of the impact of hydrogen consumption on process economics. In fact, investigation of more efficient ways to produce, use, or recover 
hydrogen has been given a high priority for research by the DOE Coal Liquefaction Research Needs (COLIRN) assessment panel (U.S. DOE 1989). Therefore, a key to developing a successful coal liquefaction process is an understanding of how hydrogen is used among the different reaction modes that yield the final products. There are a number of ways in which hydrogen participates in the direct liquefaction of coal (Wilson et al. 1982; Finseth et al. 1985; Bockrath et al. 1984). These include hydrogenolysis, alkyl bond scission, and hydrogenation.

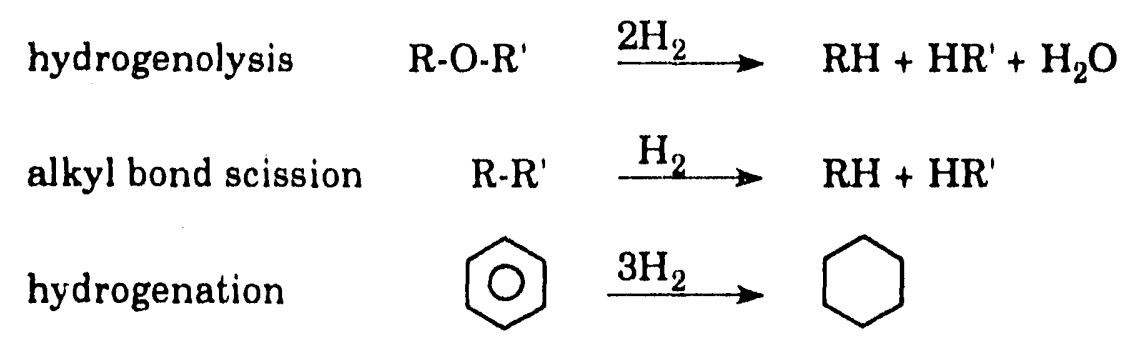

These reactions consume hydrogen during the liquefaction process. In hydrogenolysis, hydrogen is used to remove heteroatoms. In alkyl bond scission, the molecular weights of the liquefaction fragments are reduced. During hydrogenation, aromatic rings are destroyed.

The product carbon aromaticities from hydrogenolysis and alkyl bond scission are generally the same as that of the reactants (coal + solvent), whereas hydrogenation produces a product of different aromaticity than the starting materials (Wilson et al. 1982). Also, aromatization, which is the reverse of hydrogenation, and condensation, which is the reverse of bond scission, are potential sources of hydrogen during liquefaction.

Finseth et al. (1985) proposed a method by which to monitor the changes in hydrogen utilization during coal liquefaction. This method incorporates a variety of analytical methods that are already available or currently under development. In the analytical method of Finseth et al. (1985), the total hydrogen incorporated during liquefaction is given by:

$$
\Delta H_{T}=\Delta H_{C}+\Delta H_{\text {hyd }}
$$


where

$$
\begin{aligned}
& \Delta H_{\mathrm{T}}=\text { total hydrogen incorporated } \\
& \Delta \mathrm{H}_{\mathrm{C}}=\text { hydrogen incorporated in bond cleavage reactions (equations } 2 \\
& \text { and } 3 \text { ) } \\
& \Delta \mathrm{H}_{\text {hyd }}=\text { hydrogen incorporated by hydrogenation (equation 4) }
\end{aligned}
$$

The term $\Delta H_{T}$ is determined by classical elemental analysis; $\Delta H_{\text {hyd }}$ can be determined by combining solid-and liquid-state ${ }^{13} \mathrm{C}$ NMR measurements with elemental analysis measurements of the solid and liquid products and reactants. There is no satisfactory method by which to measure $\Delta H_{C}$, the number of bonds broken during the reaction. However, $\Delta H_{C}$ can be further divided into bond cleavage associated with heteroatom removal, $\Delta \mathrm{H}_{\mathrm{NOS}}$ (equation 2); alkyl bond scission (equation 3), which results in $\mathrm{C} 1 \mathrm{XC} 4$ hydrocarbon gases, $\Delta \mathrm{H}_{\mathrm{C} 1 \mathrm{XC}_{4}}$; and alkyl bond scission in the slurry mixture that yields nonvolatile solid and liquid products, $\Delta \mathrm{H}_{\text {matrix }}$ :

$$
\Delta \mathrm{H}_{\mathrm{C}}=\Delta \mathrm{H}_{\mathrm{NOS}}+\Delta \mathrm{H}_{\mathrm{C} 1 \mathrm{XC4}}+\Delta \mathrm{H}_{\text {matrix }}
$$

Substituting equation 6 into equation 5 yields:

$$
\Delta \mathrm{H}_{\mathrm{T}}=\Delta \mathrm{H}_{\text {hyd }}+\Delta \mathrm{H}_{\mathrm{NOS}}+\Delta \mathrm{H}_{\mathrm{C} 1 \mathrm{XC4}}+\Delta \mathrm{H}_{\text {matrix }}
$$

Thus, measurement of hydrogen utilization during coal liquefaction is reduced to measuring $\Delta \mathrm{H}_{\mathrm{T}}$ by elemental analysis, measuring $\Delta \mathrm{H}_{\text {hyd }}$ by NMR aromaticity measurements, and measuring $\Delta \mathrm{H}_{\mathrm{C} 1 \mathrm{XC}_{4}}$ and $\Delta \mathrm{H}_{\mathrm{NOS}}$ by quantitative gas analyses. The term $\Delta \mathrm{H}_{\text {matrix }}$ is then determined by difference. If this term is negative, hydrogen is liberated because of condensation reactions. If $\Delta H_{\text {matrix }}$ is positive, then thermolysis reactions consume hydrogen during liquefaction.

The method of Finseth et al. (1985) for determining the modes of hydrogen utilization during direct liquefaction was applied to the data from Wilsonville run 259G (Tables 6-9). Tables 6 and 7 provide the weighted elemental analyses needed for normalization to the basis of $100 \mathrm{~mol}$ of coal carbon in the products and feed. Table 8 compares the products and feed materials on the normalized basis. The data in Table 8 and equation 7 were used to determine the hydrogen utilization among the various modes of consumption listed in Table 9. These data assume that, 
on the average, 1 hydrogen atom is incorporated into the organic product for every heteroatom removed from the feed material; hydrogenation consumes one hydrogen atom for every carbon reduced (each 0.01 change in aromaticity); and two hydrogens (one mol) are consumed per mole of light hydrocarbons formed. The rationale for these assumptions is discussed in greater detail by Finseth et al. (1985) and by Beret and Reynolds (1985).

For the calculations of the light hydrocarbons, some additional assumptions were made. Data were available for $\mathrm{C}_{1} \mathrm{XC}_{3}$, and $\mathrm{C}_{4} \mathrm{XC}_{6}$ hydrocarbons, so hydrogen utilization was determined for both hydrocarbon groups. On a weight basis the distribution of $\mathrm{C}_{1} \mathrm{XC}_{3}$ gases was assumed to be $50 \% \mathrm{C}_{1}, 30 \% \mathrm{C}_{2}$, and $20 \% \mathrm{C}_{3}$. This gave an average molecular weight of $21.9 \mathrm{~g} / \mathrm{mol}$, which was used in the conversion from a weight percent basis (Tables 6 and 7) to moles (Table 8). The distribution of $\mathrm{C}_{4} \mathrm{XC}_{6}$ hydrocarbons was also assumed to be 50,30 and 20 wt \%, respectively. This gave an average molecular weight of $67.8 \mathrm{~g} / \mathrm{mol}$ for this fraction.

The hydrogen utilization during Wilsonville run $259 \mathrm{G}$ is summarized in Table 9. A number of observations can be made from these data. Overall, $84.2 \mathrm{~mol}$ of hydrogen atoms were consumed per $100 \mathrm{~mol}$ of coal carbon over the two stages of liquefaction. Of this amount, $54.8 \mathrm{~mol}(66.5 \%)$ was consumed during the first stage. Matrix cleavage reactions accounted for $40 \%$ of the total first-stage hydrogen utilization, and hydrogenation accounted for $33 \%$ during this stage. However, hydrogenation reactions accounted for nearly one-half $(48 \%)$ of the overall hydrogen consumption. Hydrogenation dominated the hydrogen consumption during the second stage of liquefaction, accounting for $77 \%$ of the total second-stage hydrogen consumption. These data are consistent with the notion that hydrogen consumption during the first stage involves molecular weight reduction of the products, whereas during the second stage, most is used for product upgrading.

Hydrogen consumption for hydrocarbon gas production $\left(\mathrm{C}_{1} \mathrm{XC}_{3}\right.$ plus $\left.\mathrm{C}_{4} \mathrm{XC}_{6}\right)$ remains relatively constant over both stages of liquefaction. Overall, $16.7 \%$ of the total two-stage hydrogen consumption is used for hydrocarbon gas production; $17.5 \%$ 
of the total first-stage hydrogen consumption is used for hydrocarbon gas production; and $15.2 \%$ of the total second-stage hydrogen consumption is used for hydrocarbon gas production. However, most (70\%) of the total hydrogen consumed for hydrocarbon gas prociuction is used during the first stage.

Heteroatom removal consumes the least amount of hydrogen, accounting for $11.4 \%$ of the overall hydrogen consumption. Proportionately, more hydrogen is consumed for heteroatom removal in the second stage (15.6\%) than in the first stage $(9.3 \%)$. These observations also support the notion of liquid product upgrading during the second stage.

The data in Table 9 show that a small amount of hydrogen $(2.2 \mathrm{~mol} / 100 \mathrm{~mol}$ of coal carbon) is liberated from condensation reactions during the second stage of liquefaction. Usually, condensation reactions are expected to occur during the first stage of liquefaction. However, as noted earlier, the hydrogen consumed for matrix cleavage reactions is obtained by difference (equation 7 ). The small amount of condensation in the second stage may reflect the fact that this number was obtained by difference and that cumulative errors in elemental, gas, and NMR analyses and mass balances all contribute to the accuracy of the hydrogen consumption value assigned to matrix cleavage. The aromatic $\mathrm{H} / \mathrm{C}$ ratios obtained by CRAMPS and CP/MAS NMR (Table 3) do not show that condensation reactions occur between the first- and second stage reactors.

Finally, it must be emphasized that this method only treats the net chemistry of hydrogen utilization and cannot determine whether internally produced hydrogen or the hydrogen atmosphere actually provides the hydrogen that is consumed.

The observations about hydrogen utilization are supported by other data that have been acquired during this study. For example, the carbon balance data (Table 5) also show that more hydrogenation occurs during the second stage as evidenced by the greater loss of aromatic carbon across the second-stage reactor. The aromatic $\mathrm{H} / \mathrm{C}$ ratio measurements and CP/MAS spectra suggest that condensation reactions 
probably occur during the first stage of liquefaction (Figures 2 and 5). In particular, the hydrogen aromaticity and aromatic $\mathrm{H} / \mathrm{C}$ ratio changes in the direction of increasing condensation across the first-stage reactor.

\section{Spectral Deconvolution for Lumped Kinetic Models}

Another task was to evaluate some of the NMR-derived parameters for use in a lumped kinetic model for coal liquefaction. Liquid-state ${ }^{1} \mathrm{H}$ and ${ }^{13} \mathrm{C}$ NMR techniques are now being used to obtzin information about structural groups in coal liquids and heavy distillates for input into lumped kinetic models (Chen and Schindler 1987; Gray 1990). Basically, for these lumped kinetic models, the concentration of certain functional groups is determined from NMR and elemental analyses. NMR is used to monitor the changes in the concentrations of these groups. Because liquid-state NMR usually provides a certain amount of resolution, the concentrations of key functional groups can be obtained.

Chen and Schindler (1987) used ${ }^{1} \mathrm{H}$ NMR to study the hydrotreating of an $850+$ - F coal extract from the Integrated Two-Stage Liquefaction Process. ${ }^{1} \mathrm{H}$ NMR was used to determine the amount of condensed and noncondensed aromatic; cyclic $\alpha+$ cyclic $\beta ;$ and $\alpha-, \beta-$, and $\gamma$-alkyl hydrogens from which the rates of hydrogenation and cracking were obtained.

Gray (1990) used ${ }^{1} \mathrm{H}$ and ${ }^{13} \mathrm{C}$ NMR in a similar approach to determine the rates of hydrotreating a Syncrude coker gas oil. By including ${ }^{13} \mathrm{C}$ NMR, Gray was able to include more functional groups in his kinetic model.

Presently, the use of NMR in the development of lumped kinetic models is restricted to NMR measurements of soluble fractions. Solid-state NMR measurements will need to be made in order to extend the models to include insoluble materials including the starting coal. Less-detailed structural information is obtained from the solid spectra so that some penalties must be expected. The main penalty results from the lack of resolution on the aliphatic hydrogens and 
carbons. For example, the lack of resolution in the CRAMPS spectra (see Appendix C) prevents discrimination of the cyclic versus alkyl hydrogens. The same is true for the aliphatic carbons. Such resolution is necessary for application of the lumped kinetic models to coal liquefaction.

In the case of the aromatic carbons, some discrimination can be made between protonated and nonprotonated aromatic carbons by using the aromatic $\mathrm{H} / \mathrm{C}$ ratio to measure the protonated aromatic carbons and obtaining the nonprotonated aromatic carbons by difference. Alternately, dipolar dephasing techniques can be used for the same purpose (Solum et al. 1989) but at the expense of using more spectrometer time.

Because there is a lack of resolution in the solid-state ${ }^{1} \mathrm{H}$ and ${ }^{13} \mathrm{C}$ NMR spectra, curve-fitting methods must be employed with the assumption that the various fitted hydrogen and carbon types are actually present in the solid samples. This assumption is probably warranted because the hydrogen and carbon types are present in the liquids produced from the solid materials. Commercial software is available for curve-fitting, but testing its use for deconvoluting the CRAMPS and CP/MAS spectra was beyond the scope of the present study.

The net result is that using solid-state NMR measurements to develop an extended lumped kinetic model that includes insoluble materials is probably feasible. However, because of the lower resolution on the solid-state spectra, particularly ${ }^{1} \mathrm{H}$ CRAMPS, spectral curve-fitting methods will have to be employed to obtain the necessary structural parameters for input to the lumped kinetic models. NMR-derived structural parameters are summarized in Table 10.

Finally, the method of Finseth et al. (1985) for determining hydrogen utilization should be investigated for its use in developing kinetic models of hydrogen utilization. With a suitable set of samples that vary as a function of time, temperature, and other operating conditions, it should be possible to obtain kinetic relationships for light hydrocarbon gas production, heteroatom removal, aromatic 
ring hydrogenation, and matrix cleavage (cracking) reactions for liquids production. Suc ' relationships will be very useful for developing a more intimate understanding of coal liquefaction chemistry and for developing methods for process improvement.

\section{SUMMARY ASSESSMENT}

A number of solid-and liquid-state NMR measurements were made on coal liquefaction products for the purpose of determining the usefulness of these measurements to bridge the gap between analytical chemistry and process development. These measurements included CP/MAS and single-pulse MAS ${ }^{13} \mathrm{C}$ NMR measurements for carbon aromaticity measurements of insoluble materials, CRAMPS measurements for hydrogen aromaticity measurements in insoluble materials, and conventional liquid-state high-resolution ${ }^{13} \mathrm{C}$ and ${ }^{1} \mathrm{H} \mathrm{NMR}$ measurements of aromaticities of process distillates. The NMR measurements were straightforward. When used in conjunction with other analysis and process conversion data, they provided useful information for understanding coal liquefaction processes.

This study showed that ${ }^{1} \mathrm{H}$ and ${ }^{13} \mathrm{C}$ NMR measurements on solids can be used to obtain a direct measurement of the aromatic $\mathrm{H} / \mathrm{C}$ ratio of coal liquefaction products. In principle, this parameter should be a useful indicator of condensation and retrograde reactions. However, some raw coals have aromatic $\mathrm{H} / \mathrm{C}$ values similar to the process resids. Therefore, a quantitative assessment of the degree of condensation relative to the starting coal is not feasible, but comparisons relative to the different process stages are feasible. The aromatic $\mathrm{H} / \mathrm{C}$ 's of the interstage and second-stage resids were fairly constant, suggesting that whatever condensation occurs takes place in the first-stage of coal liquefaction at Wilsonville.

An advantage of CP/MAS NMR measurements is that visual comparison of different spectra can provide useful interpretations. Qualitatively, condensation was inferred by comparing the CP/MAS ${ }^{13} \mathrm{C}$ NMR spectra of the coals and resids. A 
definite shift of aromatic spectral intensity into regions indicative of larger aromatic rings was observed for all coals. Some resids had lower carbon aromaticities and higher aliphatic carbon intensities than the starting coal. This is consistent with some hydrogenation of aromatic rings taking place during liquefaction.

NMR measurements, combined with elemental analysis and mass balance data, can be used to obtain aromatic carbon balances at different stages of coal liquefaction. By measuring the increase or decrease of aromatic carbon in the various liquefaction products, we can acertain the degree of hydrogenation at various stages of liquefaction and under various conditions. Application of these procedures to Wilsonville run 259G shows a deficit of $32.7 \mathrm{lb}$ of aromatic carbon. Relative to the starting coal, this means that $58.3 \%$ of the original aromatic carbon in Pittsburgh coal was hydrogenated during the overall two-stage liquefaction.

Liquid-and solid-state NMR measurements, in conjunction with other analytical and conversion data, were used to determine the modes of hydrogen utilization during liquefaction. In principle, the amount of hydrogen consumed for producing coal liquids, hydrocarbon gases, removing heteroatoms, and hydrogenating aromatic rings can be obtained from these combined measurements. Application of this analytical procedure to the data from Wilsonville run 259G shows that, during two-stage liquefaction, most of the hydrogen was consumed for hydrogenation of aromatic rings (48\%), followed by matrix cleavage (cracking) reactions $(24 \%)$, hydrocarbon gas production $17 \%$, and heteroatom removal $(11 \%)$. Hydrogenation is the major consumer of hydrogen during the second stage, accounting for $77 \%$ of the total second-stage hydrogen utilization. These data underscore the importance of hydrogenation reactions for liquids upgrading during the second stage.

The combination of NMR measurements with elemental analyses and process conversion data provides a powerful method by which to study coal liquefaction processes. The measurements can be used in a straightforward manner to obtain information about the degree of hydrogenation, modes of hydrogen utilization, and 
to some extent the degree of condensation/retrograde reactions that occur during coal liquefaction. In addition, with a suitable sulte of samples that vary as a function of time, temperature, and other process conditions, it should be possible to develop kinetic models and other predictive relationships for coal liquefaction based on structural parameters.

Finally, solid-state NMR is only one of several analytical techniques being used by Consol for characterizing and evaluating coal liquefaction process streams. At present, it is not known how the NMR data augment and complement data obtained by the other subcontractors. Therefore, the real usefulness of NMR must wait until all data are gathered and interpreted. 


\section{ACKNOWLEDGEMENT}

This work was supported by subcontract from Consolidation Coal Co. under U.S. Department of Energy Contract No. DE-AC22-89PC89883. 'Wlue author also wishes to acknowledge Dr. Sue Brandes and Mr. Dick Winschel of Consol for the many helpful discussions.

\section{DISCLAIMER}

Mention of specific brand names or models of equipment is for information only and does not imply endorsement of any particular brand. 


\section{REFERENCES}

Beret, S., and J.G. Reynolds, 1985, Hydrogen Incorporation in Residuum Conversion, ACS Div. of Petrol. Chem. preprints, 30 (4): 664-671.

Bockrath, B.C., E.G. Illig, D.H. Finseth, and R.F. Sprecher, 1984, Coal Liquefaction and Hydrogen Utilization at Low Temperatures. ACS Div. of Fuel Chem. Preprints, 29(5): 76.

Bronnimann, C.E., B.L. Hawkins, M. Zhang, and G.E. Maciel, 1988, Combined Rotation and Multiple Pulse Spectroscopy as an Analytical Proton Nuclear Magnetic Resonance Technique for Solids. Anal. Chem., 60: 1743

Chen, J.M., and H.D. Schindler, 1987, A Lumped Kinetic Model for Hydroprocessing Coal Extract, Ind. Eng. Chem. Res. 26, 921-927.

Finseth, D.H., D.L. Cillo, R.F. Sprecher, H.L. Retcofsky, and R.G. Lett, 1985, Changes in Hydrogen Utilization With Temperature During Direct Coal Liquefaction. Fuel, 64: 1718.

Gray, M.R., 1990, Lumped Kinetics of Structural Groups: Hydrotreating of Heavy Distillate, Ind. Eng. Chem. Res., 29, 505-512.

Gerstein, B.C., L.M. Ryan, and P.D. Murphy, 1981, An Estimation of Average Polynuclear Aromatic Ring Size in an Iowa Vitrain and a Virginia Vitrain, in M.L. Gorbaty and K. Ouchi, eds; Chapter 2, Coal Structure, ACS Adv. in Chem. Series 192, Amer. Chem. Soc., Washington DC, 1981.

Miknis, F.P., M. Sullivan, V.J. Bartuska, and G.E. Maciel, 1981, Cross Polarization Magic-Angle Spinning ${ }^{13} \mathrm{C}$ NMR Spectra of Coals of Varying Rank. Org. Geochem., 3: 19-28.

Solum, M.S., R.J. Pugmire, and D.M. Grant, $1989,{ }^{13} \mathrm{C}$ Solid-State NMR of Argonne Premium Coals, Energy and Fuels, 3: 187-193.

U.S. Department of Energy, March 1989, Coal Liquefaction: A Research \& Development Needs Assessment, Volume 1, DOE/ER-0400.

Wilson, M.A., R.J. Pugmire, A.M. Vassallo, D.M. Grant, P.J. Collin, and K.W. Zilm, 1982, Changes in Aromaticity During Coal Liquefaction. Ind. Eng. Chem. Prod. Res. Dev. 21: 477.

Winschel, R.A., G.A. Robbins, and F.P. Burke, 1986, Correlation of Microautoclave and ${ }^{1} \mathrm{H}$ NMR measurements of Coal Liquefaction Solvent Quality. Fuel, 65: 526-532. 
Table 1. Description of Samples

\begin{tabular}{llll}
\hline $\begin{array}{l}\text { Ref. } \\
\text { No. }\end{array}$ Coal Feed & Source/Conditions & Comments \\
\hline
\end{tabular}

Aromatic Hydrogen-to-Carbon Ratio Measurements

$\begin{array}{lll}1 & \text { Illinois No. 6 } & \text { coal } \\ 2 & \text { Pittsburgh seam } & \text { coal } \\ 3 & \text { Wyodak } & \text { coal } \\ 4 & \text { Illinois No. 6 } & \text { W; Run 257; C/C } \\ 5 & \text { Illinois No. 6 } & \text { W; Run 257; C/C } \\ 6 & \text { Pittsburgh seam } & \text { W; Run 259; C/C } \\ 7 & \text { Pittsburgh seam } & \text { W; Run 259; C/C } \\ 8 & \text { Wyodak } & \text { W; Run 251-III; C/C } \\ 9 & \text { Wyodak } & \text { W; Run 251-III;C/C }\end{array}$

Ground to pass 100 mesh Ground to pass 100 mesh Ground to pass 100 mesh 2nd-stage product resid Interstage oil resid 2nd-Stage product resid Interstage oil resid 2nd-Stage product resid Interstage oil resid

Aromatic Carbon Balance Measurements

$\begin{array}{rll}10 & \text { Black Thunder } & \text { coal } \\ 11 & \text { Black Thunder } & \text { HRI; Run CC-1 } \\ 12 & \text { Black Thunder } & \text { HRI; Run CC-1 } \\ 13 & \text { Black Thunder } & \text { HRI; Run CC-1 } \\ 2 & \text { Pittsburgh seam } & \text { coal } \\ 14 & \text { Pittsburgh seam } & \text { W; Run 259 } \\ 15 & \text { Pittsburgh seam } & \text { W; Run 259 } \\ 16 & \text { Pittsburgh seam } & \text { W; Run 259 } \\ 18 & \text { Pittsburgh seam } & \text { W; Run 259 G } \\ 19 & \text { Pittsburgh seam } & \text { W; Run 259 G }\end{array}$

Ground to pass 100 mesh

First stage PO

PFL PO

Separator overhead PD

Ground to pass 100 mesh

Product IPD

2nd-Stage product PO

Interstage PO

Separator overhead PD

Ash concentrate

Hydrogen Utilization Measurements

2 Pittsburgh seam coal

14 Pittsburgh seam W; Run $259 \mathrm{G}$

15 Pittsburgh seam W; Run 259 G

17 Pittsburgh seam W; Run 259 G

18 Pittsburgh seam W; Run 259 G

19 Pittsburgh seam W; Run 259 G

Ground to pass 100 mesh

Product: PD

2nd-sta.ge product PO

Recycle PO

Separator overhead PD

Ash concentrate

PO = Process oil (may contain IOM and ash)

$\mathrm{PD}=$ Process distillate

$\mathrm{W}=$ Wilsonville

$\mathrm{C} / \mathrm{C}=$ catalytic/catalytic

$\mathrm{T} / \mathrm{C}=$ thermal/catalytic 


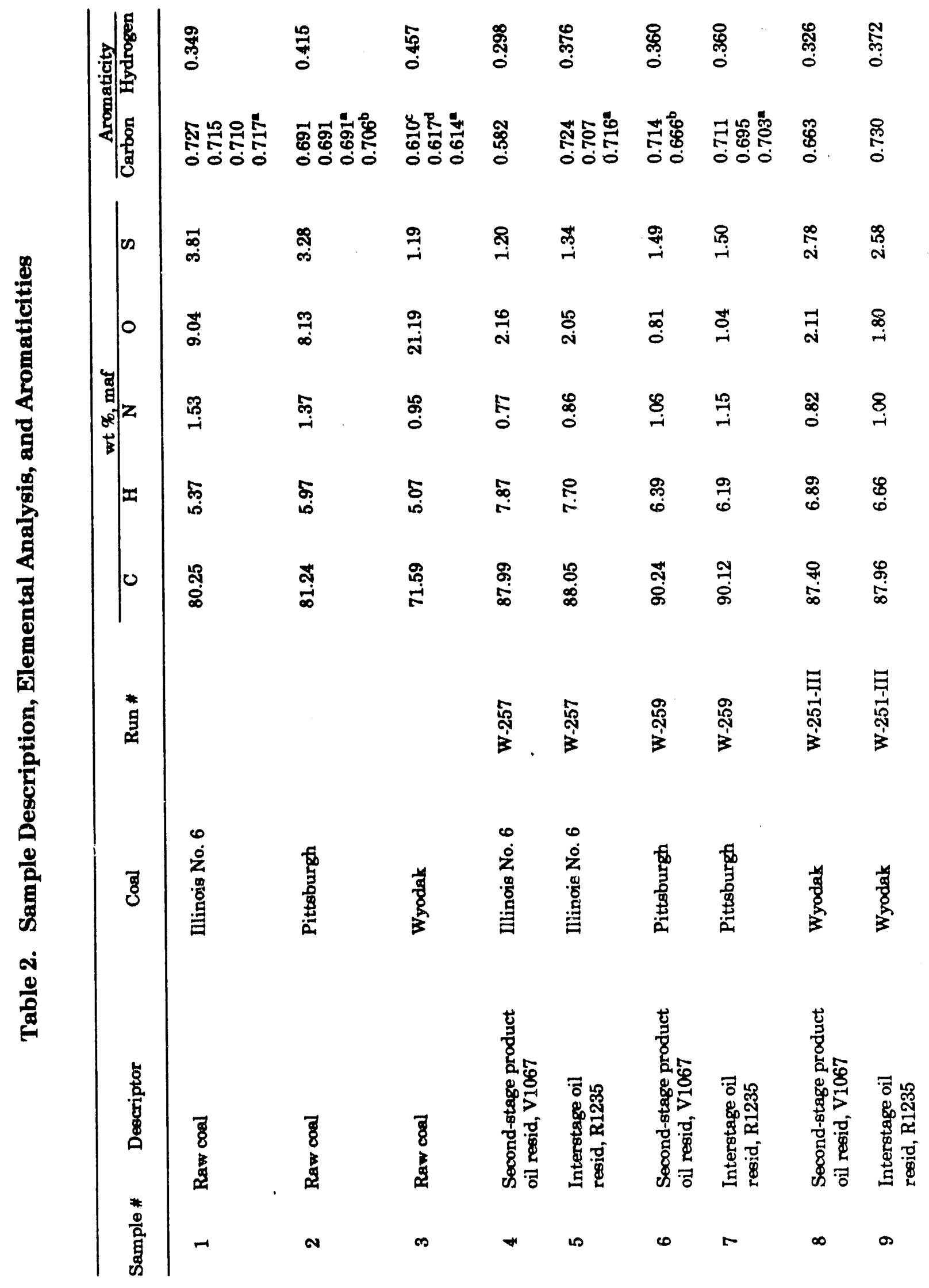




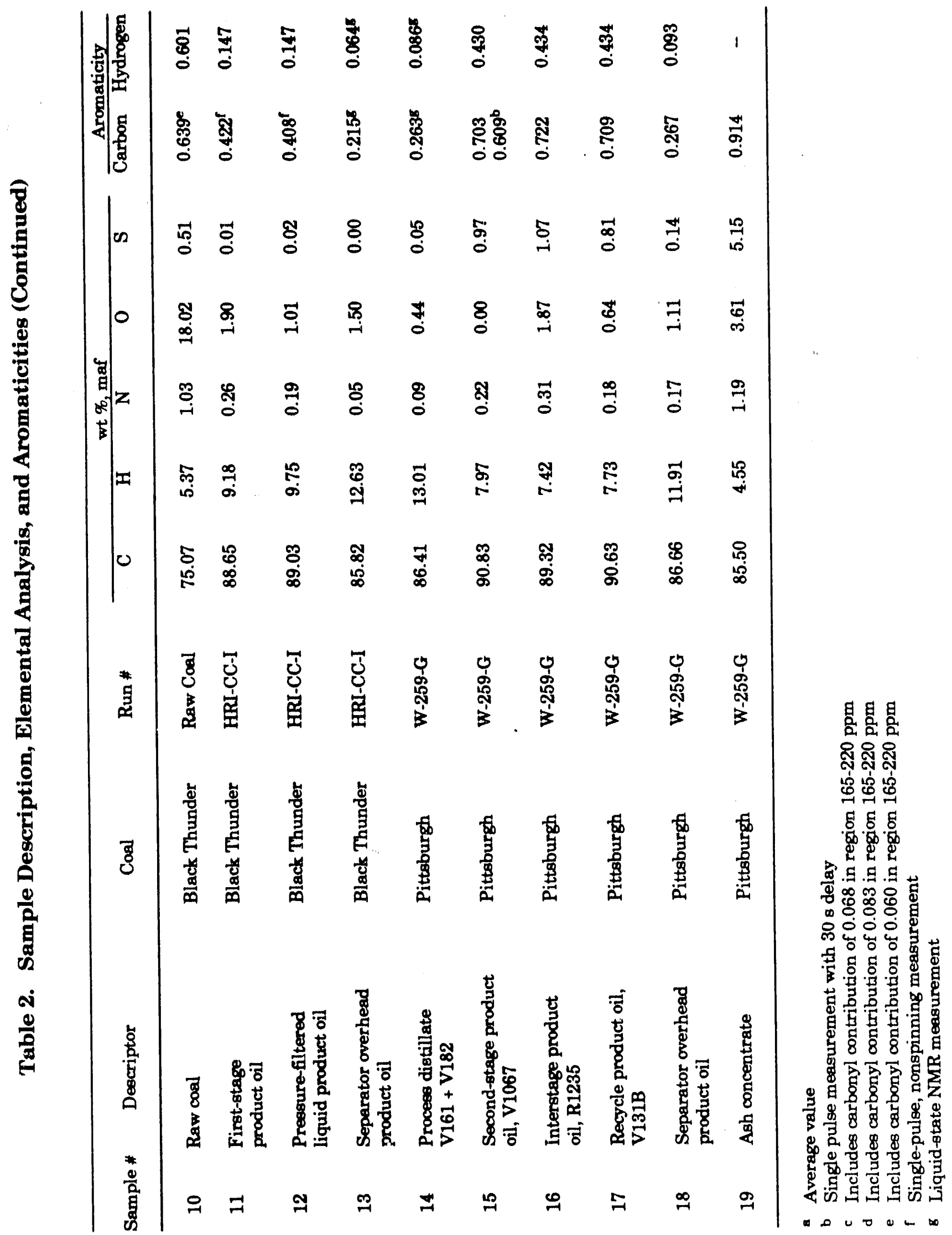




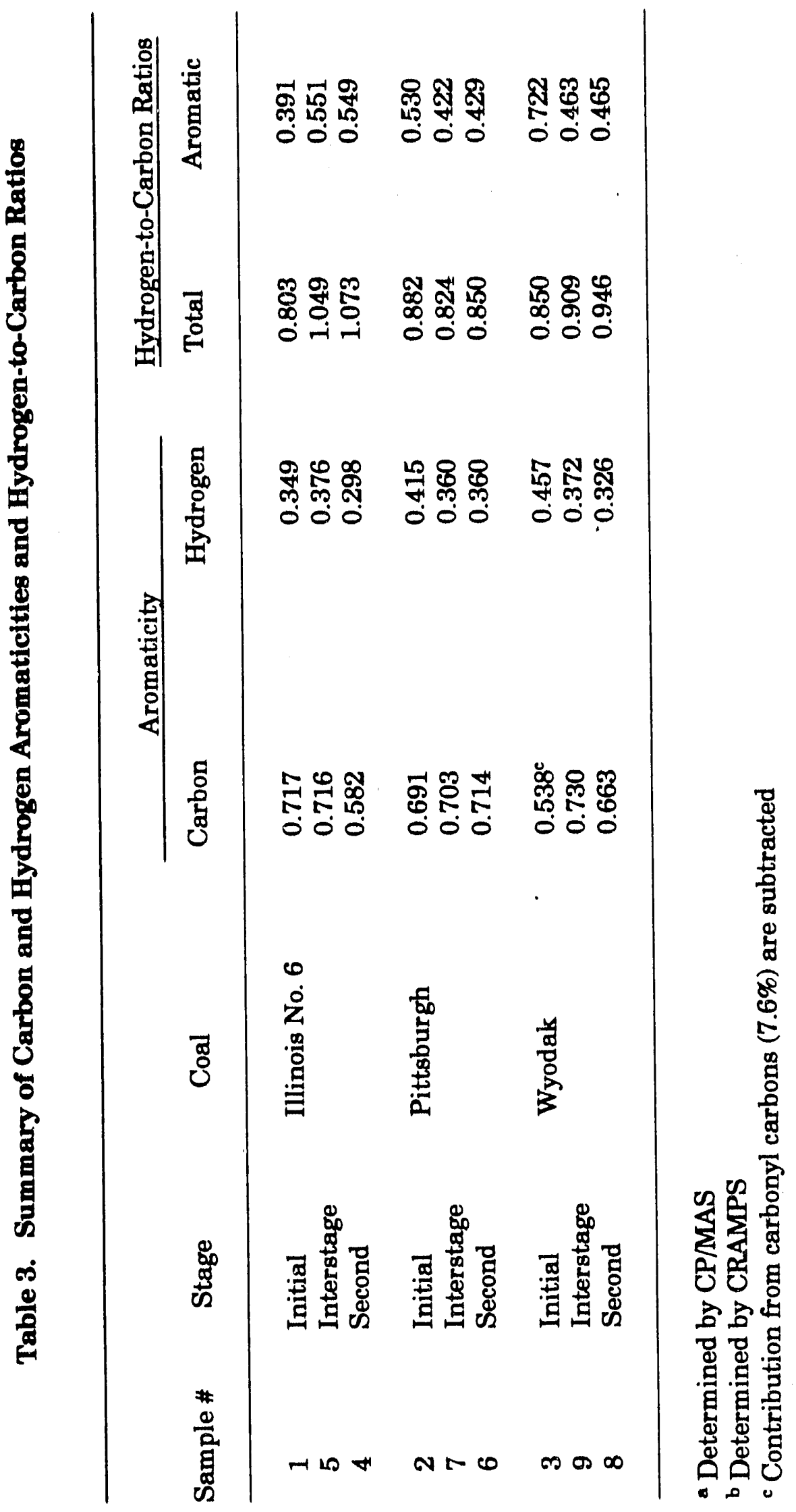


Table 4. Overall Steady-State Material Balance Two-Stage Liquefaction System and First-Stage Reactor System"

Two-Stage System + Deasher

Input

Coal (maf)

Coal Ash

$\mathrm{H}_{2}$

Seal Oil ${ }^{\mathrm{b}}$

Total

Total

$\begin{aligned} & 100 . \\ & 4.58 \\ & 6.73\end{aligned}$
$\frac{2.61}{113.92}$

Input

First Stage

$\begin{array}{lr}\text { Coal (maf) } & 100 . \\ \text { Coal Ash } & 4.58\end{array} \quad$ Ref. No. 2

Output

Output

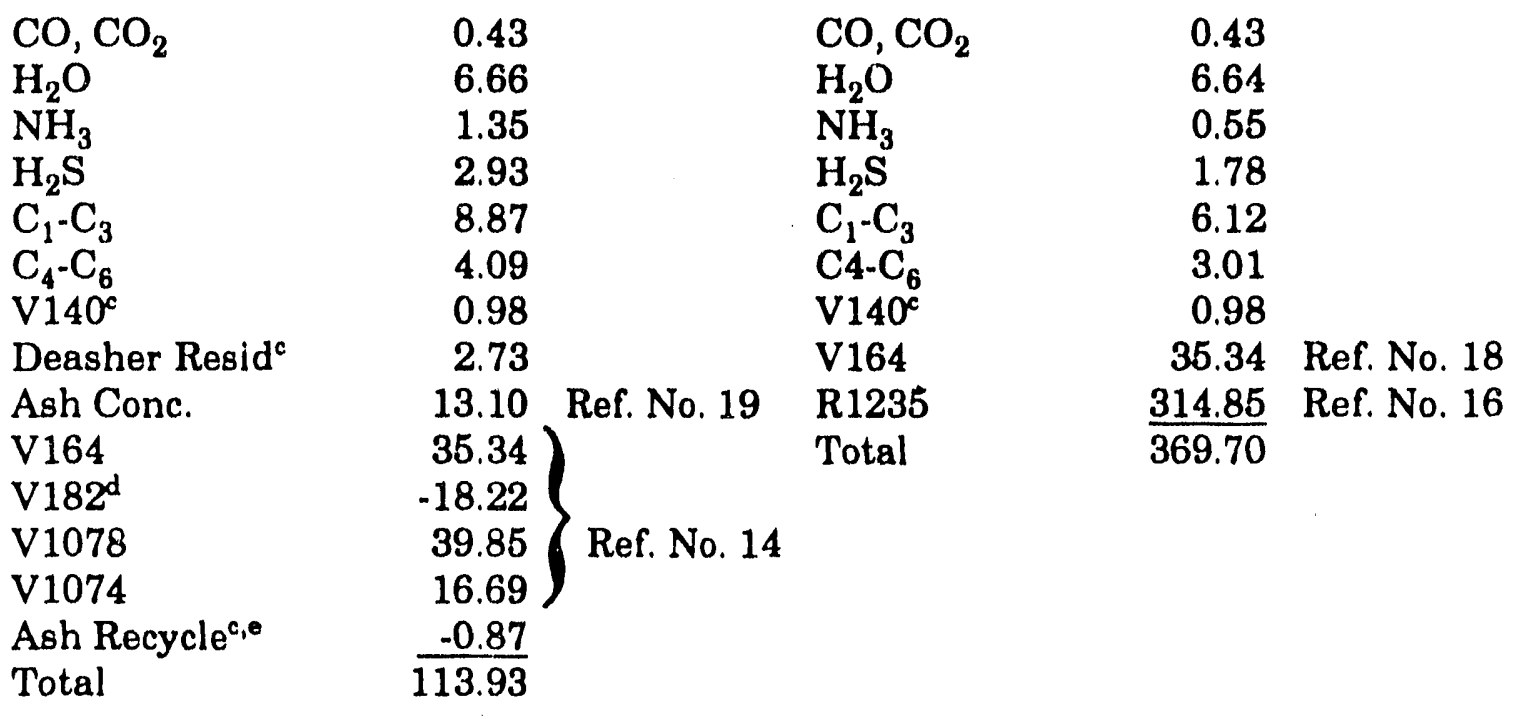

Basis: $100 \mathrm{lb} / \mathrm{hr}$ maf coal @ maf $=218.02 \mathrm{lb} / \mathrm{hr}$

- Data provided by Consol are for Run 259, Period G, Day 5/2/90

b The small amount of this additive is ignored in the material balance calculations.

c The small flow of this product is ignored in the material balance calculations.

d The negative value is the result of an accounting convention at Wilsonville. It is from this stream that all noncoal-derived materials that are introduced into the system are negated from the overall material balance.

- The negative value indicates an inventory draw down. 


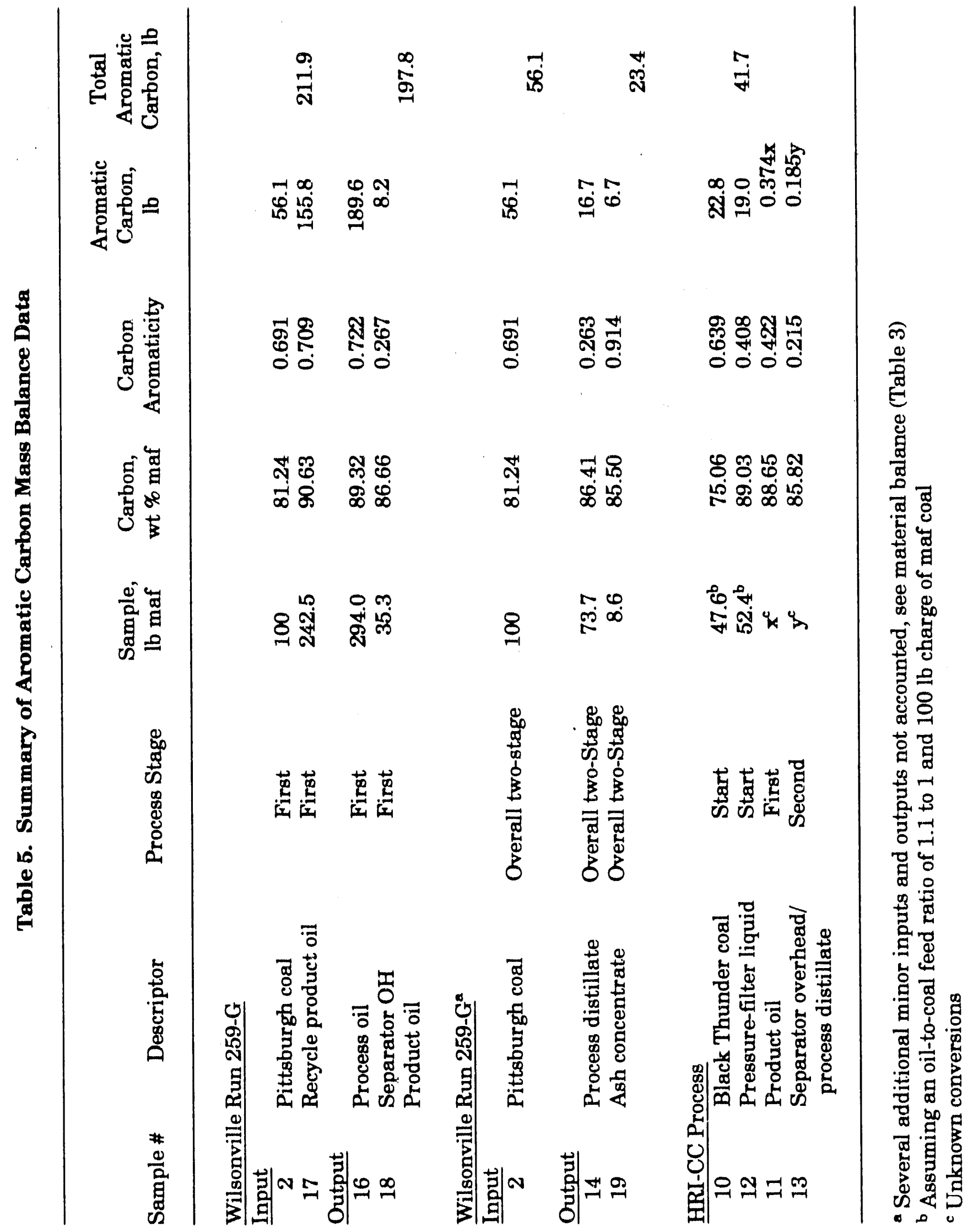




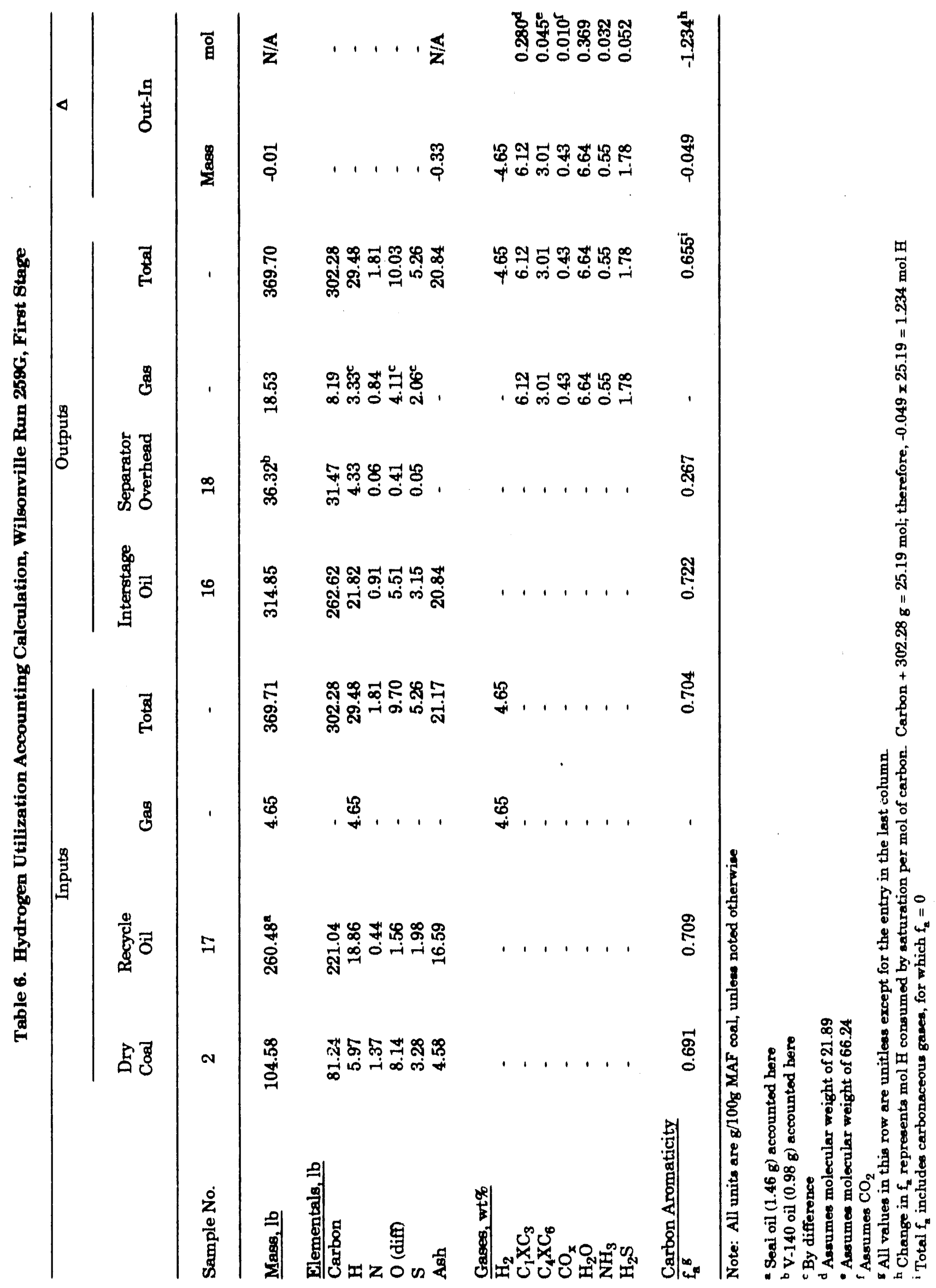




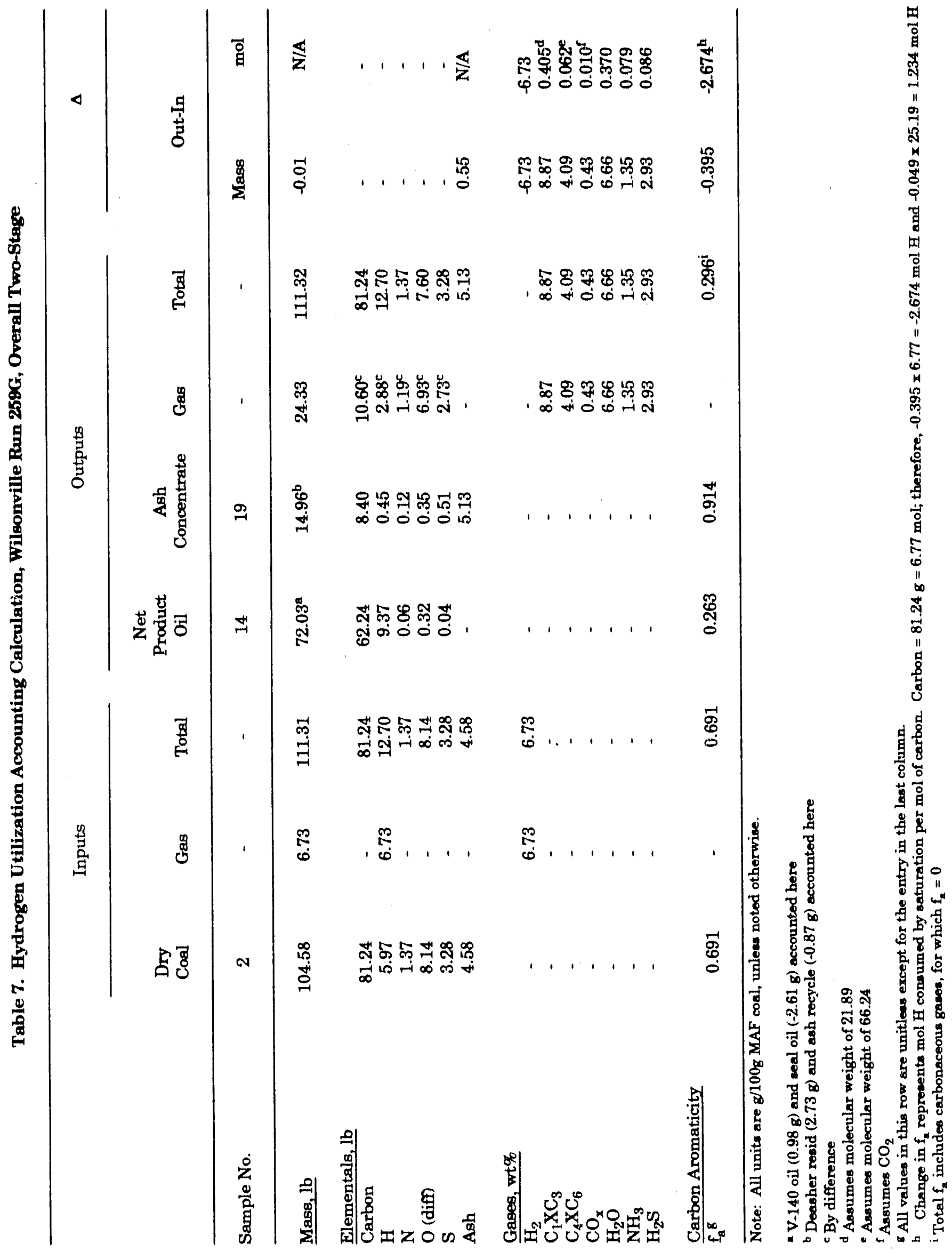


Table 8. Hydrogen Utilization Accounting Calculations, Wilsonville Run 258G

$\mathrm{mol} / 100 \mathrm{~mol}$ of Feedstock Carbon

$\mathrm{H}$

Input Output $\quad \Delta \quad$ Utilization

\section{First Stage}

Analysis, mol $/ 100 \mathrm{~mol}$ Feed C

$\mathrm{C}$
$\mathrm{H}$
$\mathrm{N}$
$\mathrm{O}$
$\mathrm{S}$

$\begin{array}{rrrr}100.00 & 100.00 & - & \\ 98.57 & 113.30 & 14.73 & 14.73 \\ 0.52 & 0.28 & -0.24 & \\ 2.41 & 1.47 & -0.94 & 1.43 \\ 0.65 & 0.40 & -0.25 & \end{array}$

Gas Yield, mol/100 mol Feed C

$\mathrm{C}_{1} \mathrm{X} \mathrm{C}_{3}$

$\mathrm{C}_{4} \times \mathrm{C}_{6}$

$\begin{array}{llll}- & 1.11 & 1.11 & \\ - & 0.18 & 0.18 & 2.6\end{array}$

Carbon Aromaticity

$f_{a}$

0.704

$0.655 \quad-0.049$

4.9

Overall Two Stage

Analysis, $\mathrm{mol} / 100 \mathrm{~mol} \mathrm{Coal} \mathrm{C}$

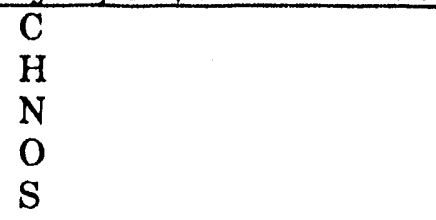

Gas Yield, mol $/ 100 \mathrm{~mol} \mathrm{Coal} \mathrm{C}$

$$
\begin{aligned}
& \mathrm{C}_{1} \times \mathrm{C}_{3} \\
& \mathrm{C}_{4} \mathrm{X} \mathrm{C}_{6}
\end{aligned}
$$

$\begin{array}{rrrc}100.00 & 100.00 & - & \\ 88.18 & 170.60 & 82.42 & 82.42 \\ 1.45 & 0.20 & -1.25 & \\ 7.51 & 0.62 & -6.89 & 9.4 \\ 1.51 & 0.25 & -1.26 & \end{array}$

Carbon Aromaticity
$f_{a}$
0.691
$\begin{array}{ll}-0.395 & 39.5\end{array}$

$\begin{array}{lll}- & 5.99 & 5.99 \\ - & 0.91 & 0.91\end{array}$

5.99

$\begin{array}{lll}- & 5.99 & 5.99 \\ - & 0.91 & 0.91\end{array}$

13.8

a This output total includes liquid streams plus non-heteroatom gases 
Table 9. Hydrogen Utilization Accounting Results, Wilsonville Run 258G

Hydrogen Utilization by Organic Products

mol H/100 mol

$\mathrm{mol} \mathrm{H} / 100 \mathrm{~mol}$

Slurry Carbon

Coal Carbon ${ }^{b}$

\section{First Stage}

$\mathrm{C}_{1} \mathrm{X} \mathrm{C}_{3}$ Production

$\mathrm{C}_{4} \mathrm{X} \mathrm{C}_{6}$

Heteroatom Removal

Hydrogenation

Matrix Cleavage

Total

\begin{tabular}{cc}
2.2 & 8.3 \\
0.4 & 1.3 \\
$1.4^{\mathrm{c}}$ & $5.1^{\mathrm{c}}$ \\
4.9 & 18.2 \\
$\frac{5.8}{14.7^{\mathrm{a}}}$ & $\underline{21.9}$ \\
\hline $54.8^{\mathrm{a}}$
\end{tabular}

Overall Two Stage

$\mathrm{C}_{1} \mathrm{X} \mathrm{C}_{3}$

$\mathrm{C}_{4} \mathrm{X} \mathrm{C}_{6}$

Heteroatom Removal

Hydrogenation

Matrix Cleavage

Total

12.0

1.8

$9.4^{\mathrm{c}}$

39.5

19.7

$82.4^{\mathrm{a}}$

\section{Second Stage (By Diff.)}

$\mathrm{C}_{1} \times \mathrm{C}_{3}$ Production

$\mathrm{C}_{4} \mathrm{X} \mathrm{C}_{6}$

Heteroatom Removal

Hydrogenation

Matrix Cleavage

Total

$\begin{array}{lc}- & 3.7 \\ - & 0.5 \\ - & 4.3^{\mathrm{c}} \\ - & 21.3 \\ - & \frac{-2.2}{27.6^{\mathrm{a}}}\end{array}$

a Does not include $\mathrm{H}$ consumed as $\mathrm{H}_{2} \mathrm{O}, \mathrm{H}_{2} \mathrm{~S}$, or $\mathrm{NH}_{3}$. Those values are $13.9,17.0$ and 3.1 $\mathrm{mol} / 100 \mathrm{~mol}$ of coal carbon, respectively, for first stage, overall two stage, and second stage. That value, when added to this total, will exactly equal total hydrogen consumption as shown in material balance.

b Coal carbon-to-slurry carbon ratio $=81.24 / 302.28$

c Refers to $\mathrm{H}$ added to carbonaceous products to replace carbon-heteroatom bonds. 


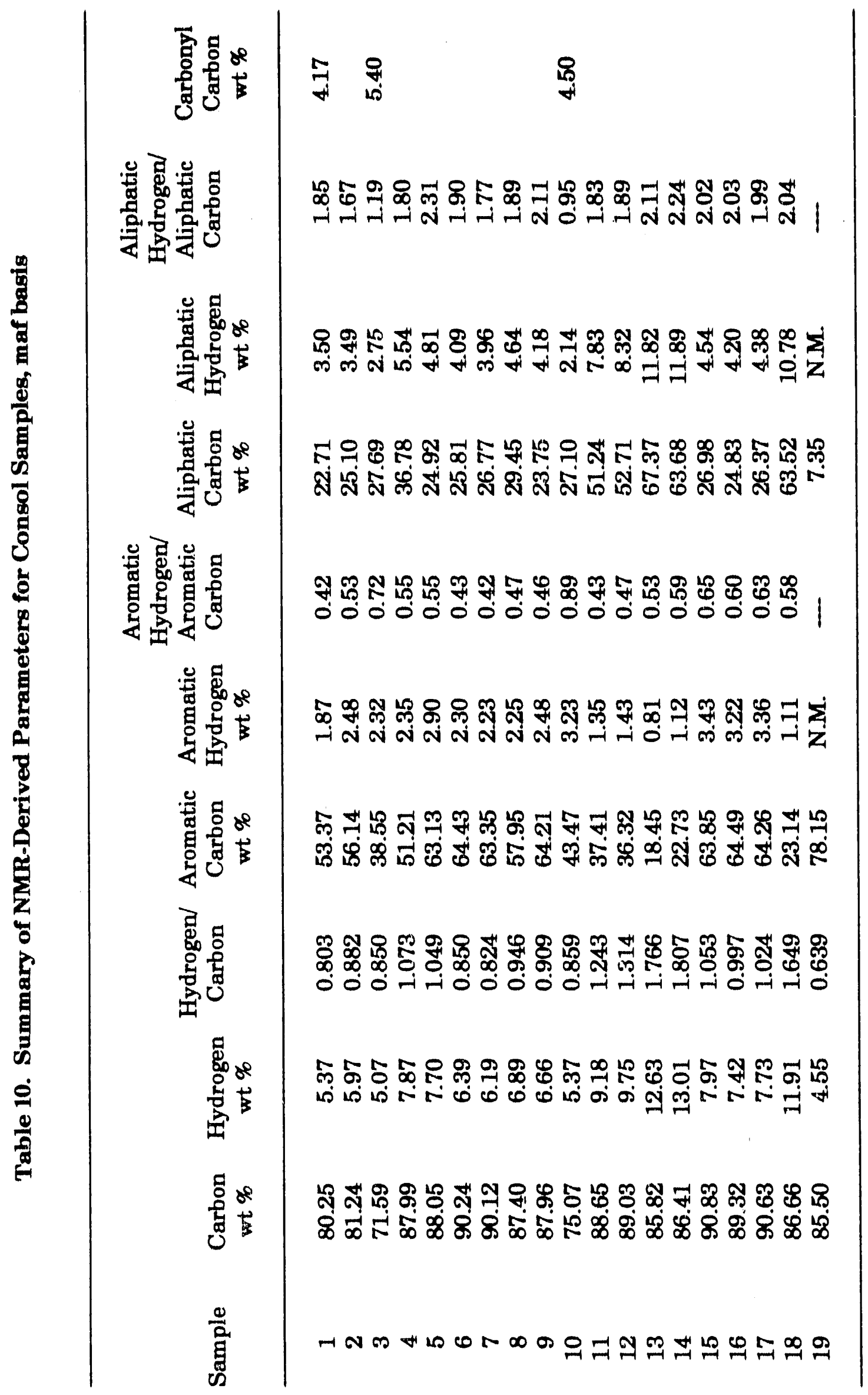



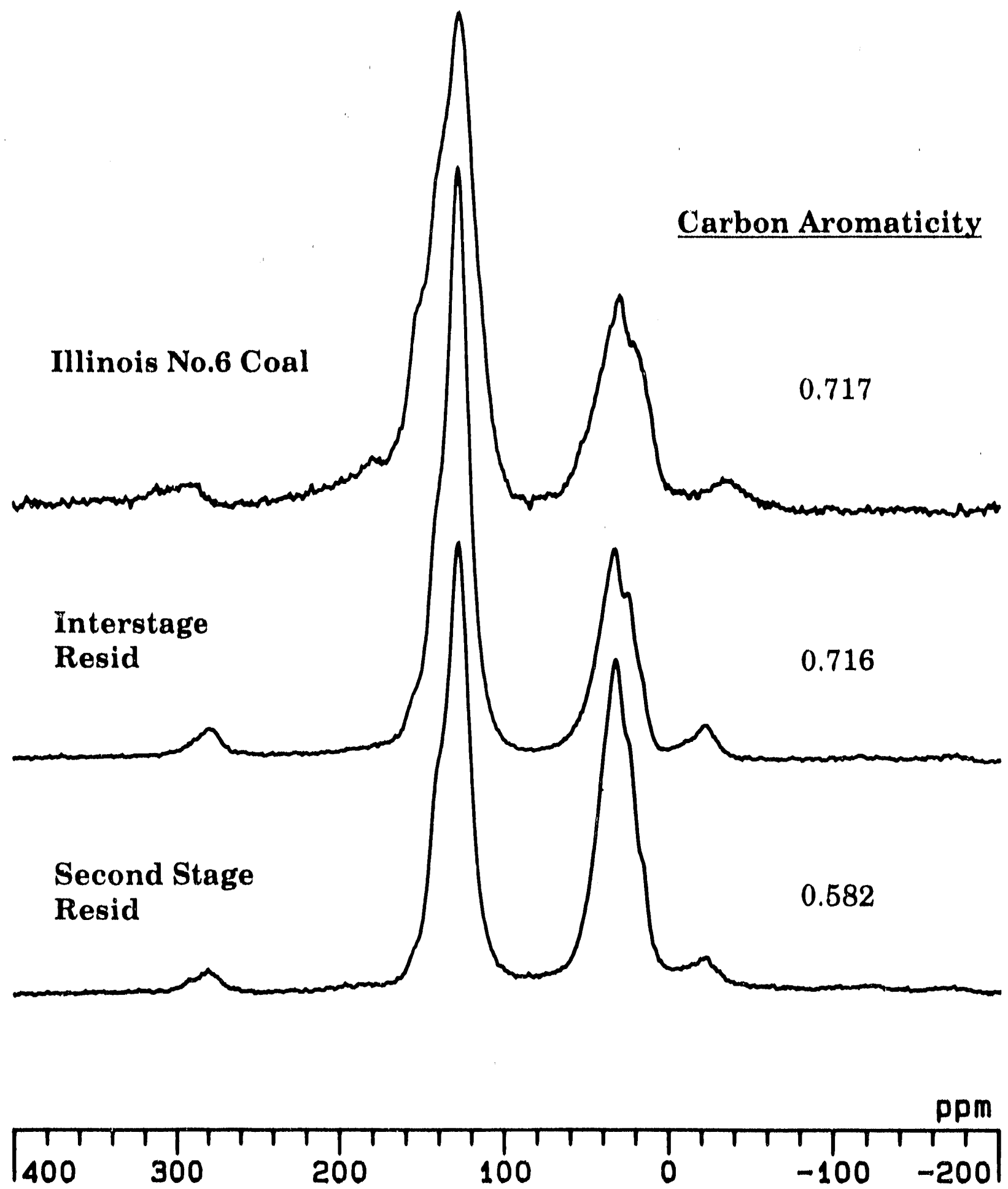

Figure 1. CP/MAS ${ }^{13} \mathrm{C}$ NMR Spectra and Carbon Aromaticities of Resids From Wilsonville Run 257 on Illinois No. 6 Coal 

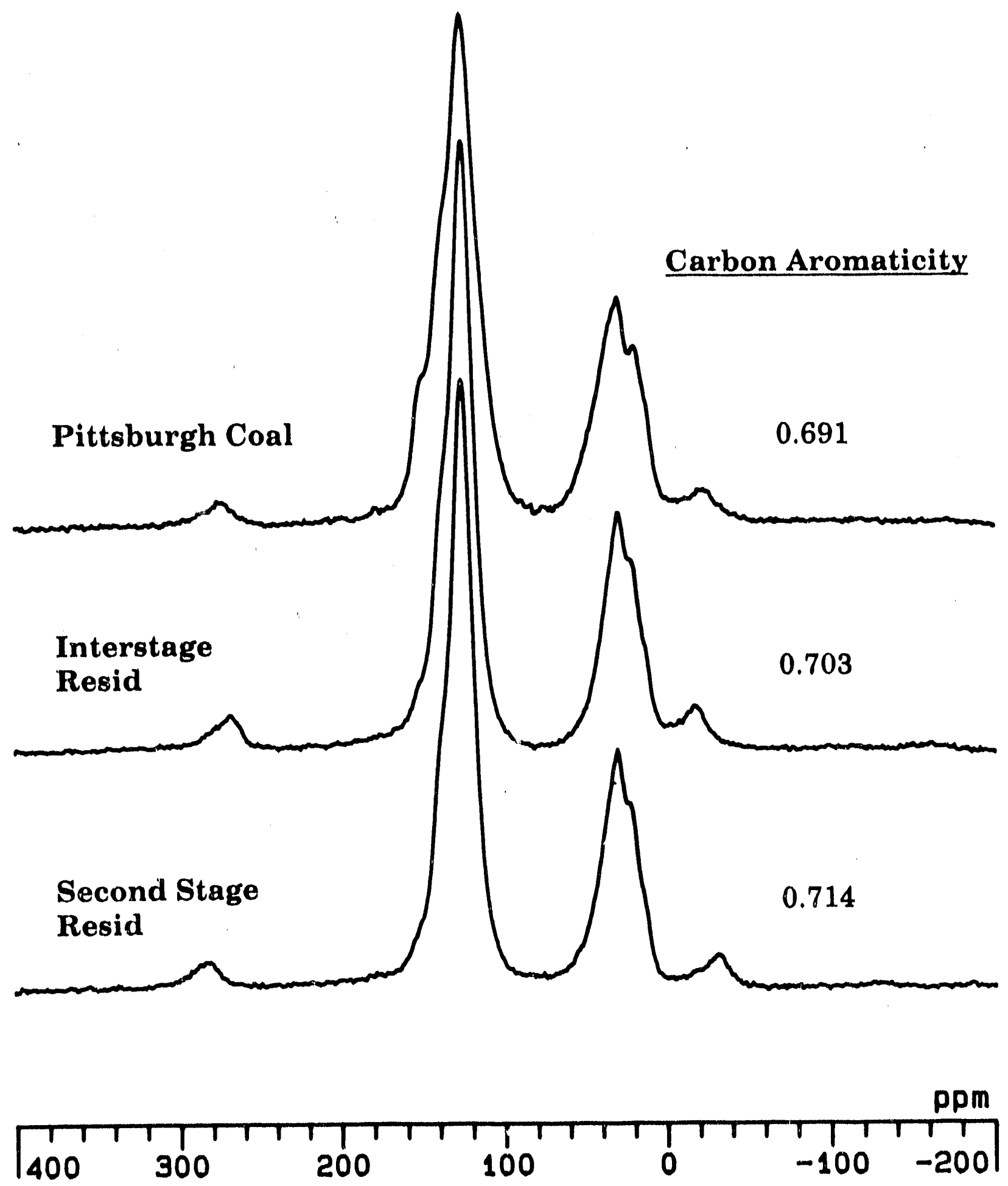

Figure 2. CP/MAS ${ }^{13} \mathrm{C}$ NMR Spectra and Carbon Aromaticities of Resids From Wilsonville Run 259 on Pittsburgh Seam Coal 

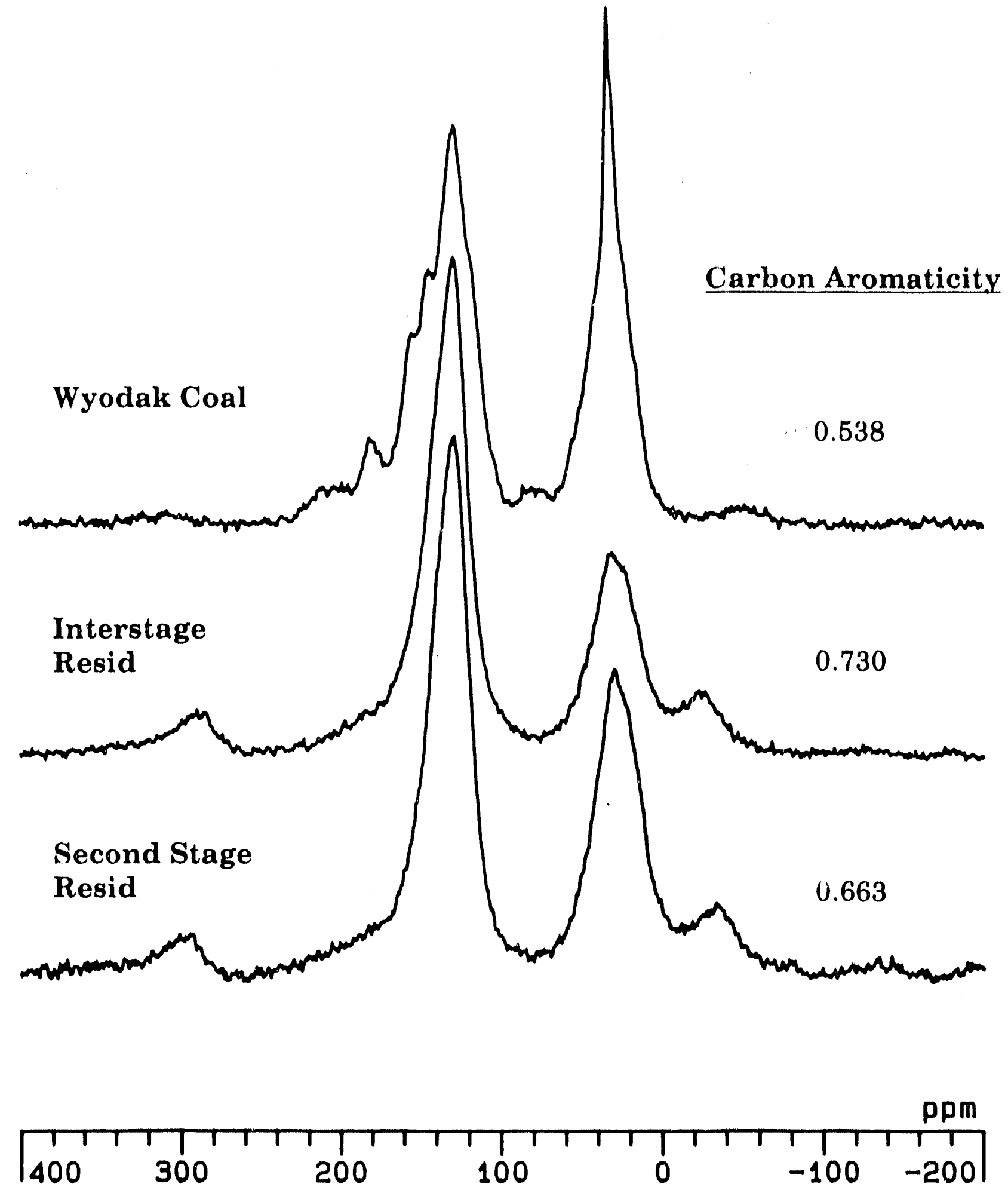

Figure 3. CP/MAS ${ }^{13} \mathrm{C}$ NMR Spectra and Carbon Aromaticities of Resids From Wilsonville Run 251-III on Wyodak Coal 

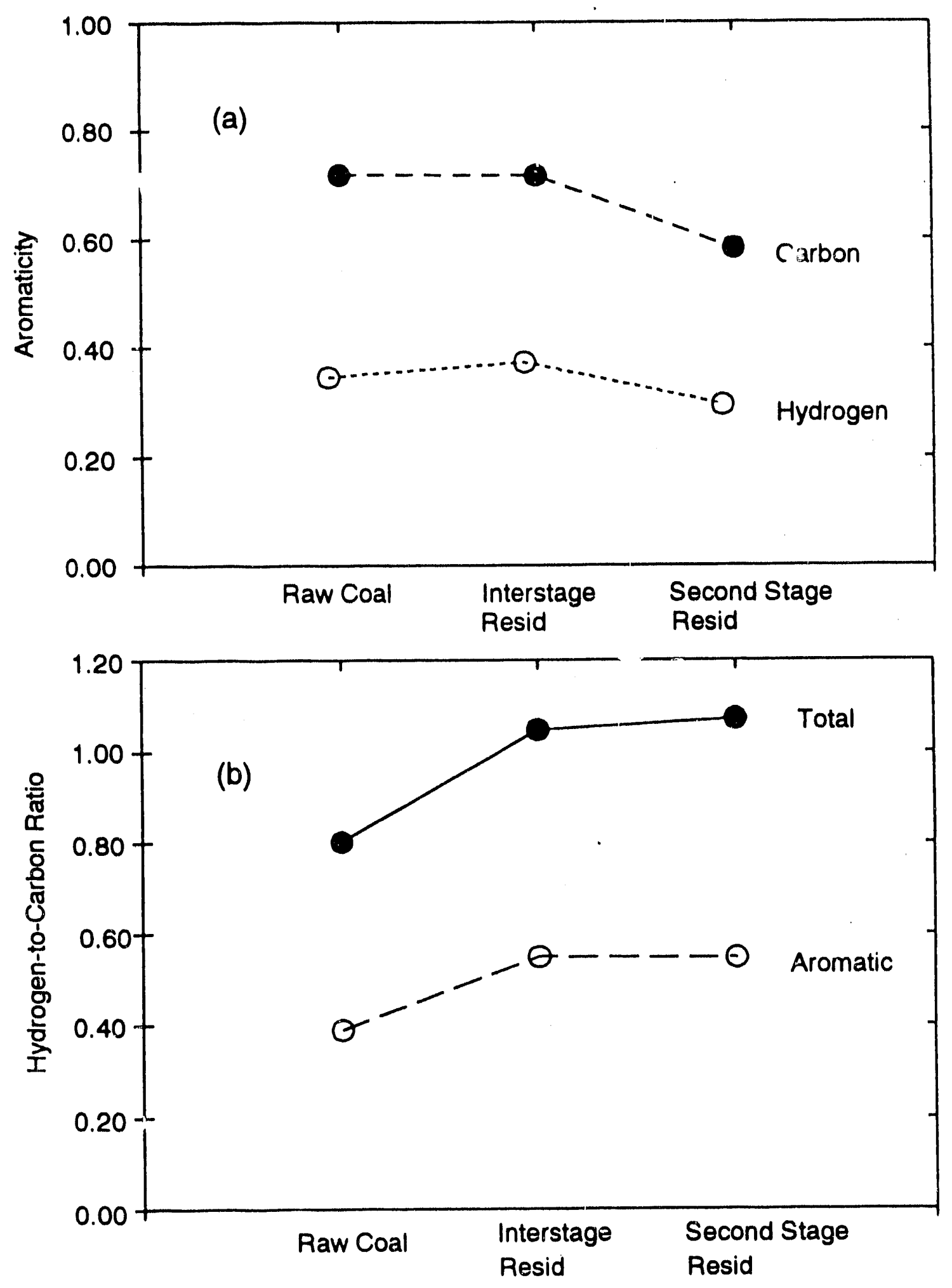

Figure 4. Plots of (a) Aromaticities and (b) Hydrogen-to-Carbon Ratios of Resids From Wilsonville Run 25" on Illinois No. 6 Coal 

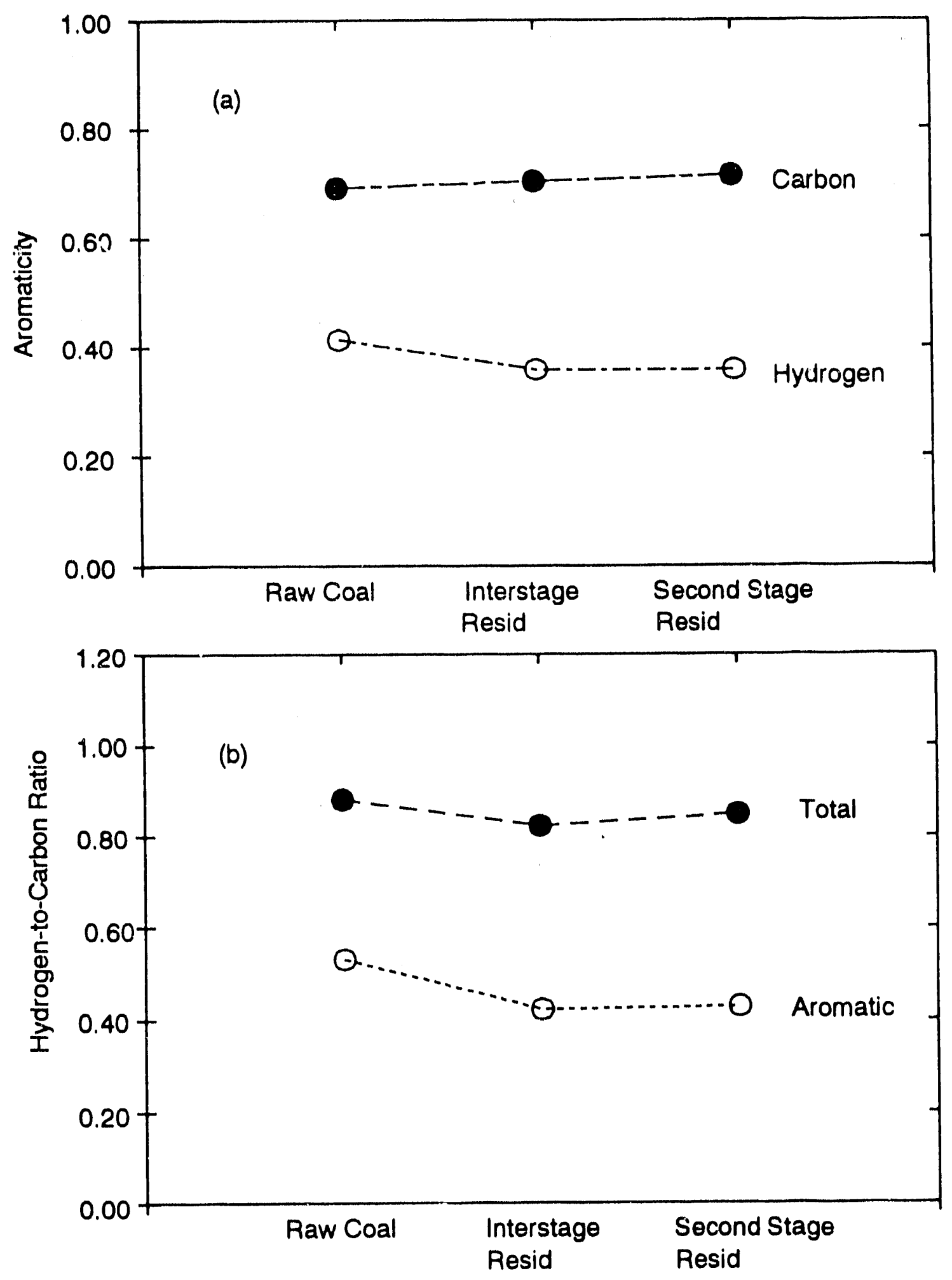

Figure 5. Plots of (a) Aromaticities and (b) Hydrogen-to-Carbon Ratios of Resids From Wilsonville Run on 259 on Pittsburgh Seam Coal 

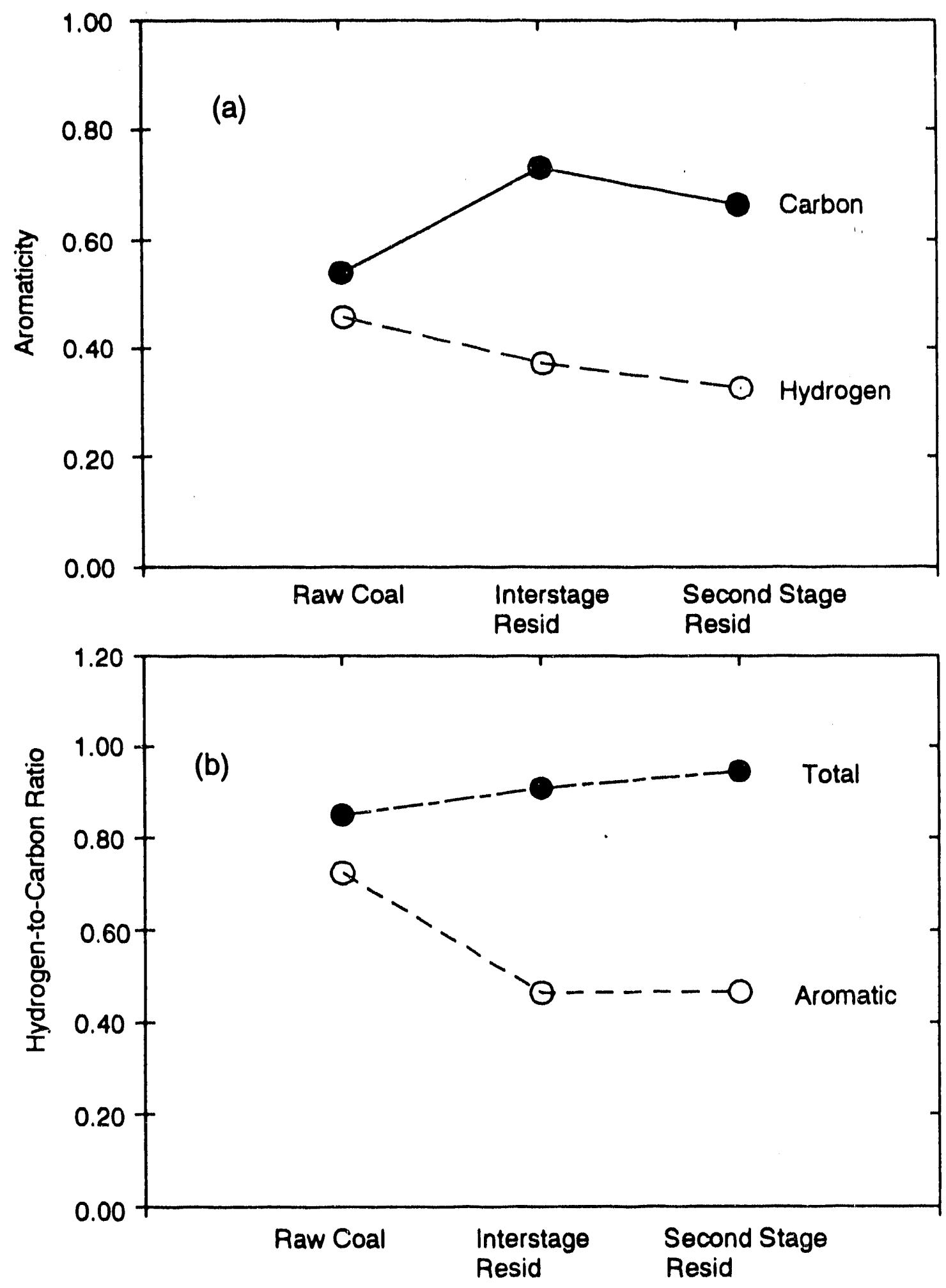

Figure 6. Plots of (a) Aromaticities and (b) Hydrogen-to-Carbon Ratios of Resids From wilsonville Run 251-III on Wyodak Coal 
APPENDIX A

Chemical Shift Ranges and Liquid-State NMR-Derived Structural Parameters 


\section{Contents of Appendix A}

Table

Page

A-1. ${ }^{1} \mathrm{H}$ and ${ }^{13} \mathrm{C}$ NMR Chemical Shift Ranges ........................................ 43

A-2. Structural Parameters for Consol Samples ........................................ 44 
Table A-1. ${ }^{1} \mathrm{H}$ and ${ }^{18} \mathrm{C}$ NMR Chemical Shift Ranges

Definitions

Total aromatic hydrogens

Monoaromatic hydrogens

Diaromatic hydrogens

Total alkane hydrogen

Methylene hydrogens $\alpha$ to aromatic ring

Methyl hydrogens $\alpha$ to aromatic ring

Naphthene hydrogens $\beta$ to aromatic ring

$\beta-\mathrm{CH}_{2}$ and $\beta-\mathrm{CH}_{3}$ to aromatic ring and normal alkane $-\mathrm{CH}_{2}$ - hydrogens

$\gamma-\mathrm{CH}_{3}$ to arumatic ring and normal or branch alkane $-\mathrm{CH}_{3}$ hydrogens

Total aromatic carbons

Total aliphatic carbons

Methyl carbons of n-alkanes

$\mathrm{C}_{2}$-methylene carbons of n-alkanes

$\mathrm{C}_{3}$-methylene carbons of $\mathrm{n}$-alkanes

$\mathrm{C}_{4,5, \mathrm{n}}$-methylene carbons of $\mathrm{n}$-alkanes
Chemical Shift, range

$\mathrm{ppm}$ from TMS

6.6-8.3

6.6-7.2

$7.2-8.3$

$0.5-4.0$

$2.3-4.0$

1.9-2.3

$1.6-1.9$

1.0-1.6

$0.5-1.0$

100-150

5-50

13.8-14.2

22.7-23.0

31.8-32.0

29-30 
Parameter

Separator Overhead

Process Distillate,

Sample \#13

Product Process

Distillate,

Sample \#15

Fraction of

Aromatic carbons

0.215

0.263

Tertiary aromatic carbons

0.113

0.155

Quaternary aromatic carbons

0.101

0.108

Alkane carbons

0.785

0.737

$\mathrm{N}$-alkane carbons

Branched, cyclo and

alkylaromatic carbons

Aromatic hydrogens

0.064

0.086

Monoaromatic hydrogens

0.043

0.053

Diaromatic hydrogens

0.021

0.032

Alkane hydrogens

0.936

0.914

Methylene hydrogens $a$ to aromatic ring

0.071

0.088

Methyl hydrogens $\alpha$ to aromatic ring

Naphthene hydrogens $\beta$ to aromatic ring

$\beta$-methylene and $\beta$-methyl hydrogens

to aromatic ring and n-alkane

methylene hydrogens

$\gamma$-methyl to aromatic ring and normal or branched alkane methyl hydrogens

a HI run CC-1

b Wilsonville run 259G 


\section{APPENDIX B}

${ }^{13}$ C NMR Spertra 


\section{Contents of Appendix B}

Figure

Page

B-1. CP/MAS ${ }^{13} \mathrm{C}$ NMR Spectrum of Illinois No. 6 Coal, Ref No. 1

B-2. CP/MAS ${ }^{13}$ C NMR Spectrum of Illinois No. 6 Coal, Ref No. 1

B-3. CP/MAS ${ }^{13}$ C NMR Spectrum of Illinois No. 6 Coal, Ref No. 1

B-4. CP/MAS ${ }^{13} \mathrm{C}$ NMR Spectrum of Pittsburgh Coal, Ref No. 2................ 51

B-5. CP/MAS ${ }^{13} \mathrm{C}$ NMR Spectrum of Pittsburgh Coal, Ref No. 2................ 52

B-6. Single-Pulse ${ }^{13} \mathrm{C}$ NMR Spectrum of Pittsburgh Coal, Ref No. 2

B-7. CP/MAS ${ }^{13} \mathrm{C}$ NMR Spectrum of Wyodak Coal, Ref No. 3...................... 54

B-8. CP/MAS ${ }^{13}$ C NMR Spectrum of Wyodak Coal, Ref No. 3....................... 55

B-9. CP/MAS ${ }^{13} \mathrm{C}$ NMR Spectrum of Second-Stage Product Resid from Illinois No. 6 Coal, Ref No. 4 ....................................................

B-10. CP/MAS ${ }^{13} \mathrm{C}$ NMR Spectrum of Interstage Oil Resid from Illinois No. 6 Coal, Ref No. 5..................................................................

B-11. CP/MAS ${ }^{13} \mathrm{C}$ NMR Spectrum of Interstage Oil Resid from Illinois No. 6 Coal, Ref No. 5.................................................................... 58

B-12. CP/MAS ${ }^{13} \mathrm{C}$ NMR Spectrum of Second-Stage Product Resid from Pittsburgh Coal, Ref No. 6

B-13. Single-Pulse CP/MAS ${ }^{13} \mathrm{C}$ NMR Spectrum of Second-Stage Product Resid from Pittsburgh Coal, Ref No. 6...

B-14. CP/MAS ${ }^{13} \mathrm{C}$ NMR Spectrum of Interstage Oil Resid from Pittsburgh Coal, Ref No. 7 .

B-15. CP/MAS ${ }^{13} \mathrm{C}$ NMR Spectrum of Interstage Oil Resid from Pittsburgh Coal, Ref No. 7..

B-16. CP/MAS ${ }^{13} \mathrm{C}$ NMR Spectrum of Second-Stage Product Resid from Wyodak Coal, Ref No. 8

B-17. CP/MAS ${ }^{13} \mathrm{C}$ NMR Spectrum of Interstage Oil Resid from Wyodak Coal, Ref No. 9

B-18. CP/MAS ${ }^{13} \mathrm{C}$ NMR Spectrum of Black Thunder Coal, Ref No. 10 
B-19. Single-Pulse ${ }^{13}$ C NMR Spectrum of First-Stage Product

Oil from Black Thunder Coal, Ref No. 11 ....

B-20. Single-Pulse ${ }^{13} \mathrm{C}$ NMR Spectrum of Pressure Filter Liquid

Process Oil from Black Thunder Coal, Ref No. 12.

B-21. High-Resolution Liquid-State ${ }^{13} \mathrm{C}$ NMR Spectrum of Separator

Overhead Process Distillate from Black Thunder Coal,

Ref No. 13.

B-22. High-Resolution Liquid-State ${ }^{13} \mathrm{C}$ NMR Product Process

Distillate from Pittsburgh Coal, Ref No. 14....

B-23. CP/MAS ${ }^{13} \mathrm{C}$ NMR Spectrum of Second-Stage Product Process

Oil from Pittsburgh Coal, Ref No. 15.

B-24. Single-Pulse ${ }^{13} \mathrm{C}$ NMR Spectrum of Second-Stage Product

Process Oil from Pittsburgh Coal, Ref No. 15

B-25. CP/MAS ${ }^{13} \mathrm{C}$ NMR Spectrum of Interstage Product Oil from

Pittsburgh Coal, Ref No. 16.

B-26. CP/MAS ${ }^{13} \mathrm{C}$ NMR Spectrum of Recycle Product Oil from

Pittsburgh Coal, Ref No. 17.

B-27. High-Resolution Liquid-State ${ }^{13} \mathrm{C}$ NMR Spectrum of Separator Overhead Process Distillate from Pittsburgh Coal,

Ref No. 18.

B-28. CP/MAS ${ }^{13} \mathrm{C}$ NMR Spectrum of Ash Concentrate from Pittsburgh

Coal, Ref No. 19. 


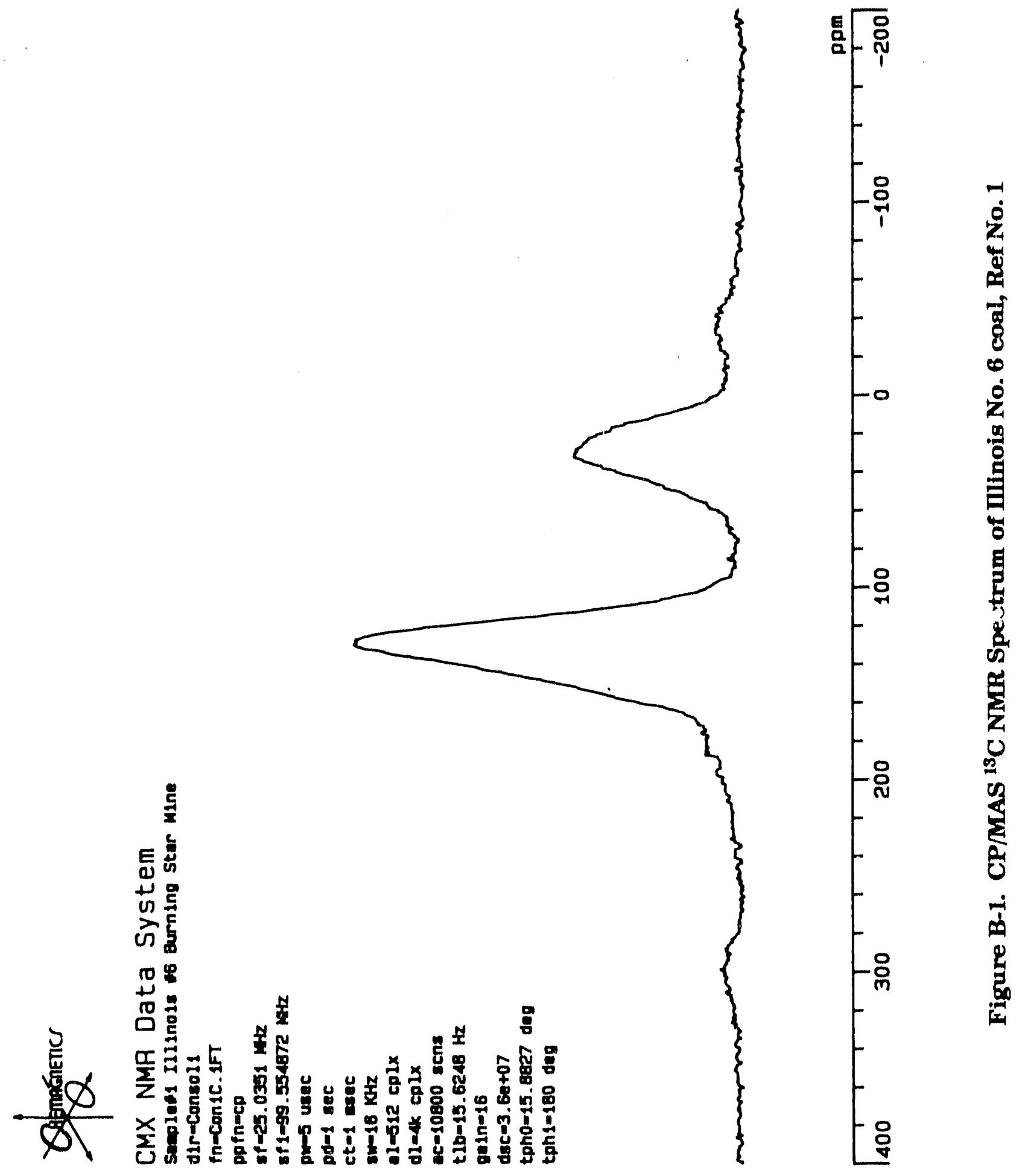




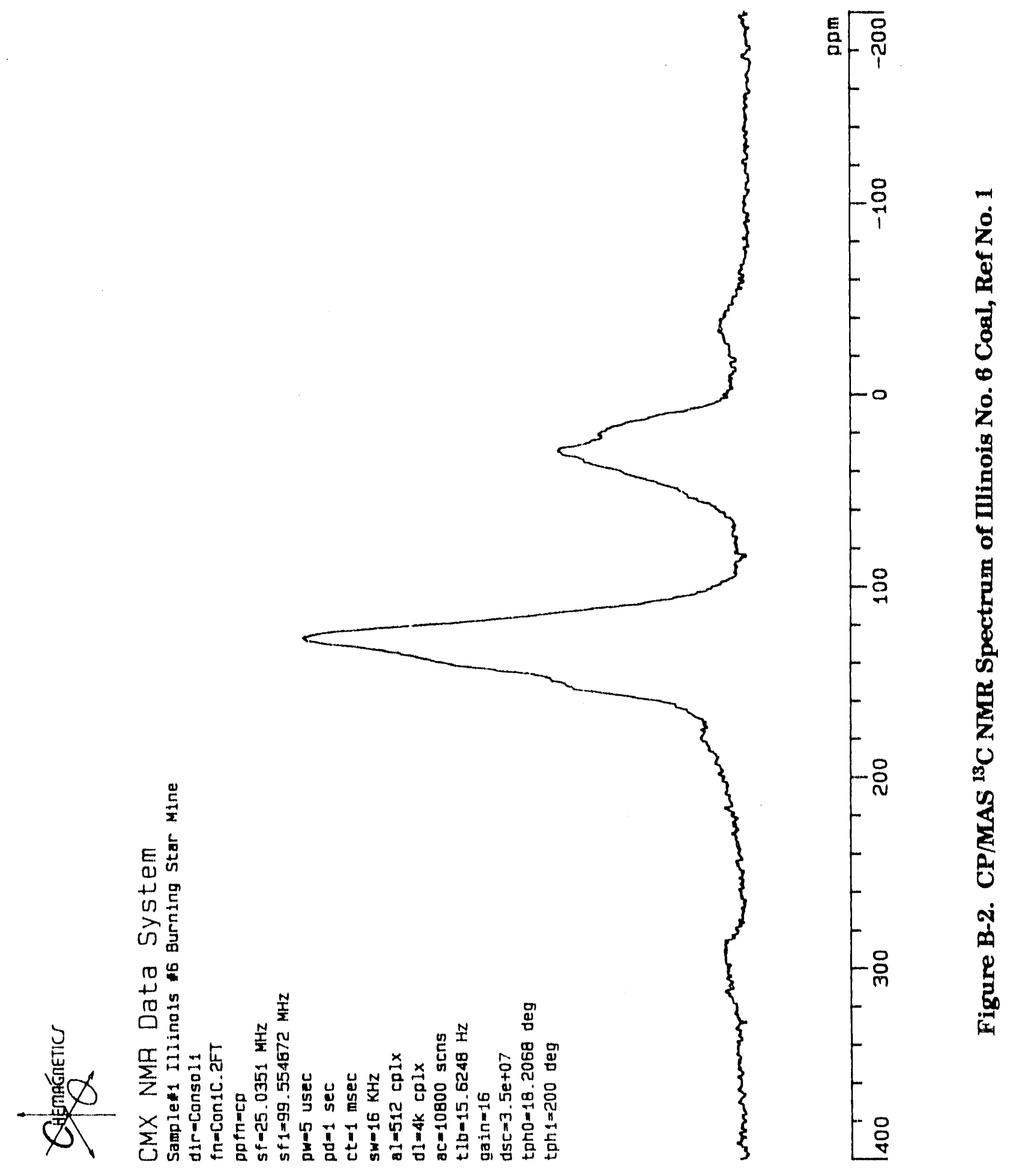




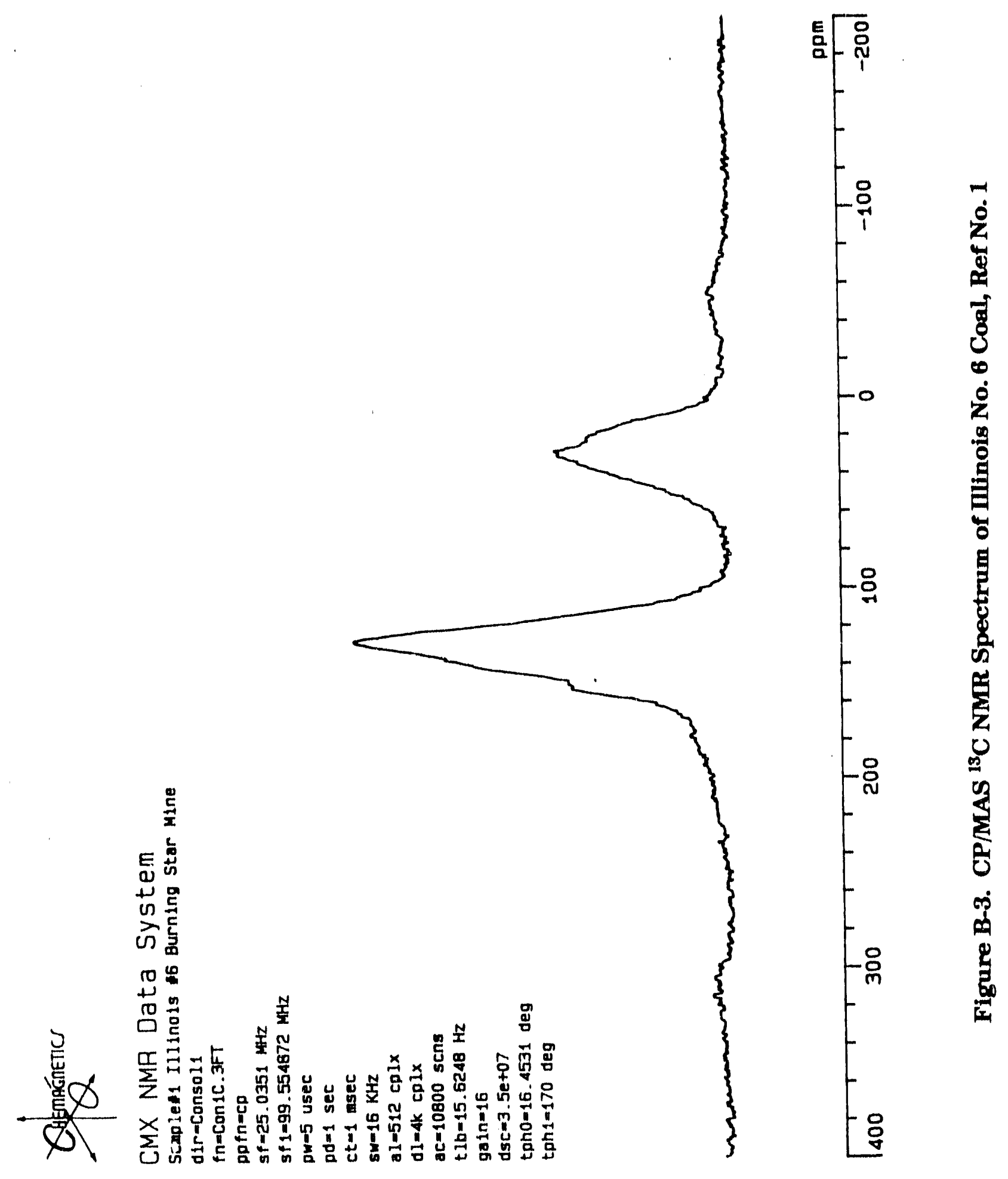




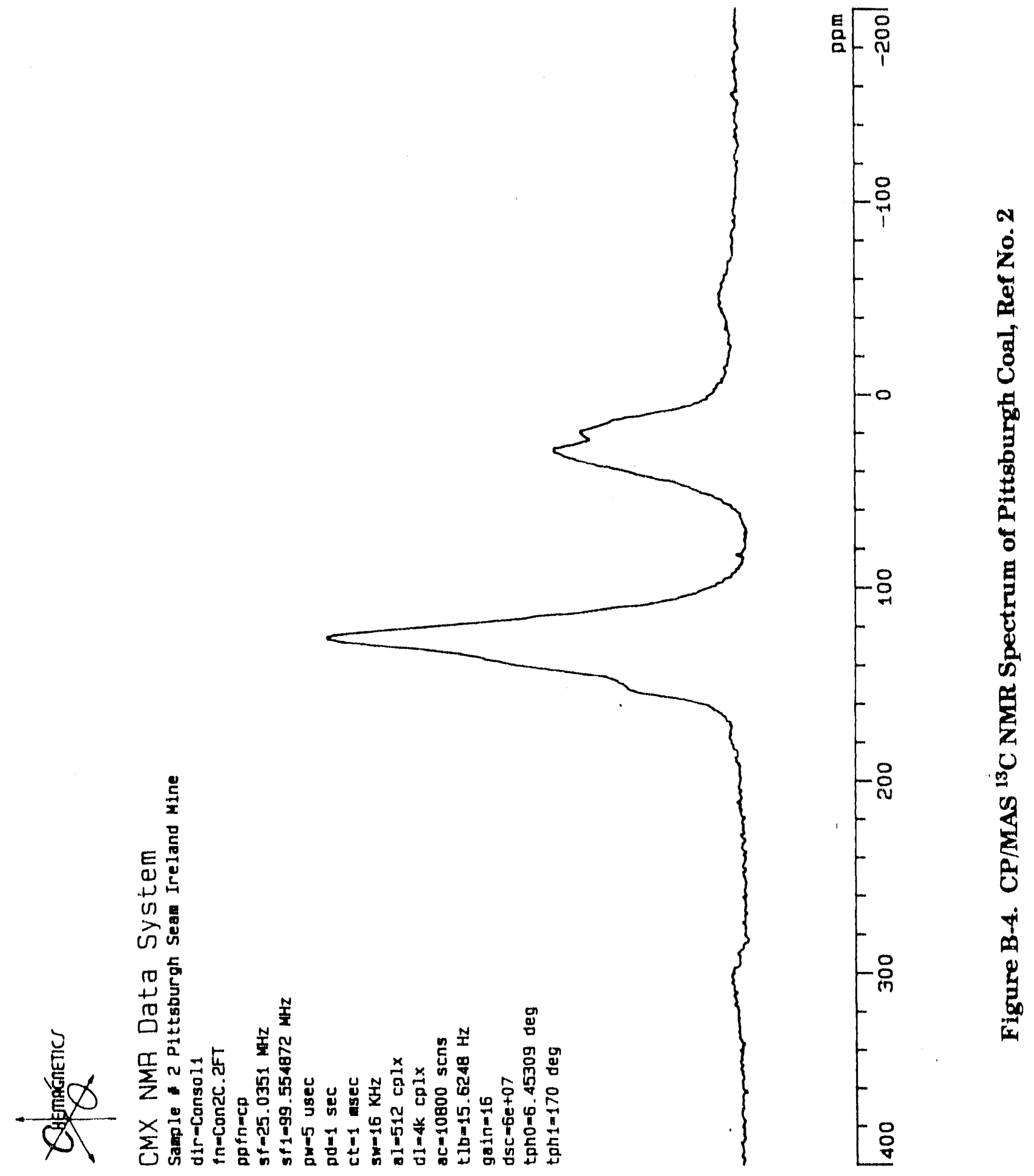




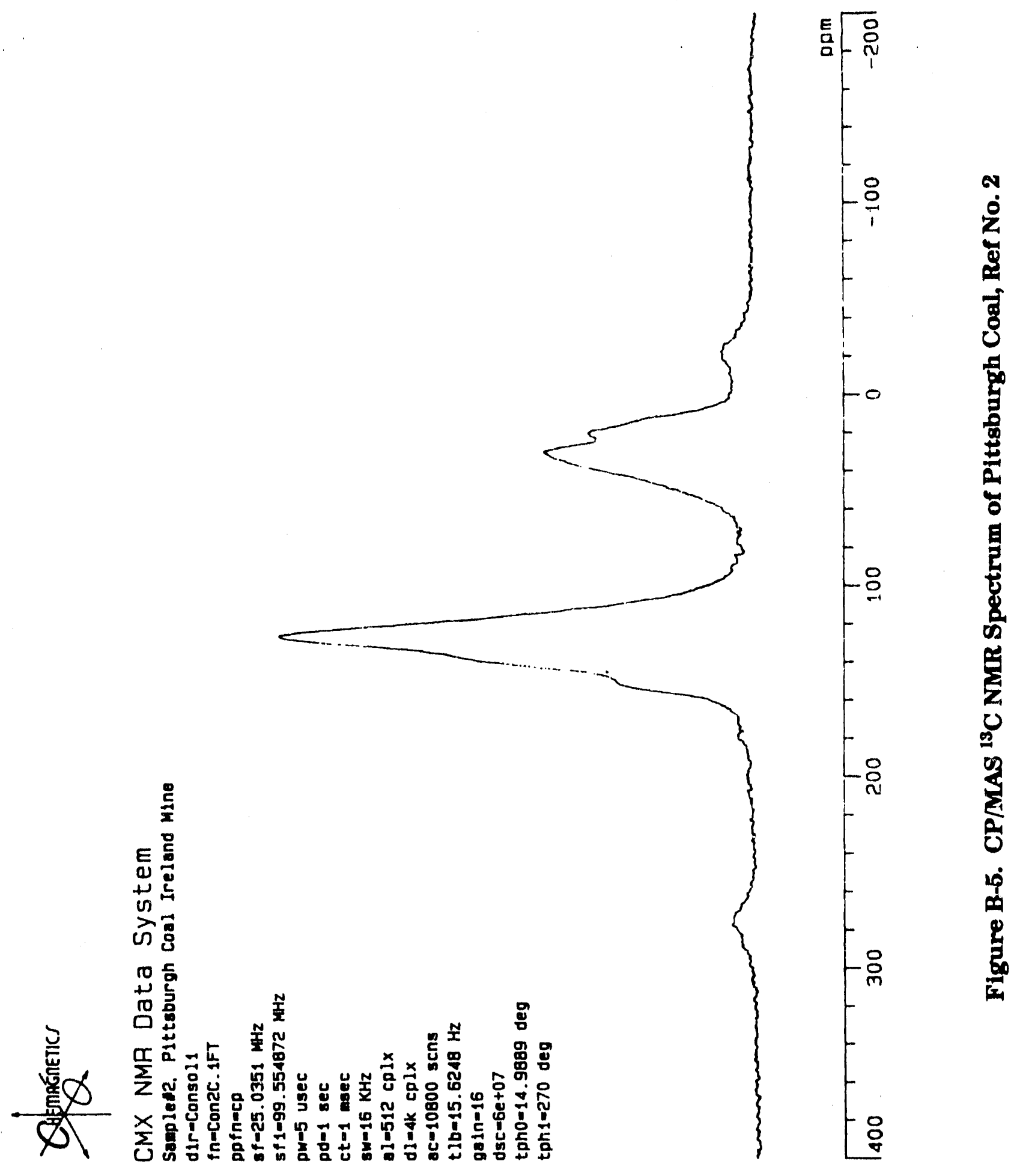




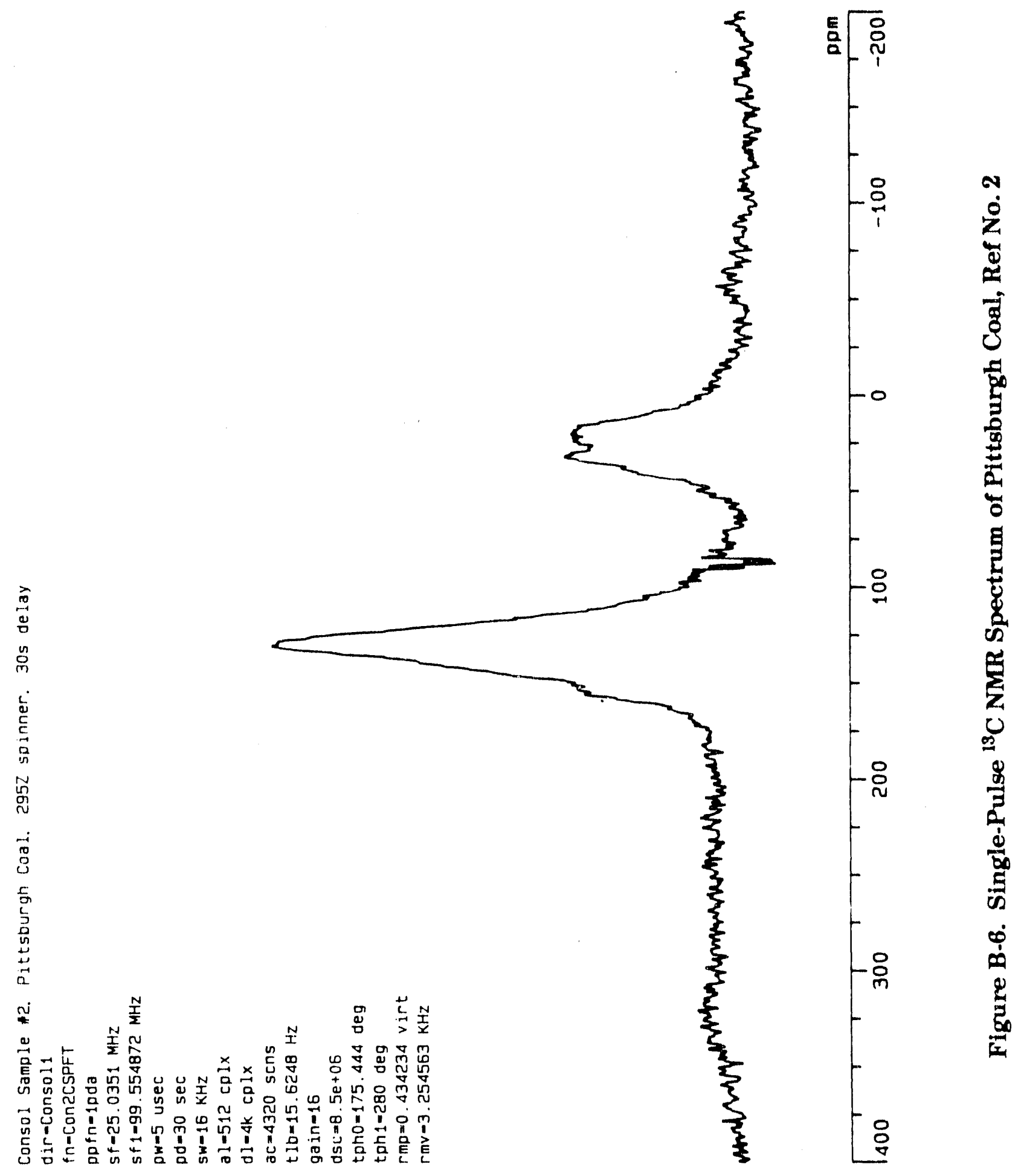




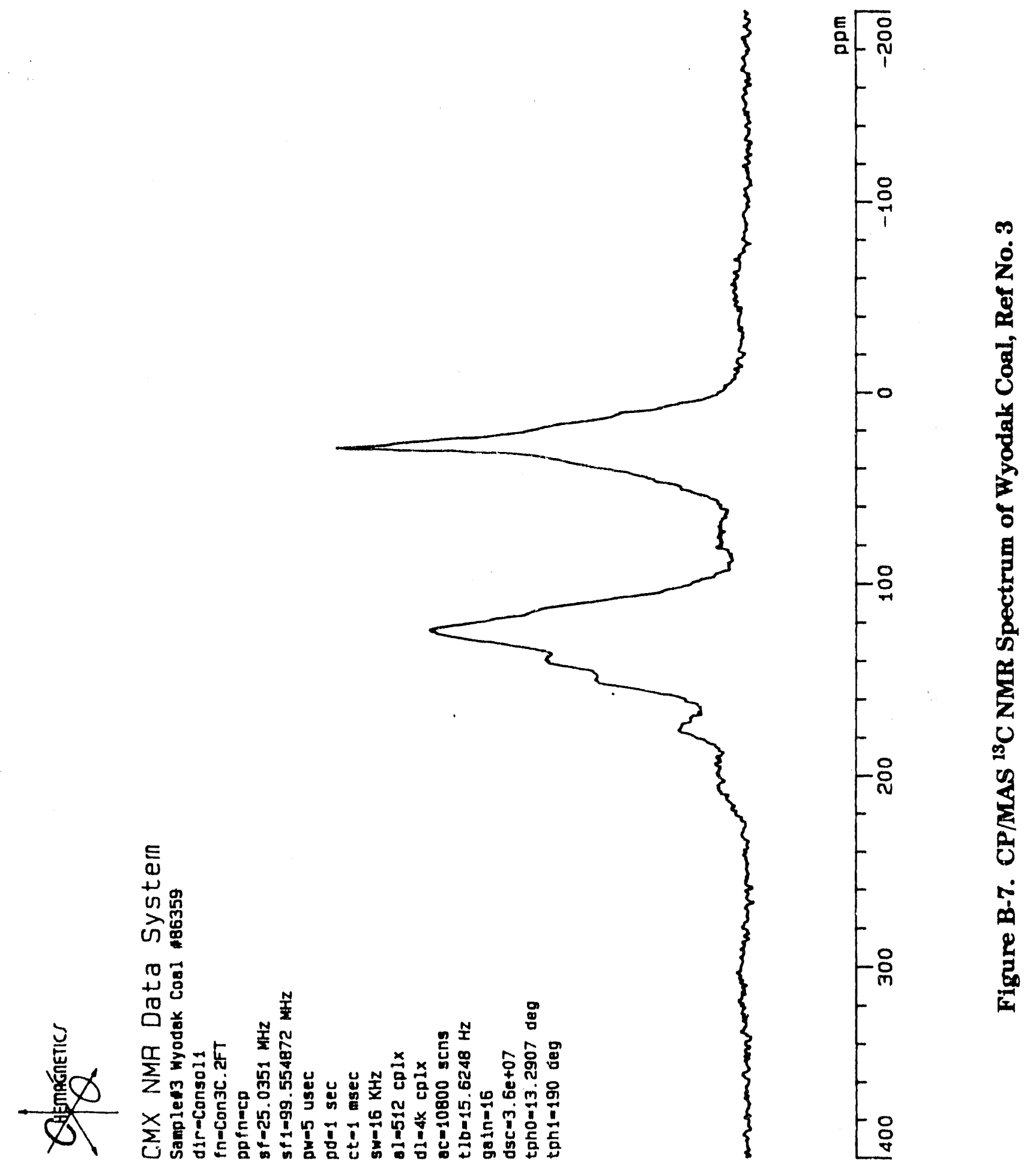




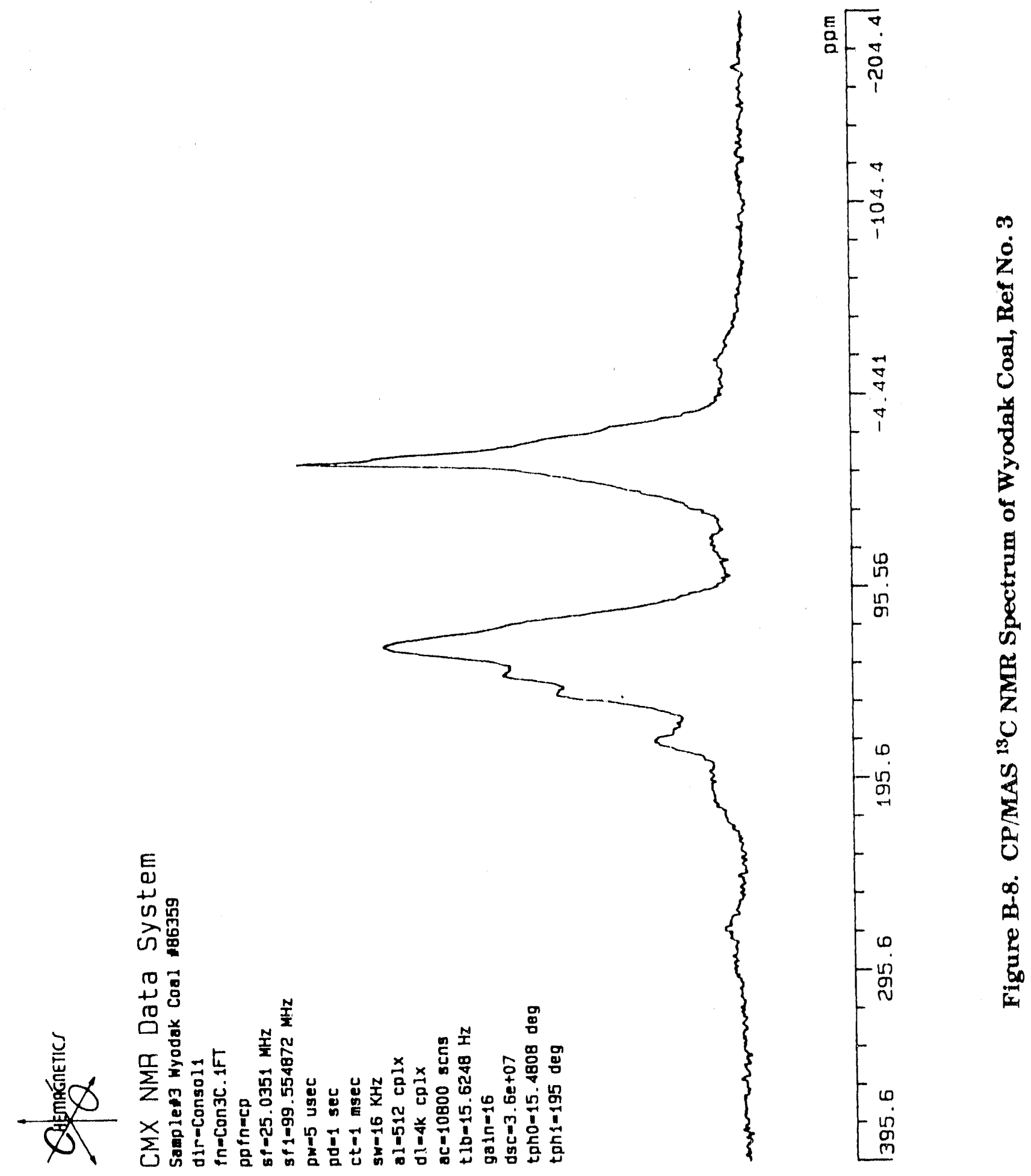




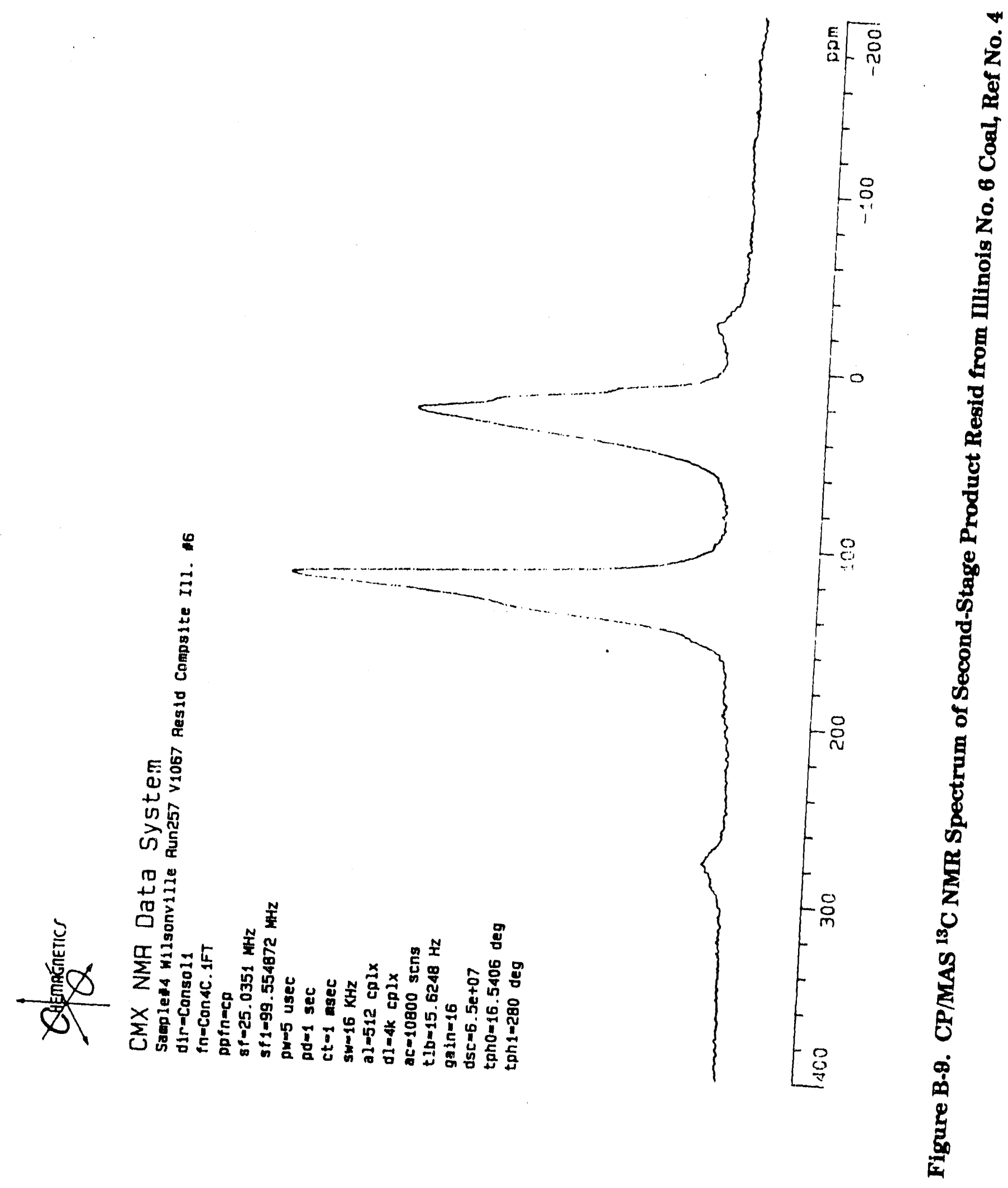




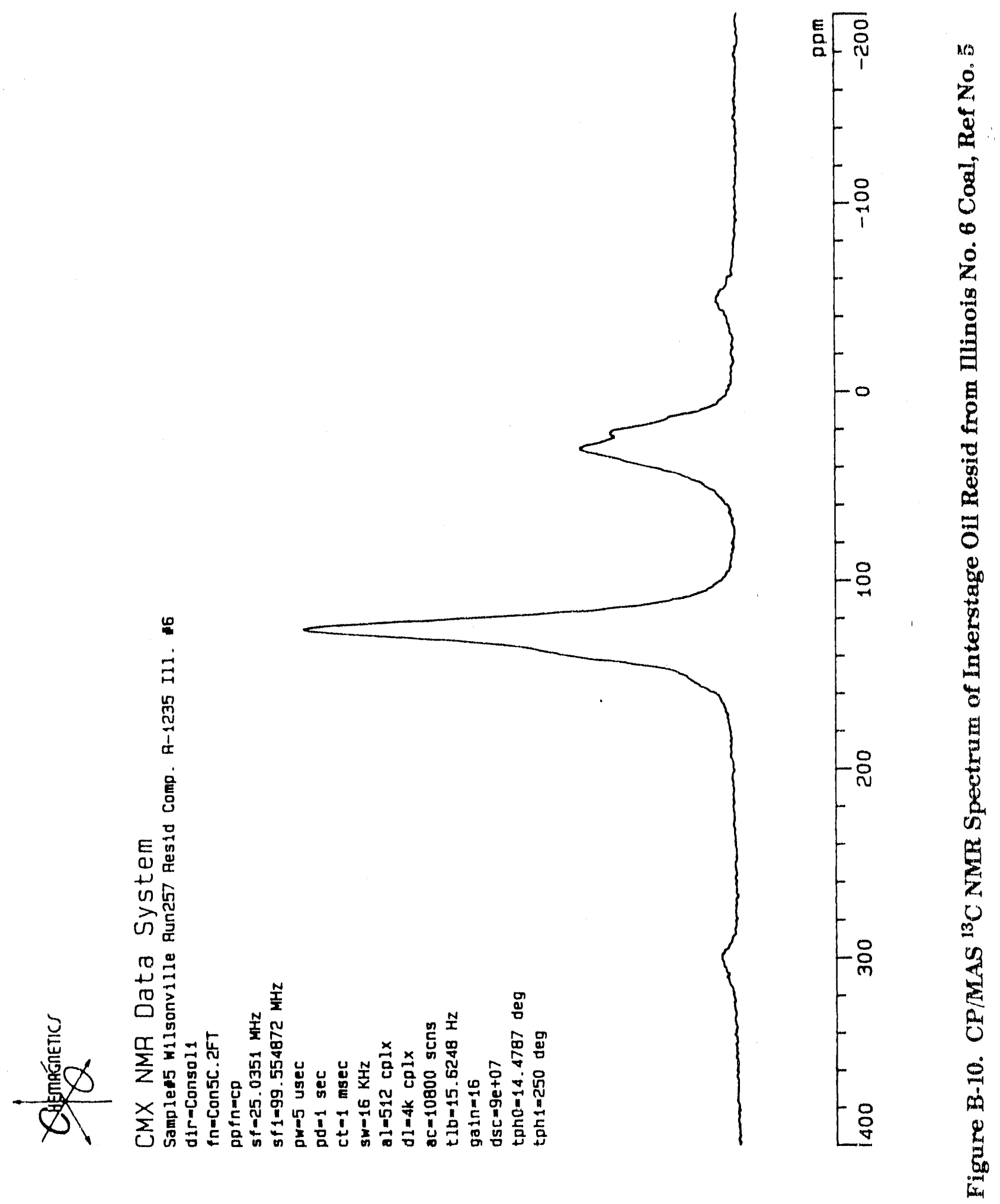




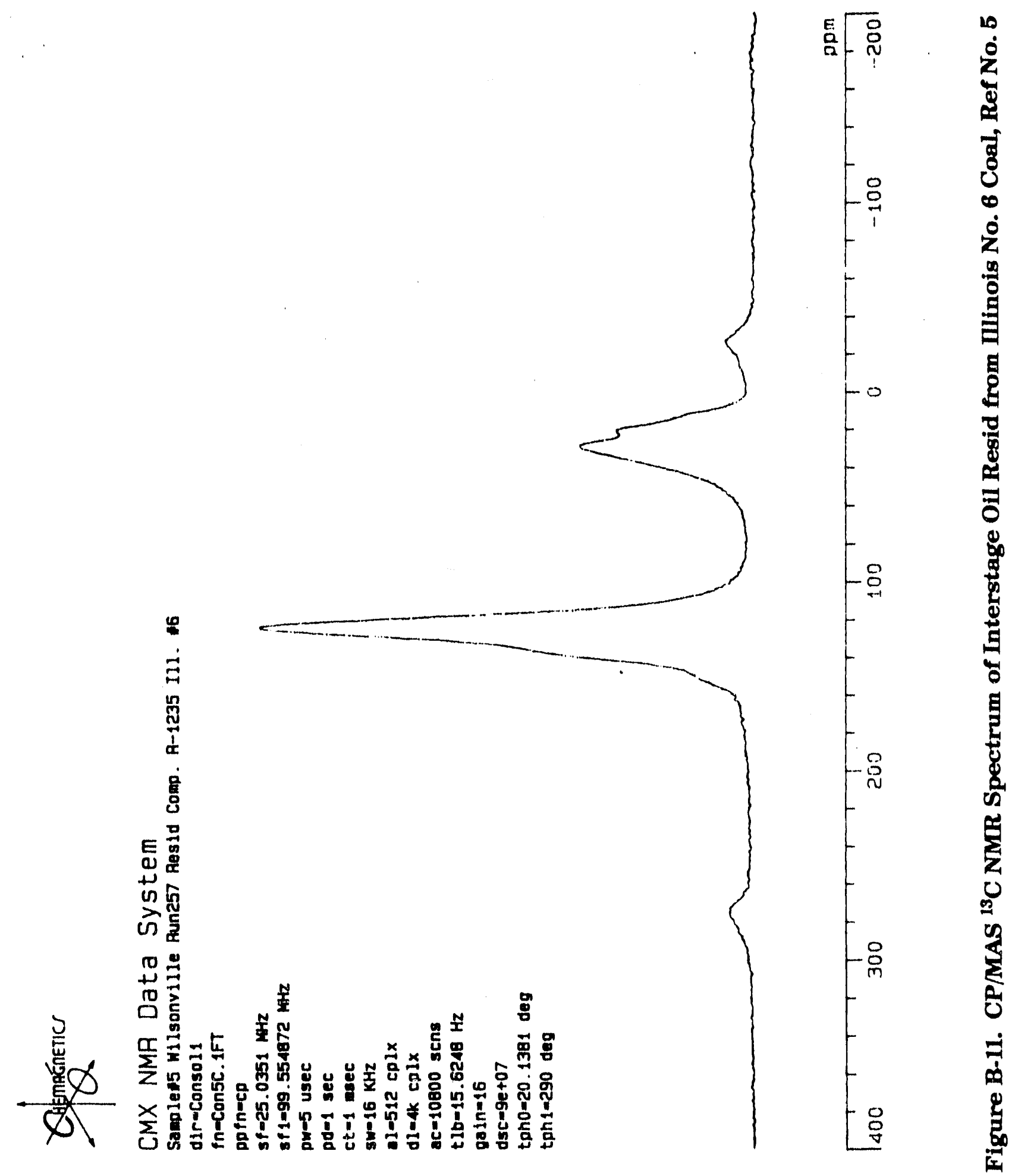




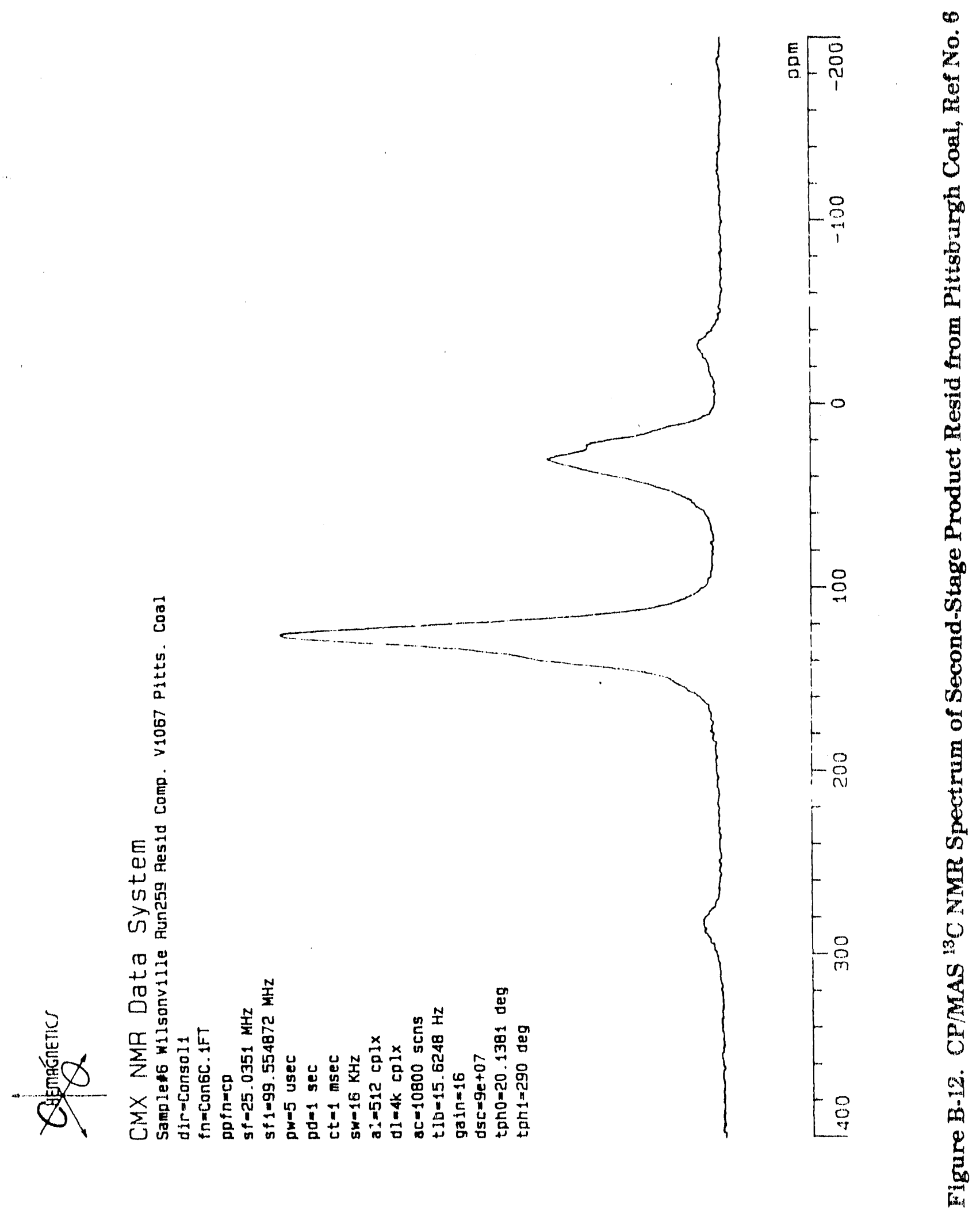




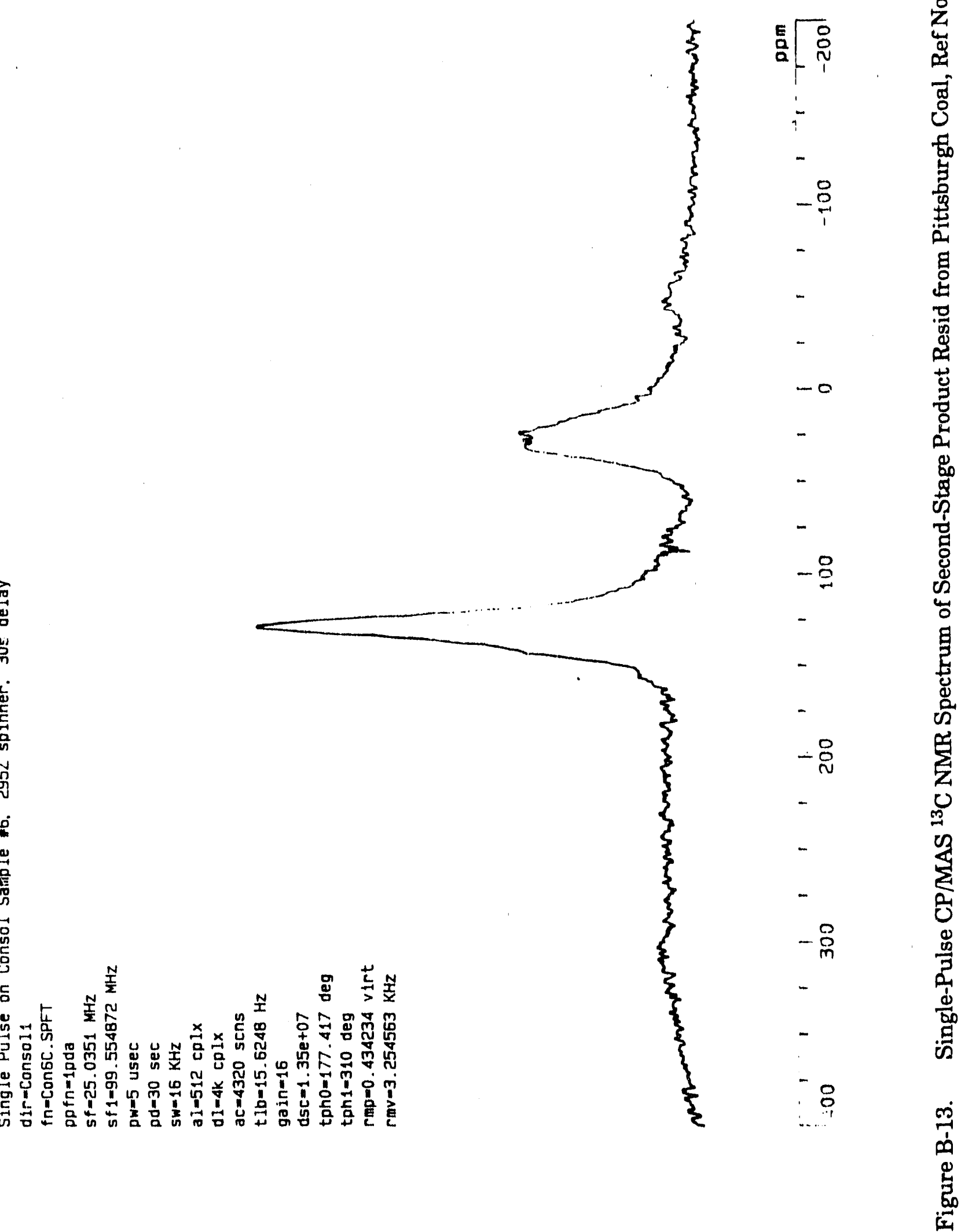




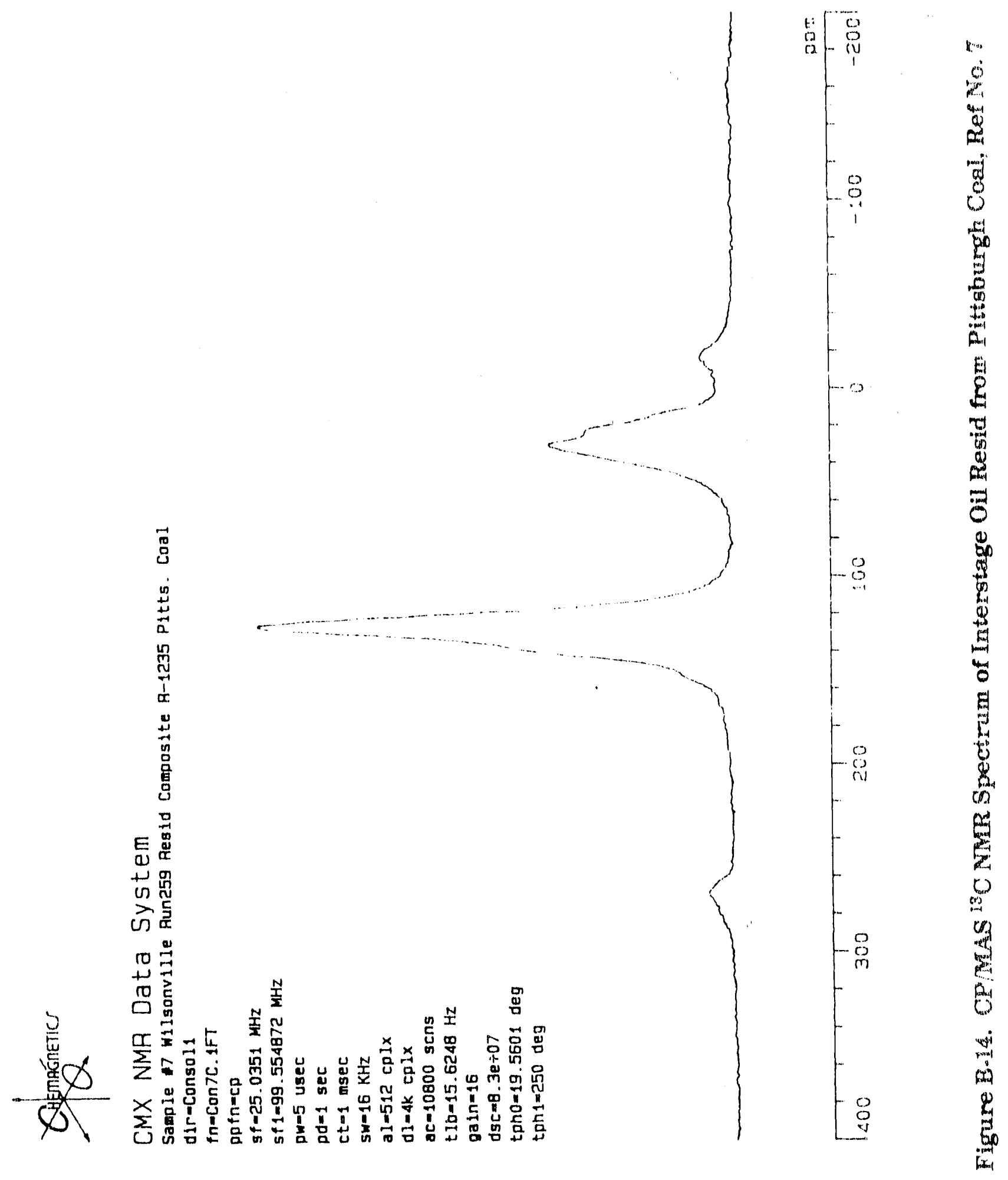




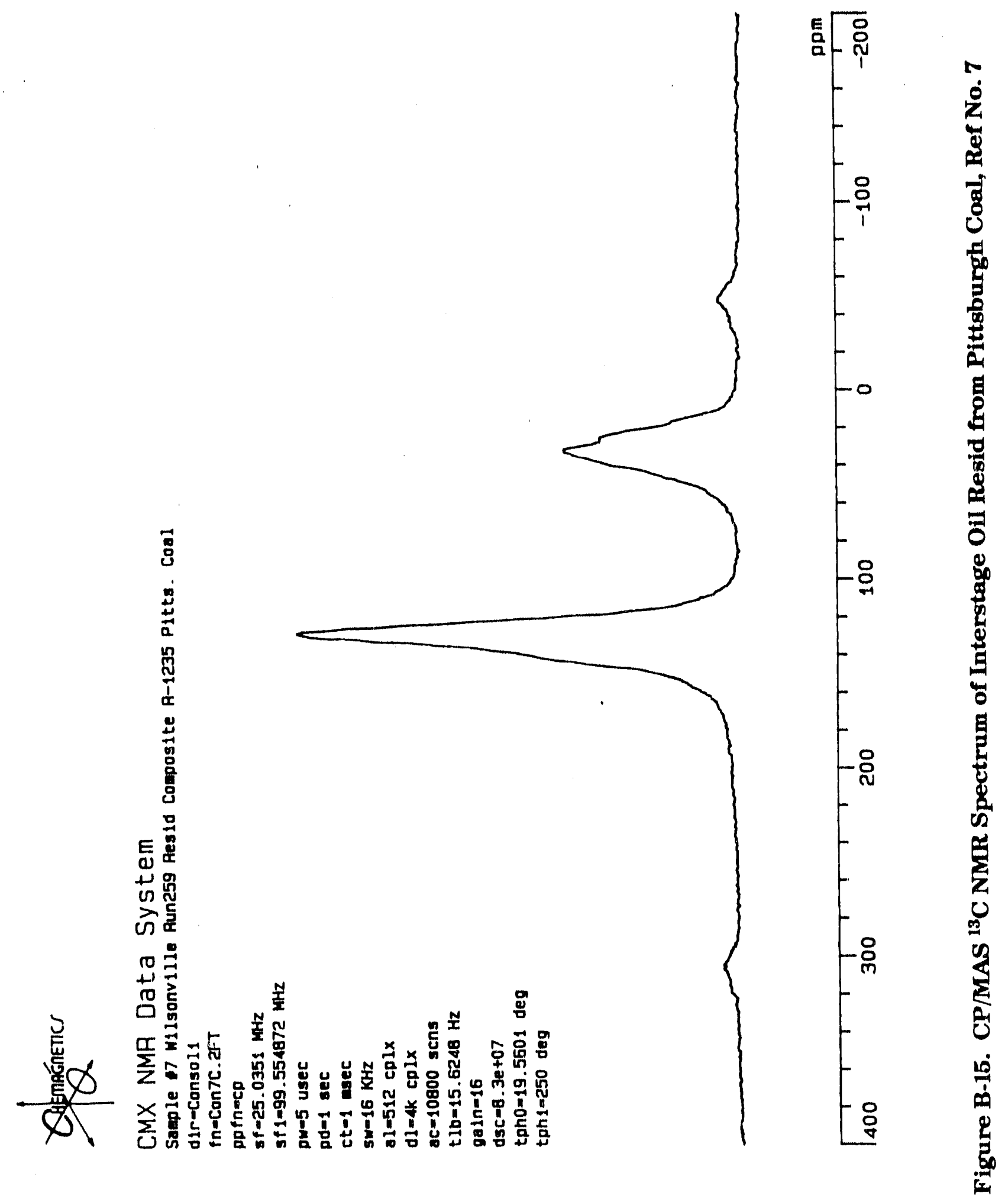




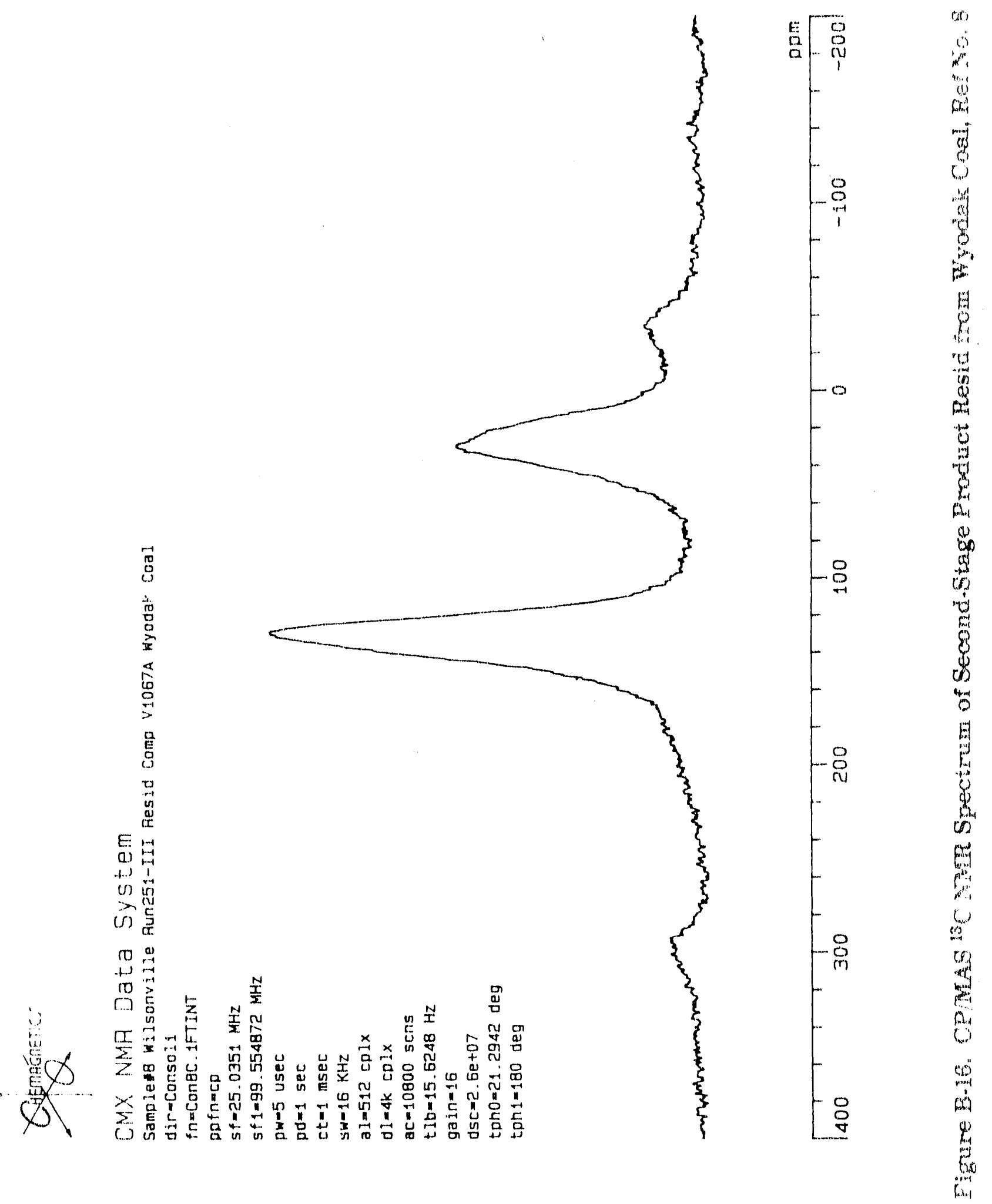




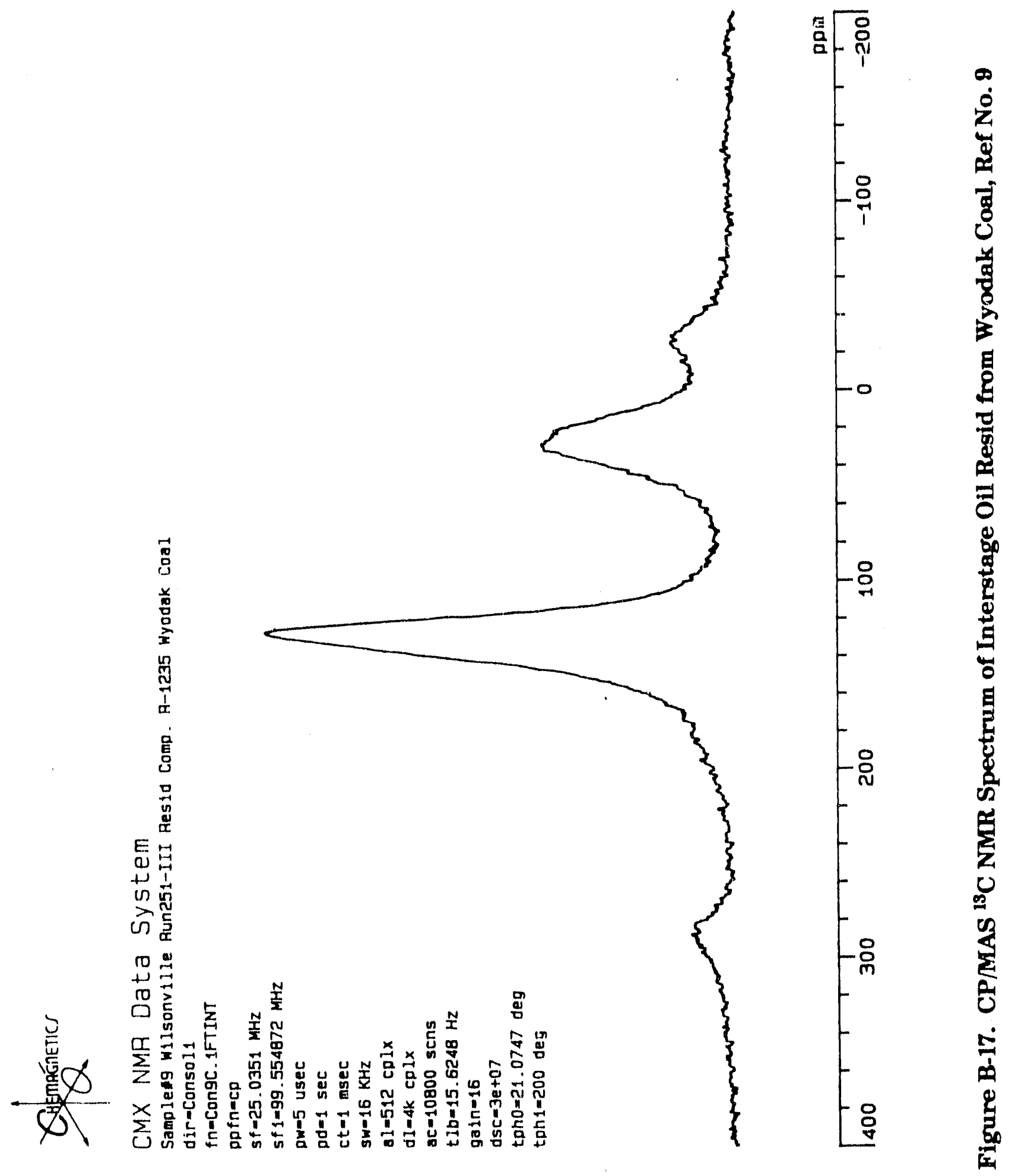




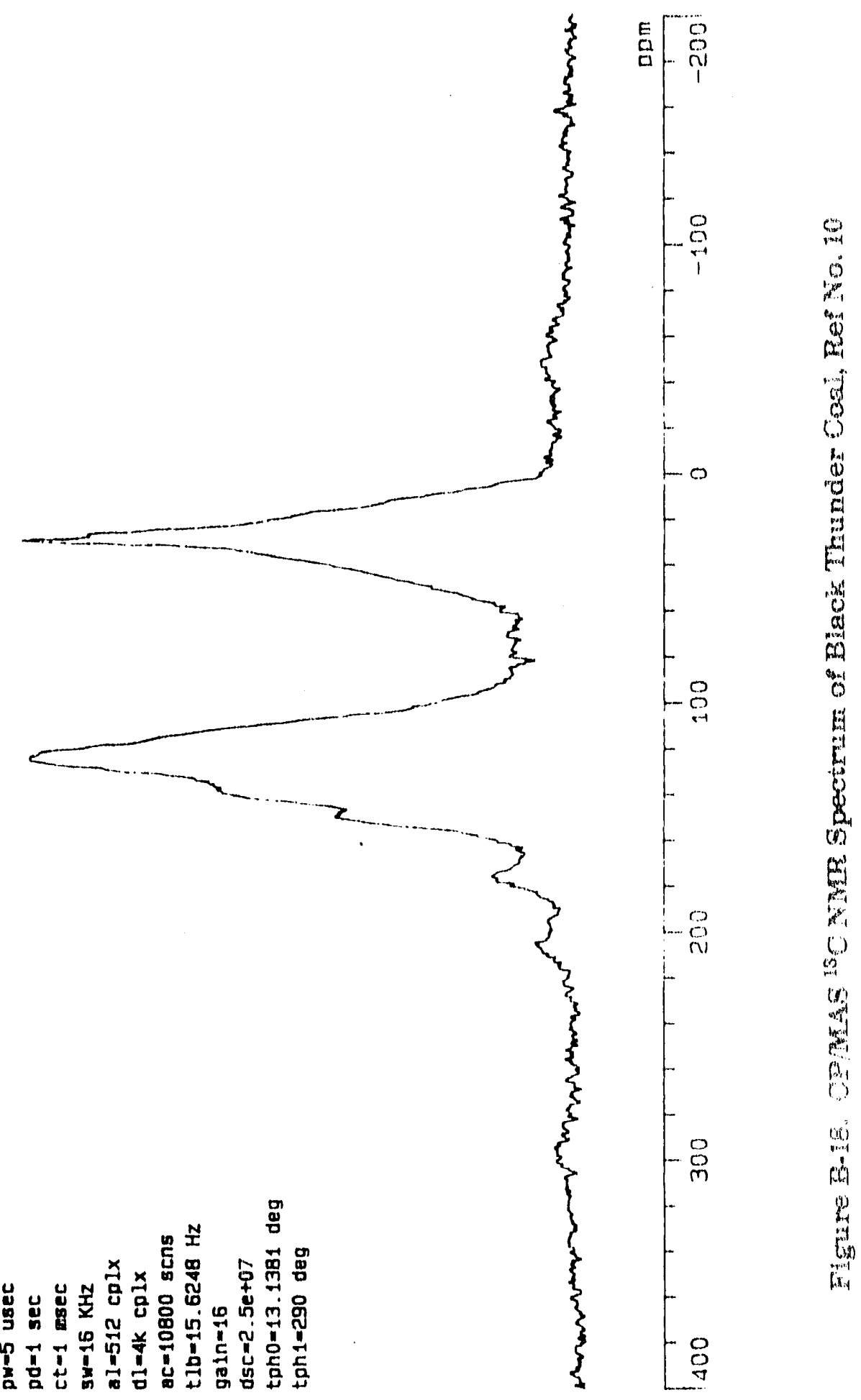




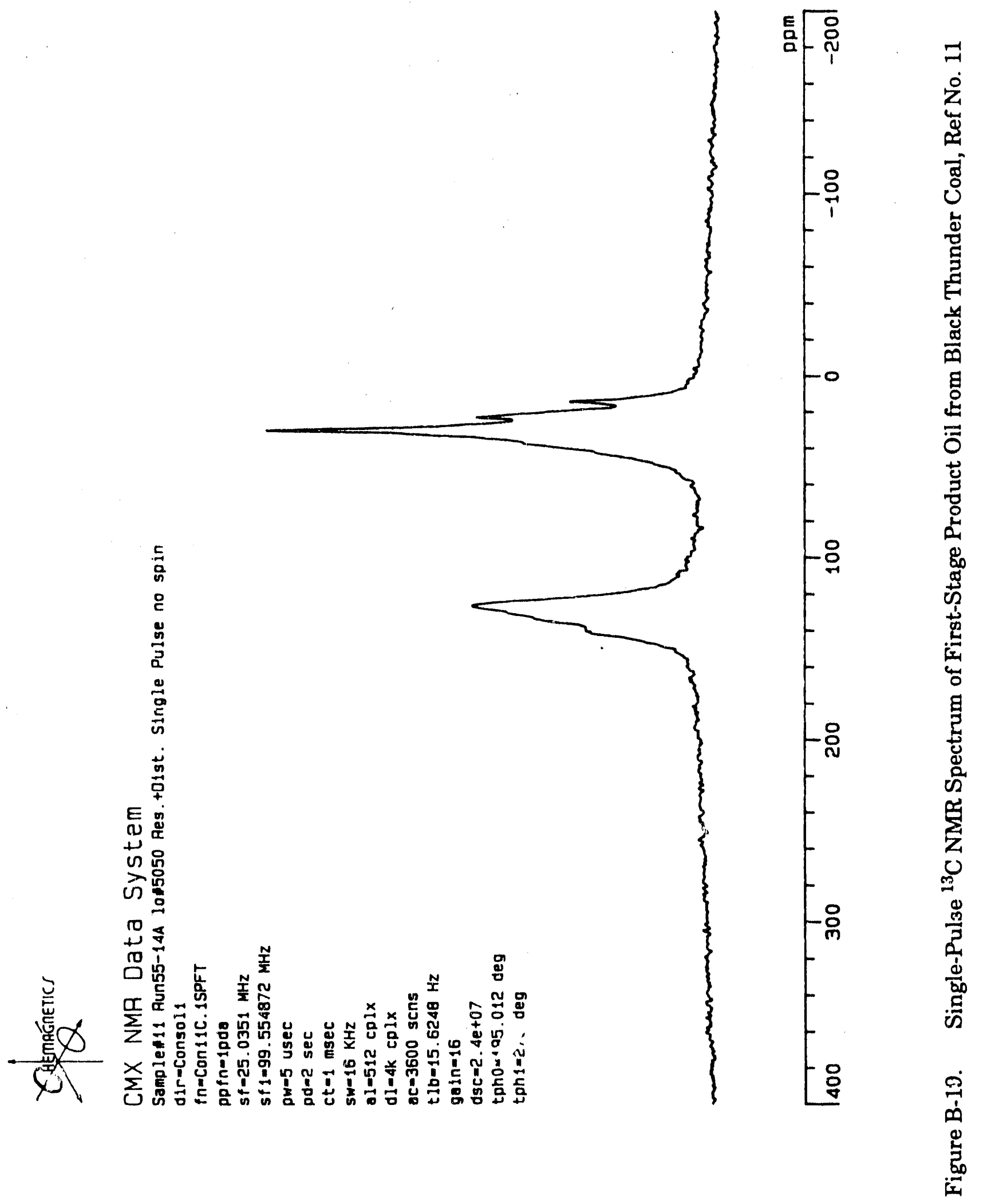




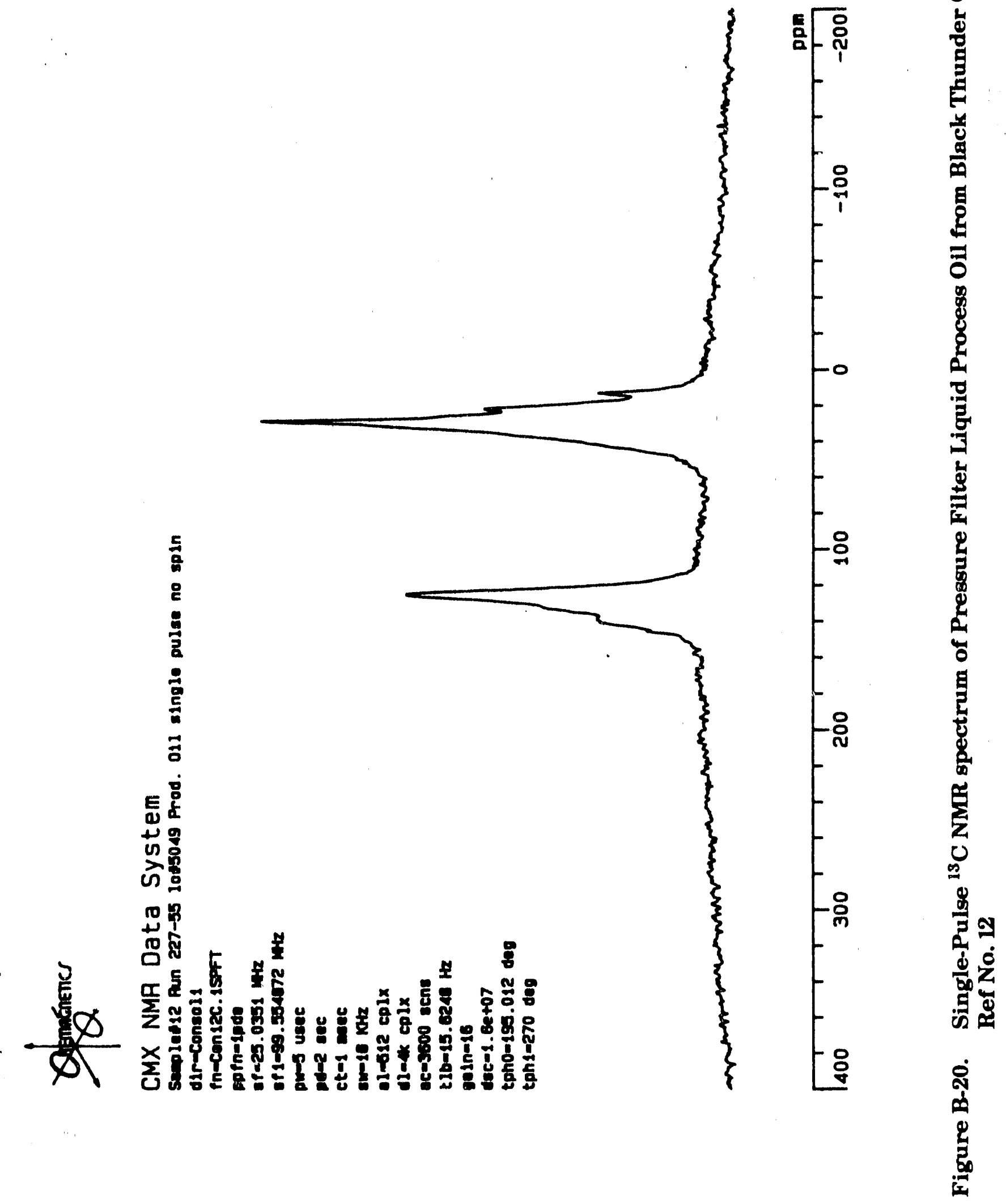




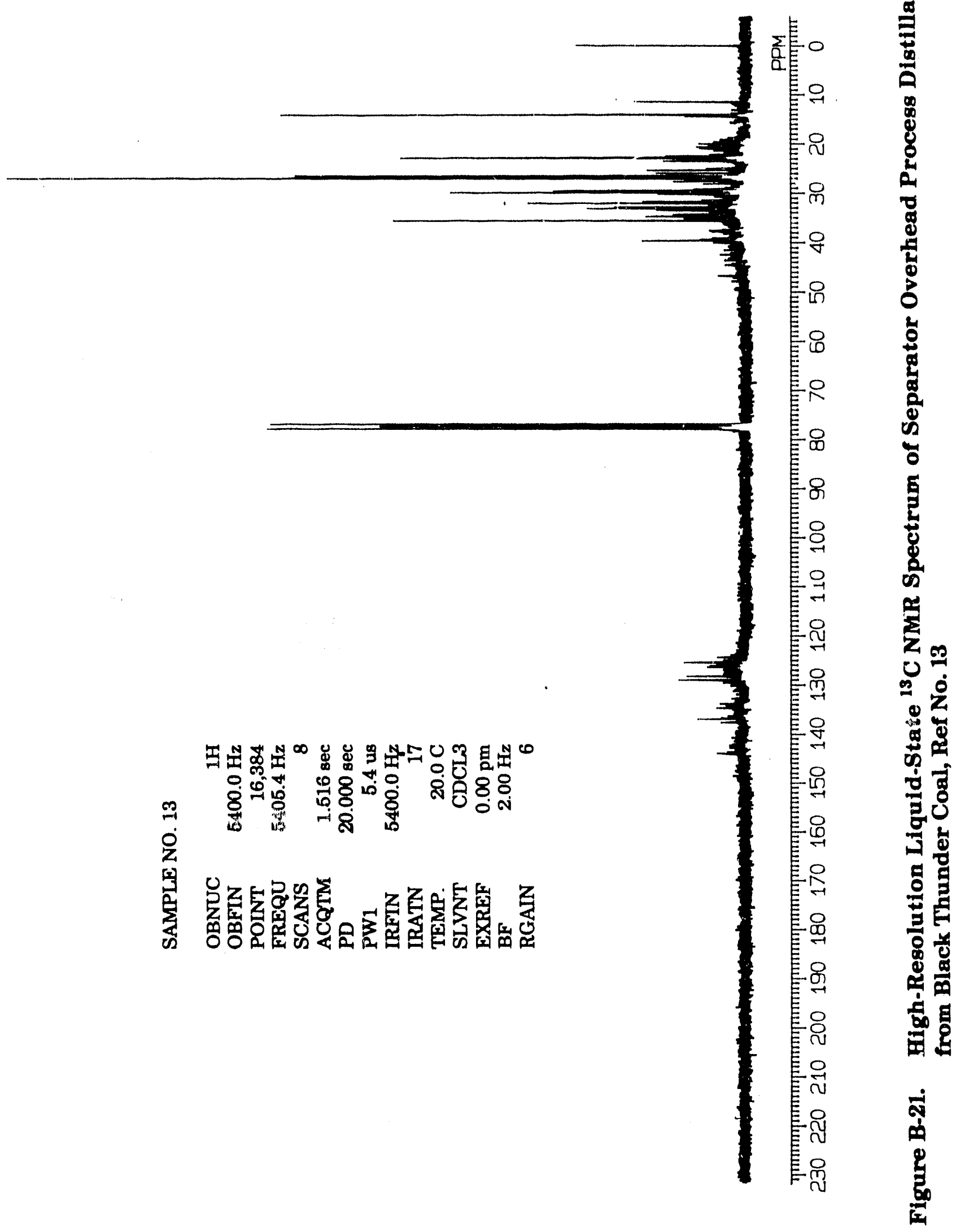




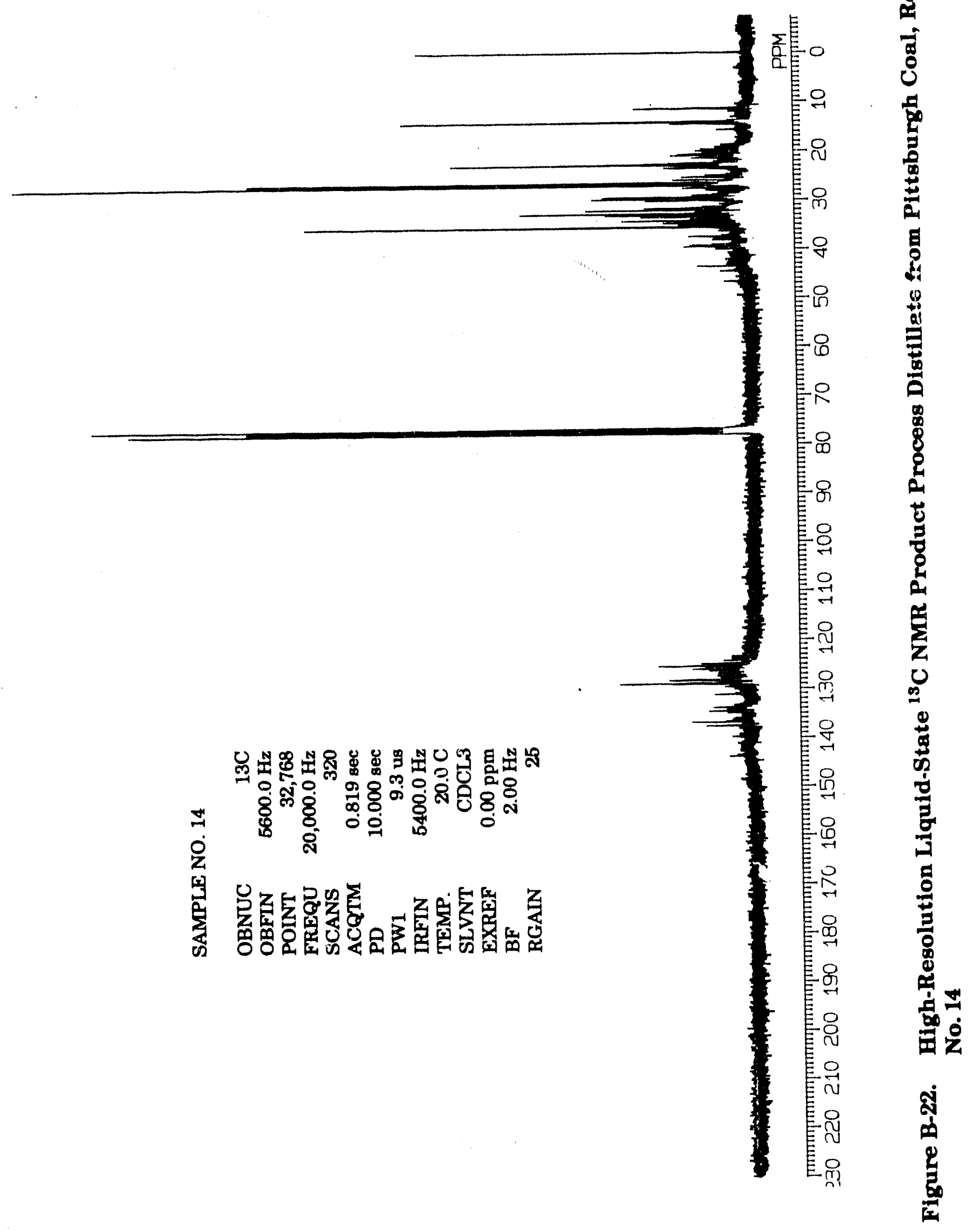




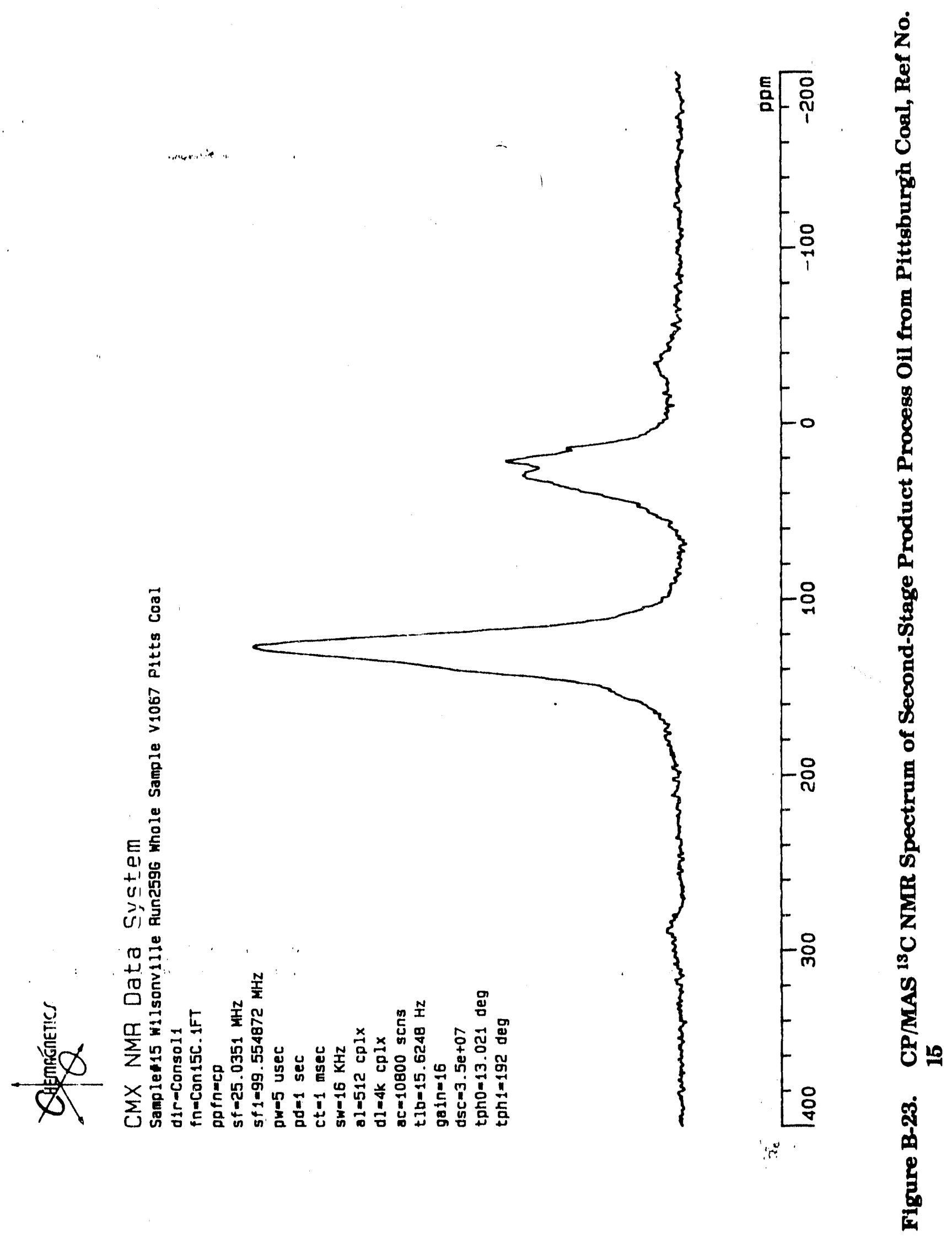




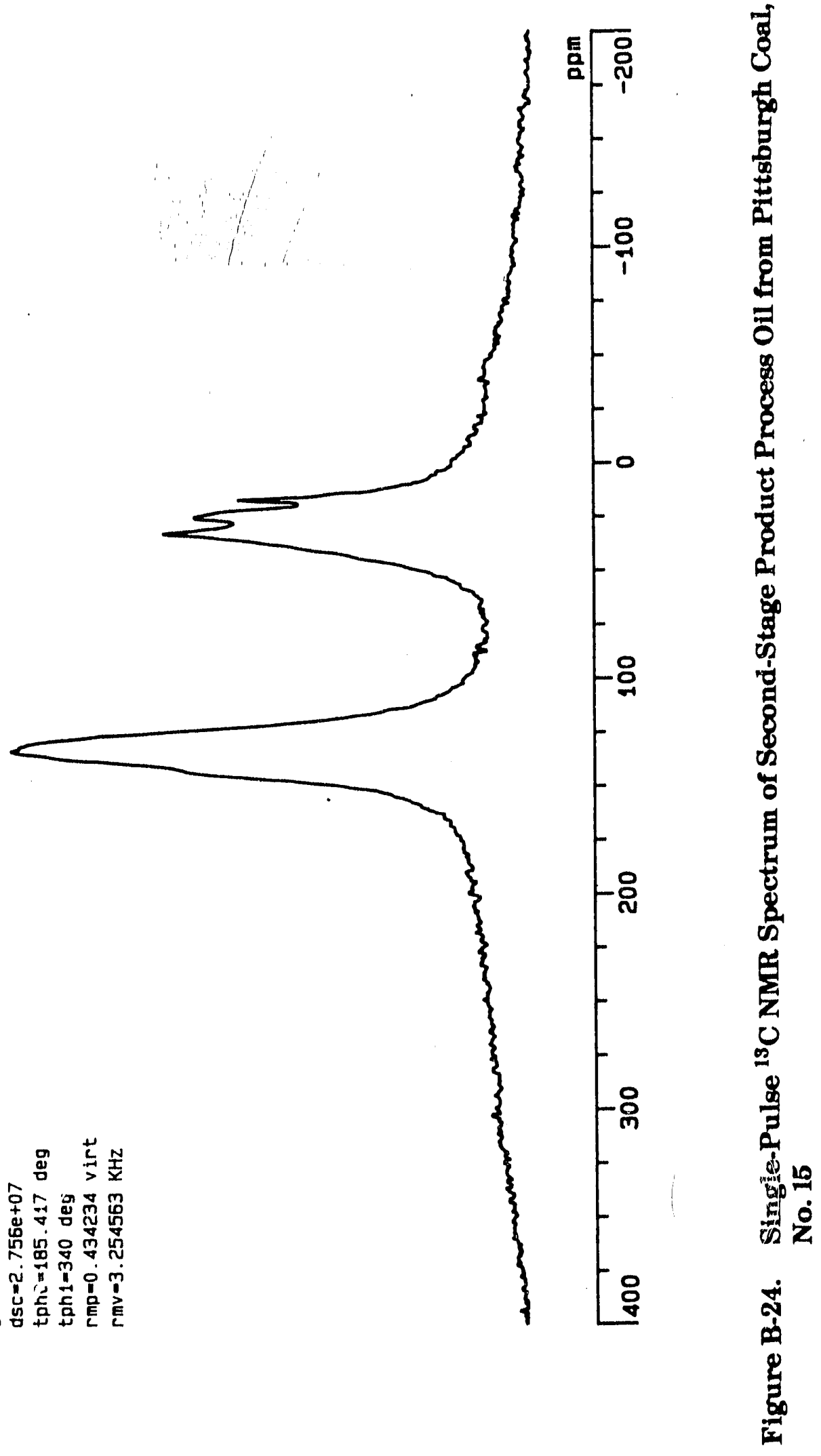




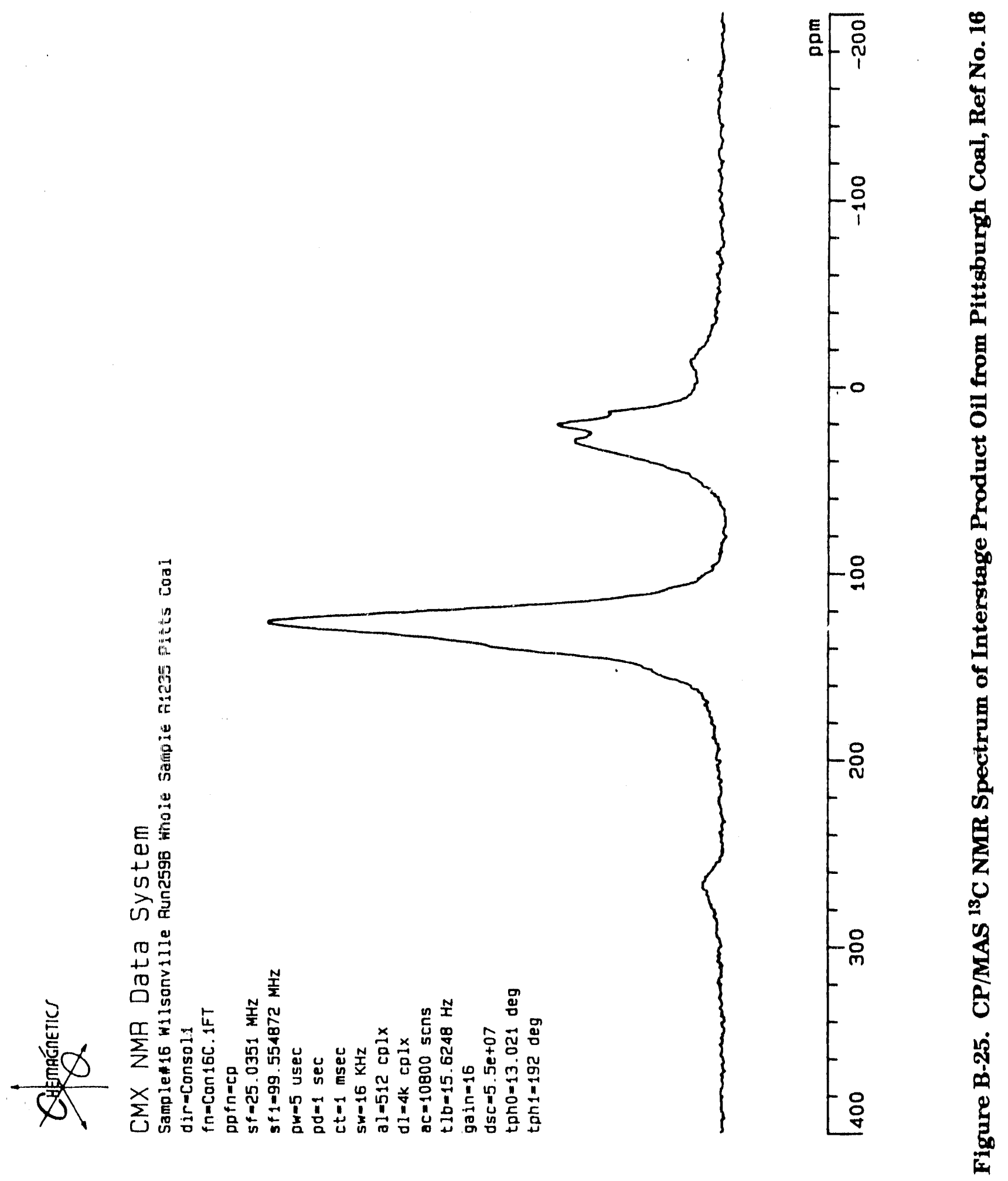




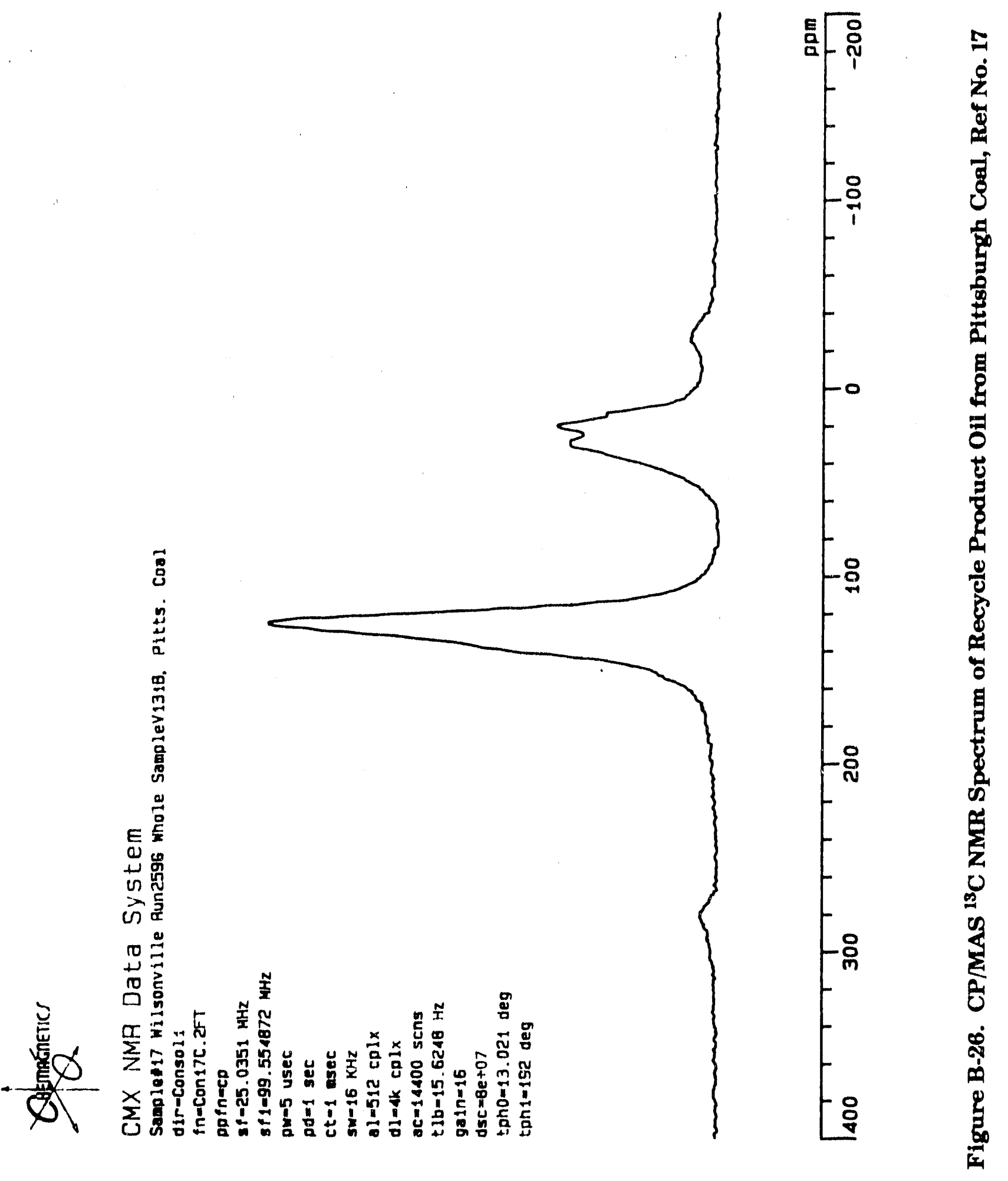




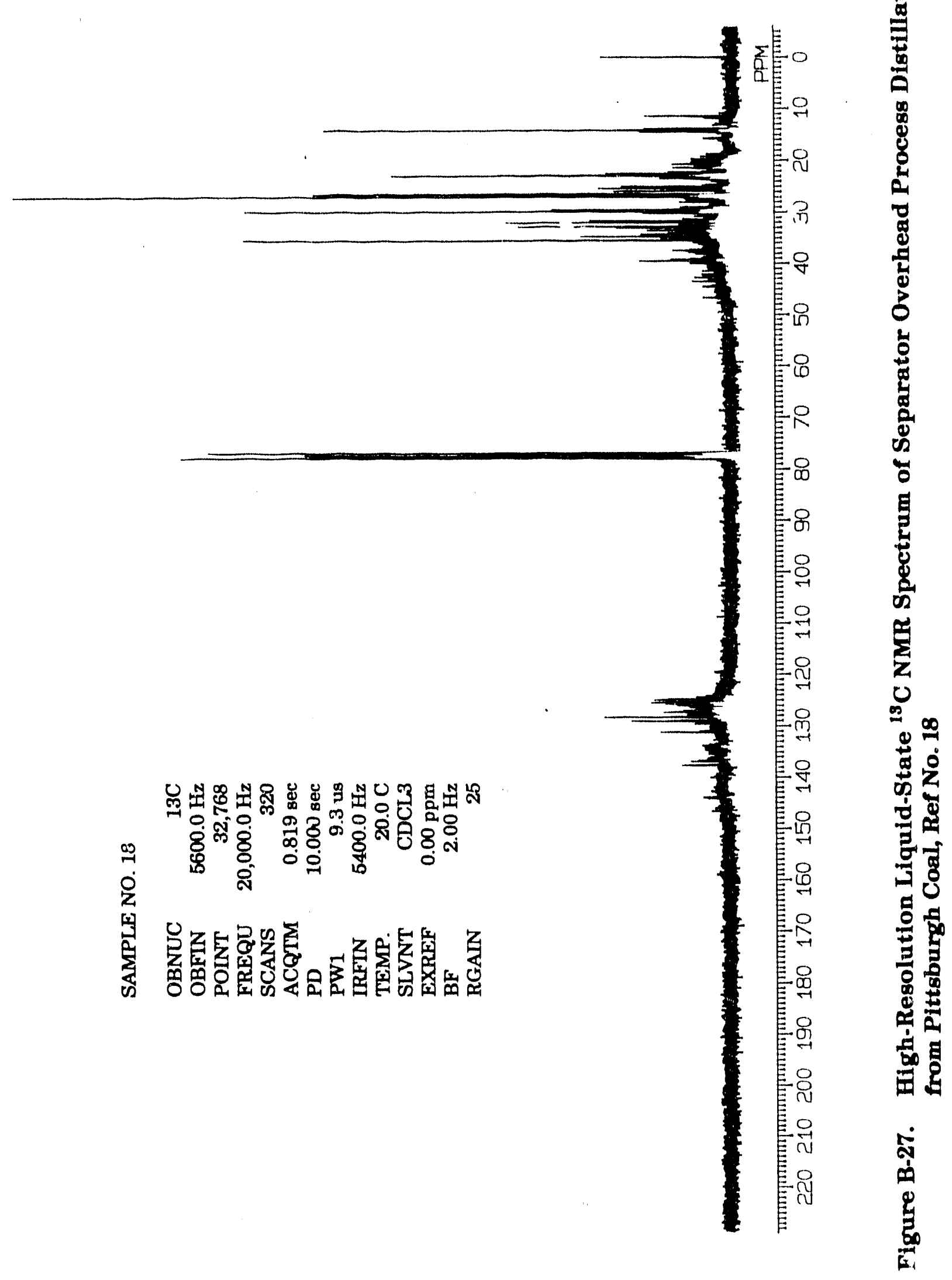




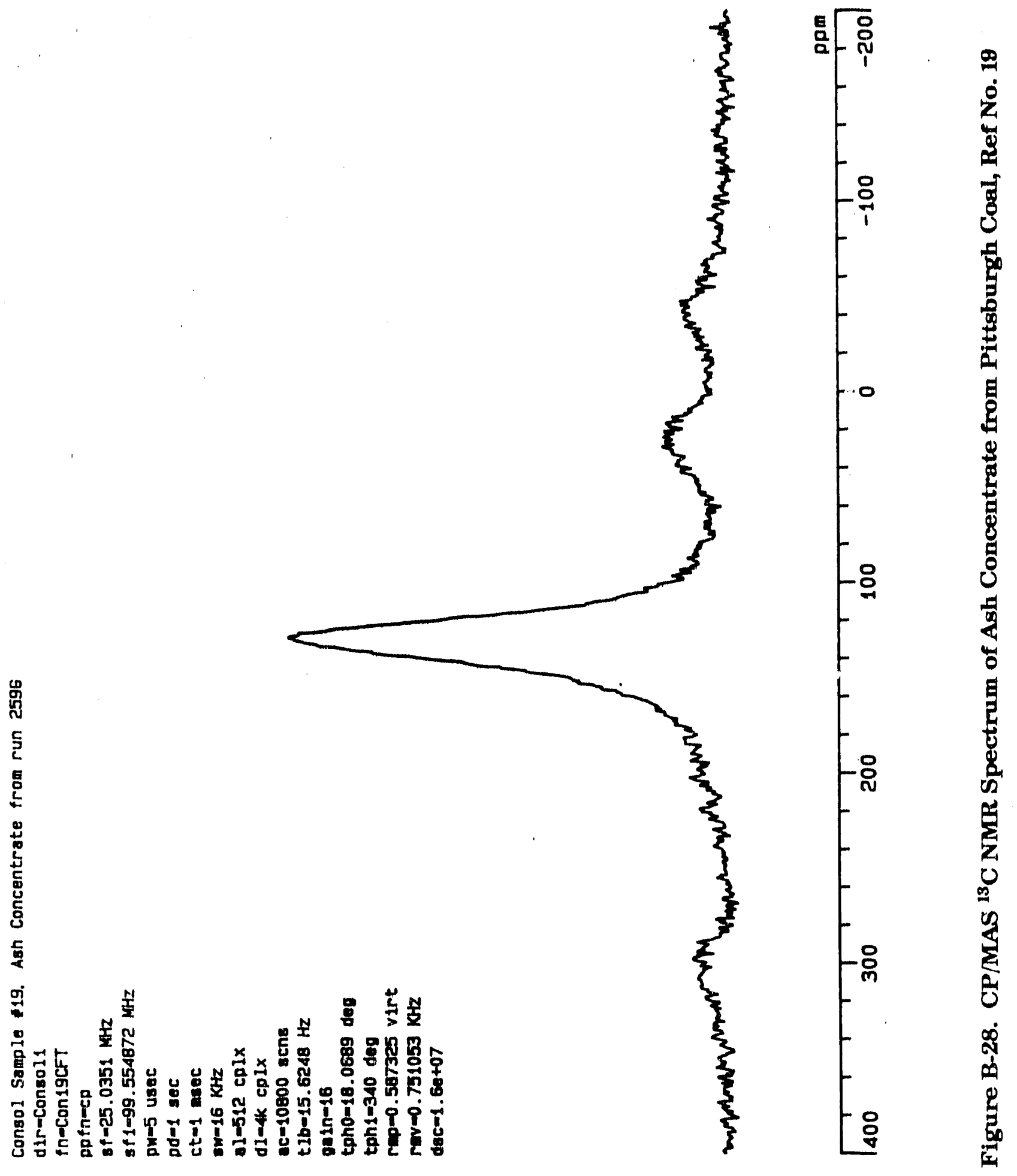


APPENDIX C

${ }^{1}$ H NMR Spectra 


\section{Contents of Appendix C}

\section{List of Figures}

Figure

Page

C-1. CRAMPS ${ }^{1} \mathrm{H}$ NMR Spectrum of Illinois No. 6 Coal; Ref No. 1........... 79

C-2. CRAMPS ${ }^{1} \mathrm{H}$ NMR Spectrum of Pittsburgh Coal, Ref No. 2.............. 80

C-3. CRAMPS ${ }^{1} \mathrm{H}$ NMR Spectrum of Wyodak Coal, Ref No. 3................... 81

C-4. CRAMPS ${ }^{1} \mathrm{H}$ NMR Spectrum of Second-Stage Product Resid from Illinois No. 6 Coal, Ref No. 4

C-5. CRAMPS ${ }^{1} \mathrm{H}$ NMR Spectrum of Interstage Oil Resid from Illinois No. 6 Coal, Ref No. 5 ......

C-6. CRAMPS ${ }^{1} \mathrm{H}$ NMR Spectrum of Second-Stage Product Resid from Pittsburgh Coal, Ref No. 6.

C-7. CRAMPS ${ }^{1} \mathrm{H}$ NMR Spectrum of Interstage Oil Resid from Pittsburgh Coal, Ref No. 7.

C-8. CRAMPS ${ }^{1} \mathrm{H}$ NMR Spectrum of Second-Stage Product Resid from Wyodak Coal, Ref No. 8

C-9. CRAMPS ${ }^{1} \mathrm{H}$ NMR Spectrum of Interstage Oil Resid from Wyodak Coal, Ref No. 9.

C-10. CRAMPS 'H NMR Spectrum of Black Thunder Coal, Ref No. 10......

C-11. Single-Pulse ${ }^{1} \mathrm{H}$ HMR Spectrum of First-Stage Process Oil from Black Thunder Coal, Ref No. 11 ......

C-12. Single-Pulse ${ }^{1} \mathrm{H}$ HMR Spectrum of Pressure Filter Liquid Process Oil from Black Thunder Coal, Ref No. 12.

C-13. High-Resolution Liquid-State ${ }^{1} \mathrm{H}$ NMR Spectrum of Separator Overhead Process Distillate from Black Thunder Coal, Ref No. 13.

C-14. High-Resolution Liquid-State ${ }^{1} \mathrm{H}$ NMR Spectrum of Product Process Separator Distillate from Pittsburgh Coal, Ref No. 14.

C-15. CRAMPS ${ }^{1} \mathrm{H}$ NMR Spectrum of Second-Stage Product Process Oil from Pittsburgh Coal, Ref No. 15. 
C-16. High-Resolution Liquid-State ${ }^{1} \mathrm{H}$ NMR Spectrum of Interstage

Process Oil from Pittsburgh Coal, Ref No. 16.

C-17. High-Resolution Liquid-State ${ }^{1} \mathrm{H}$ NMR Spectrum of Recycle

Process Oll from Pittsburgh Coal, Ref No. 17

95

C-18. High-Resolution Liquid-State ${ }^{1} \mathrm{H}$ NMR Spectrum of Separator

Overhead Process Distillate from Pittsburgh Coal, Ref No. 18 


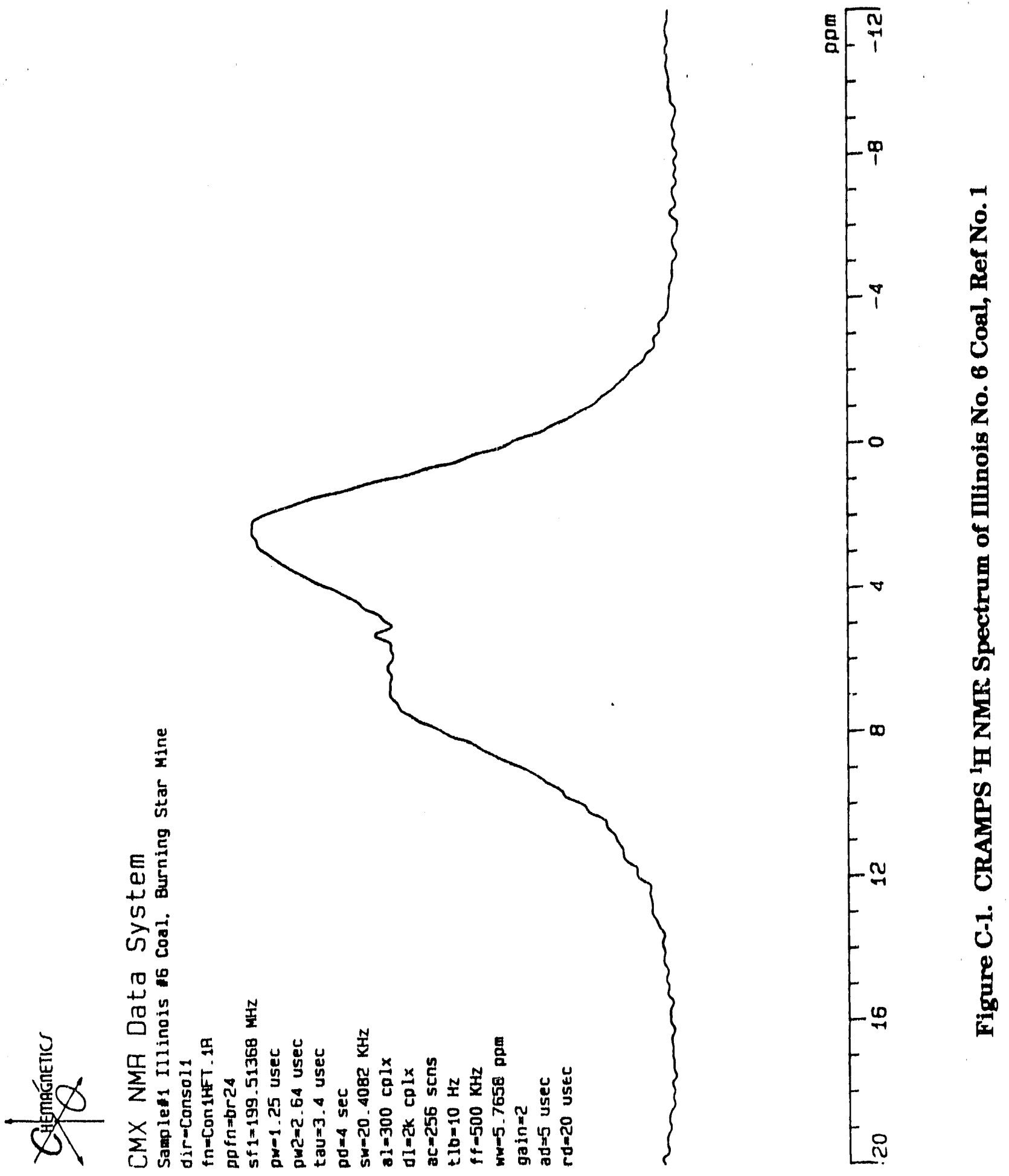



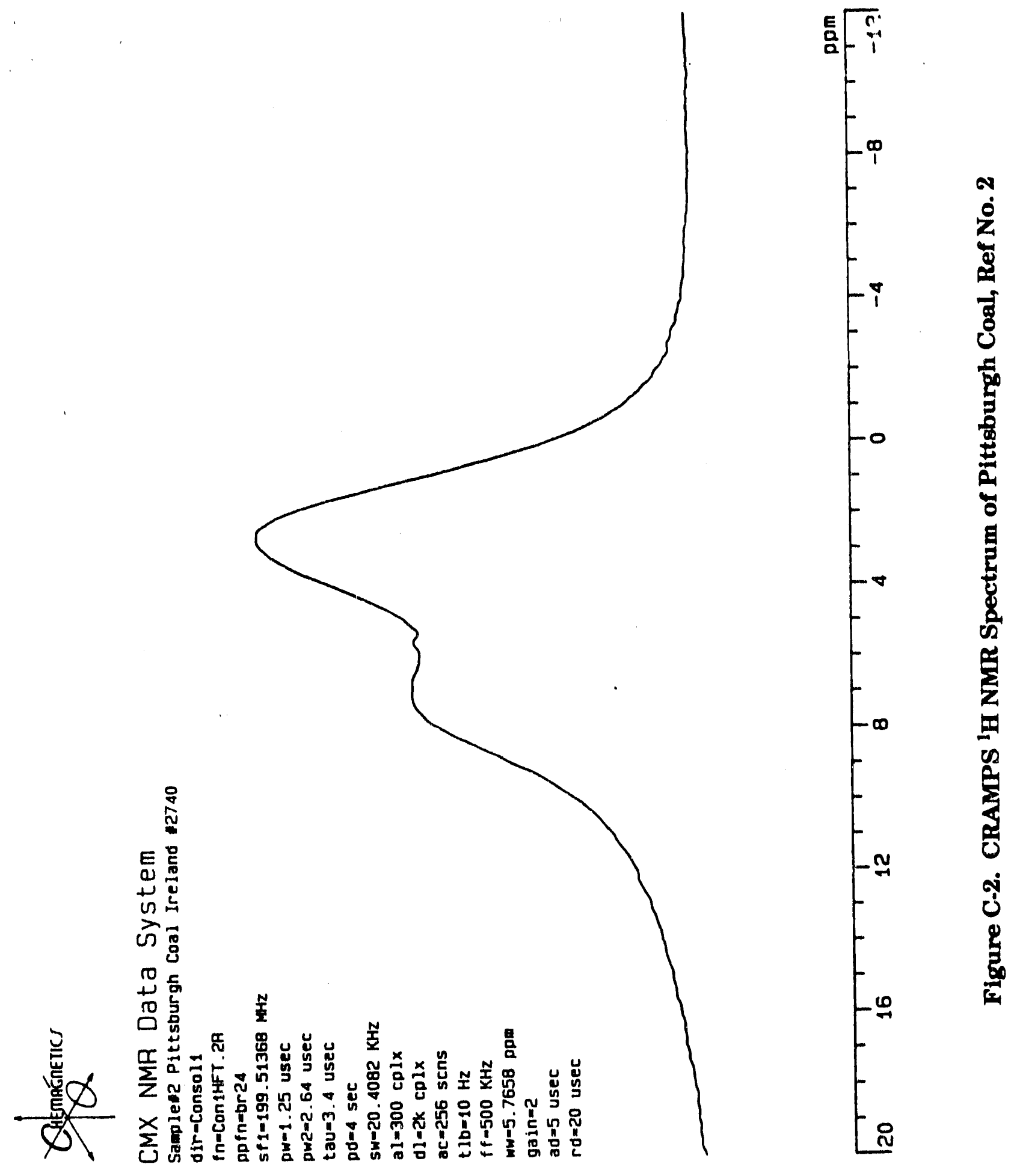


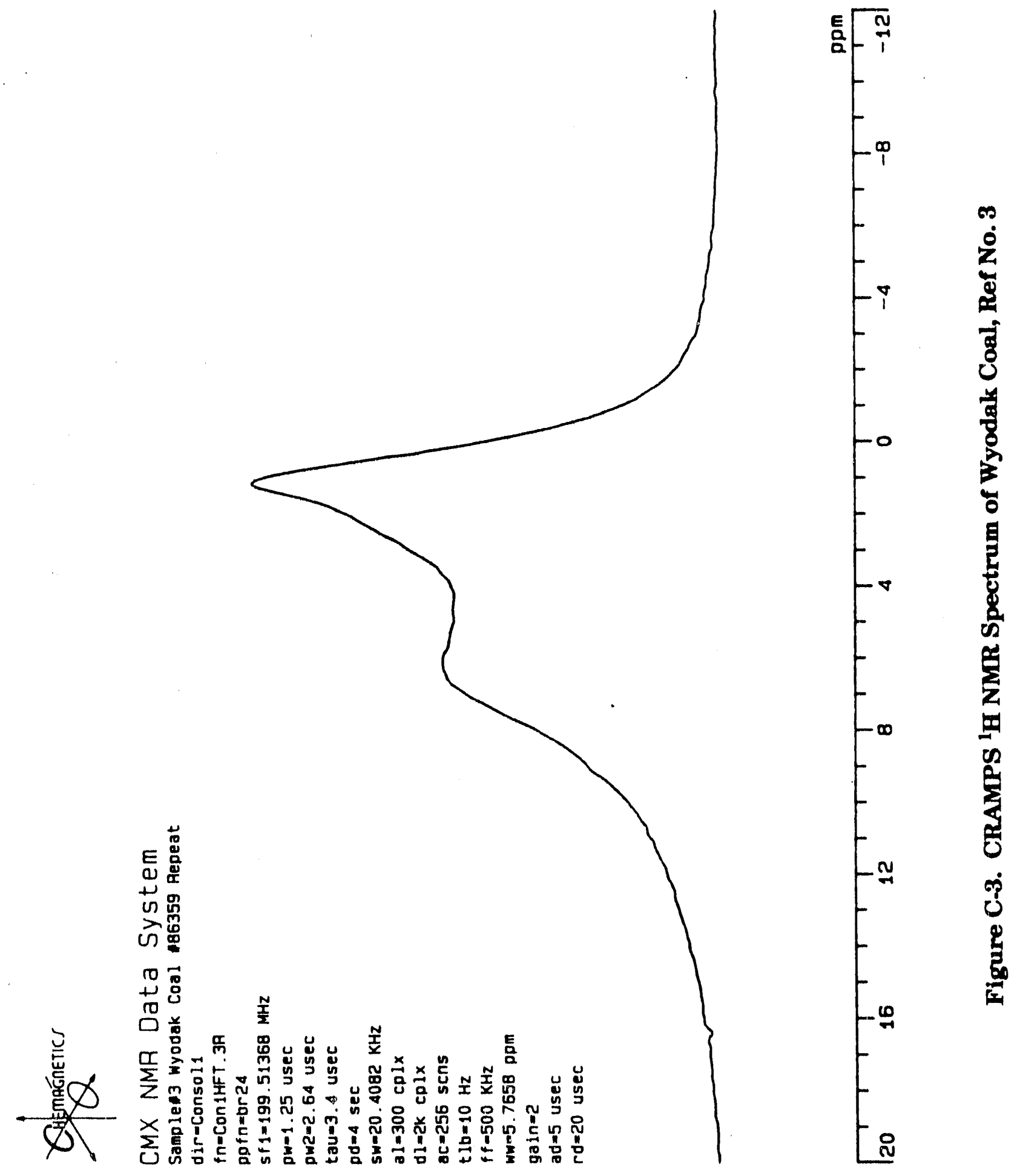




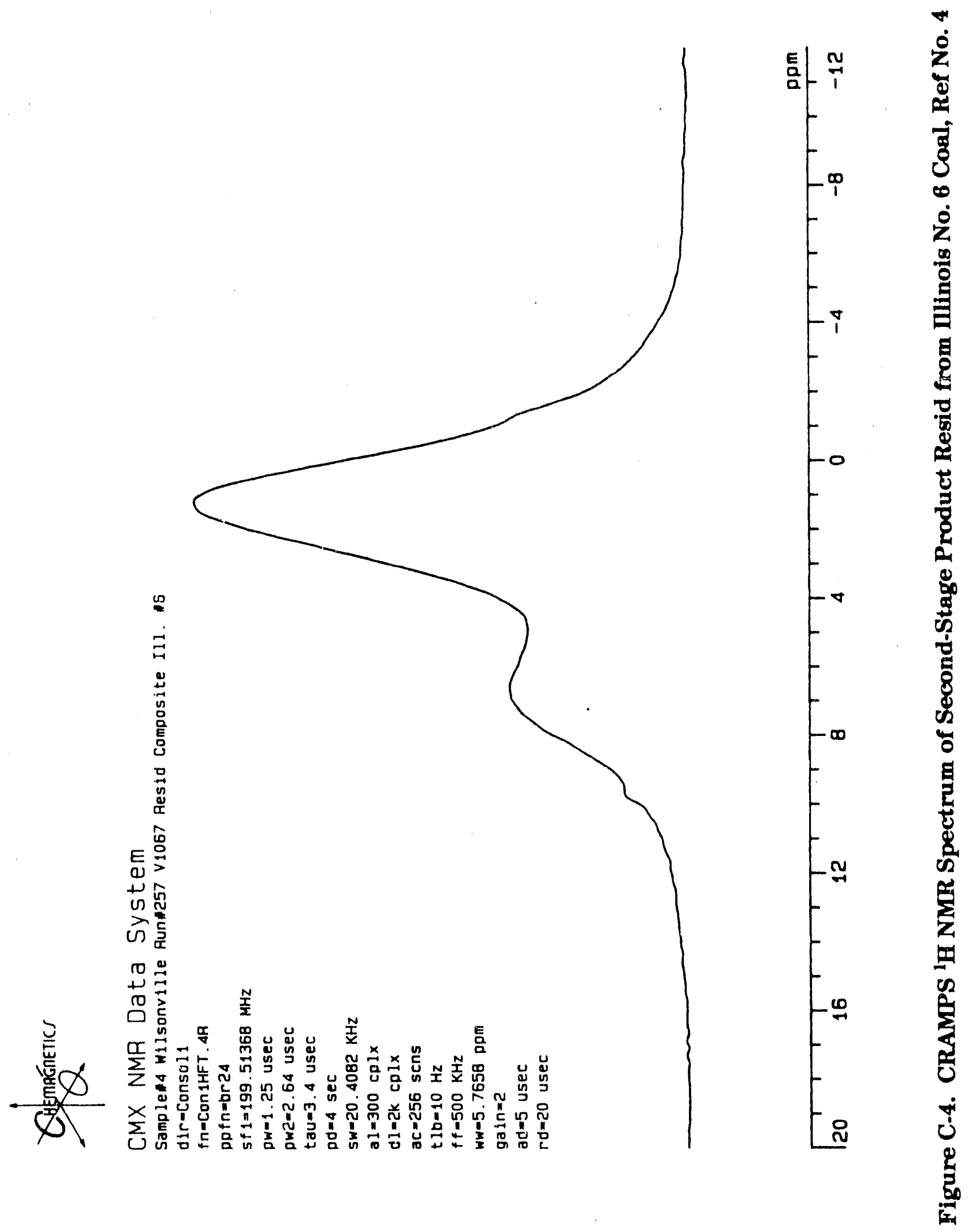




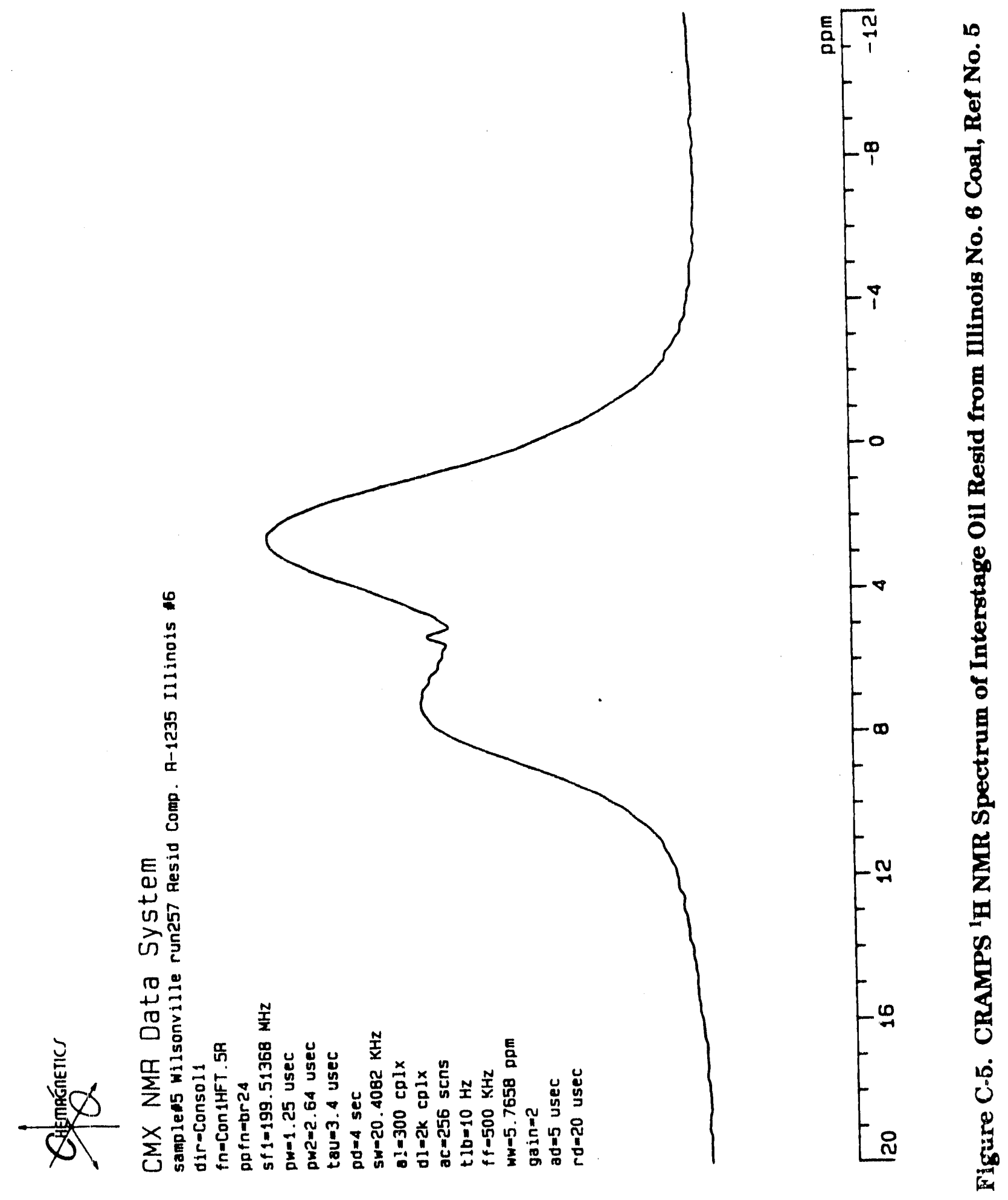




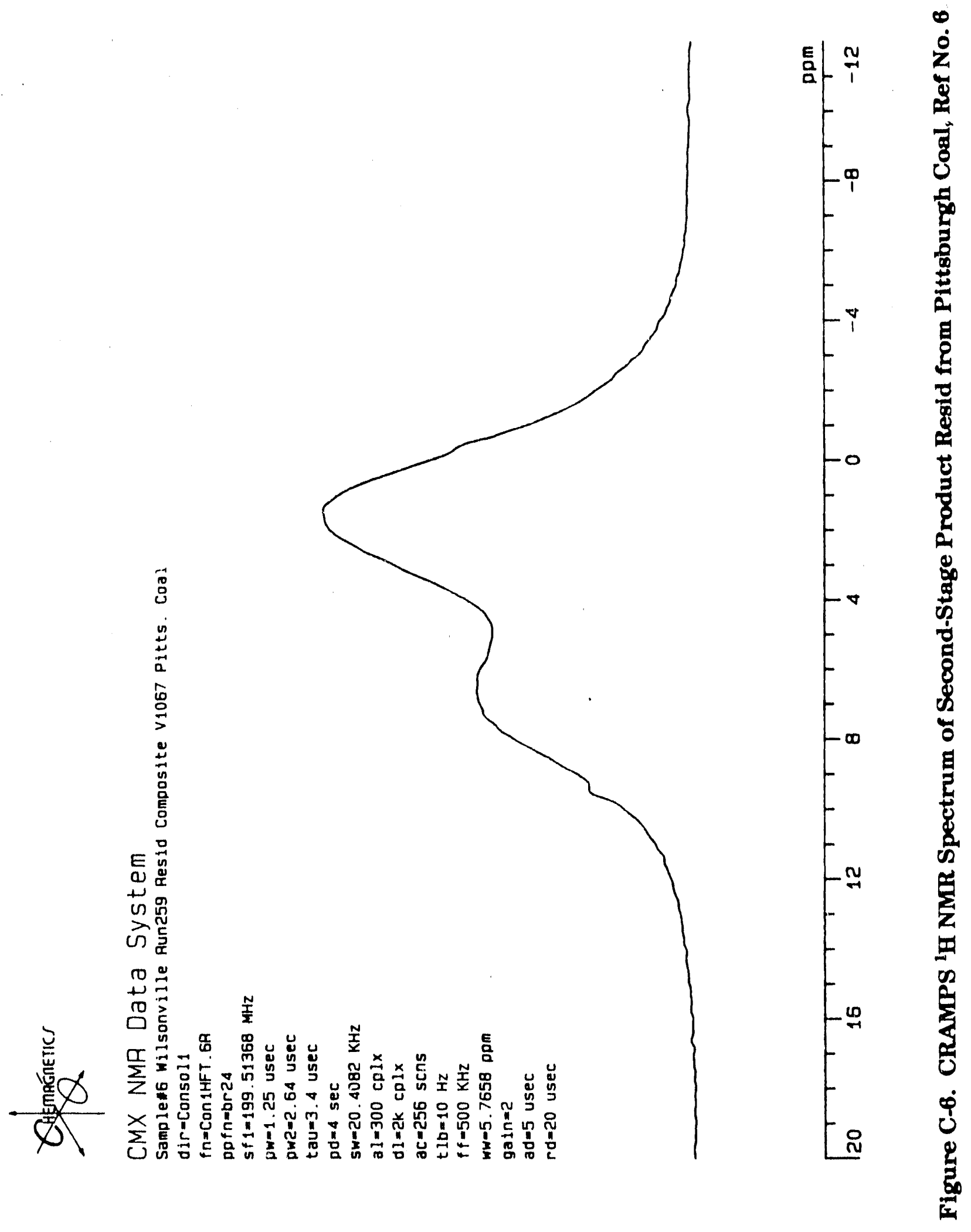




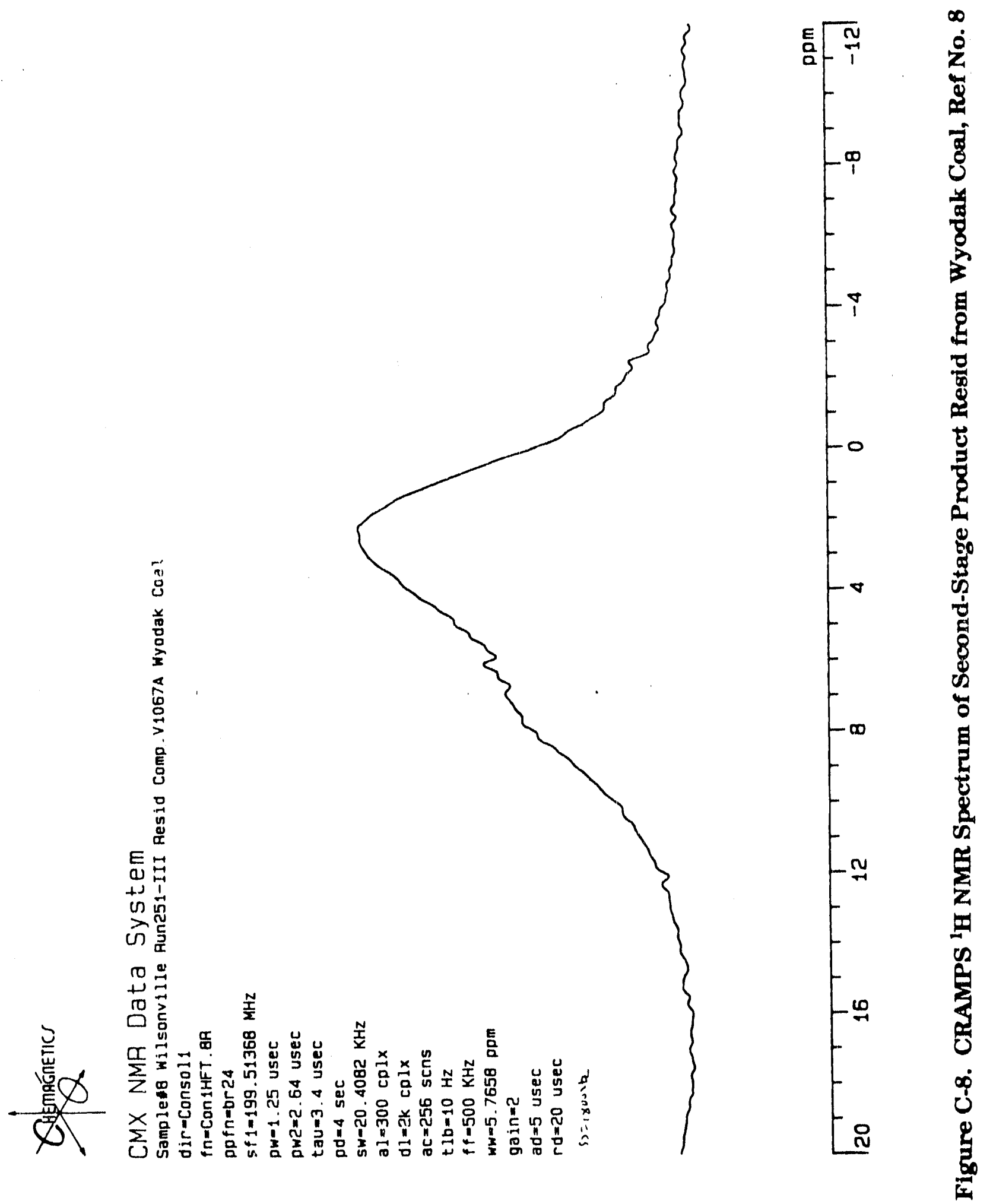




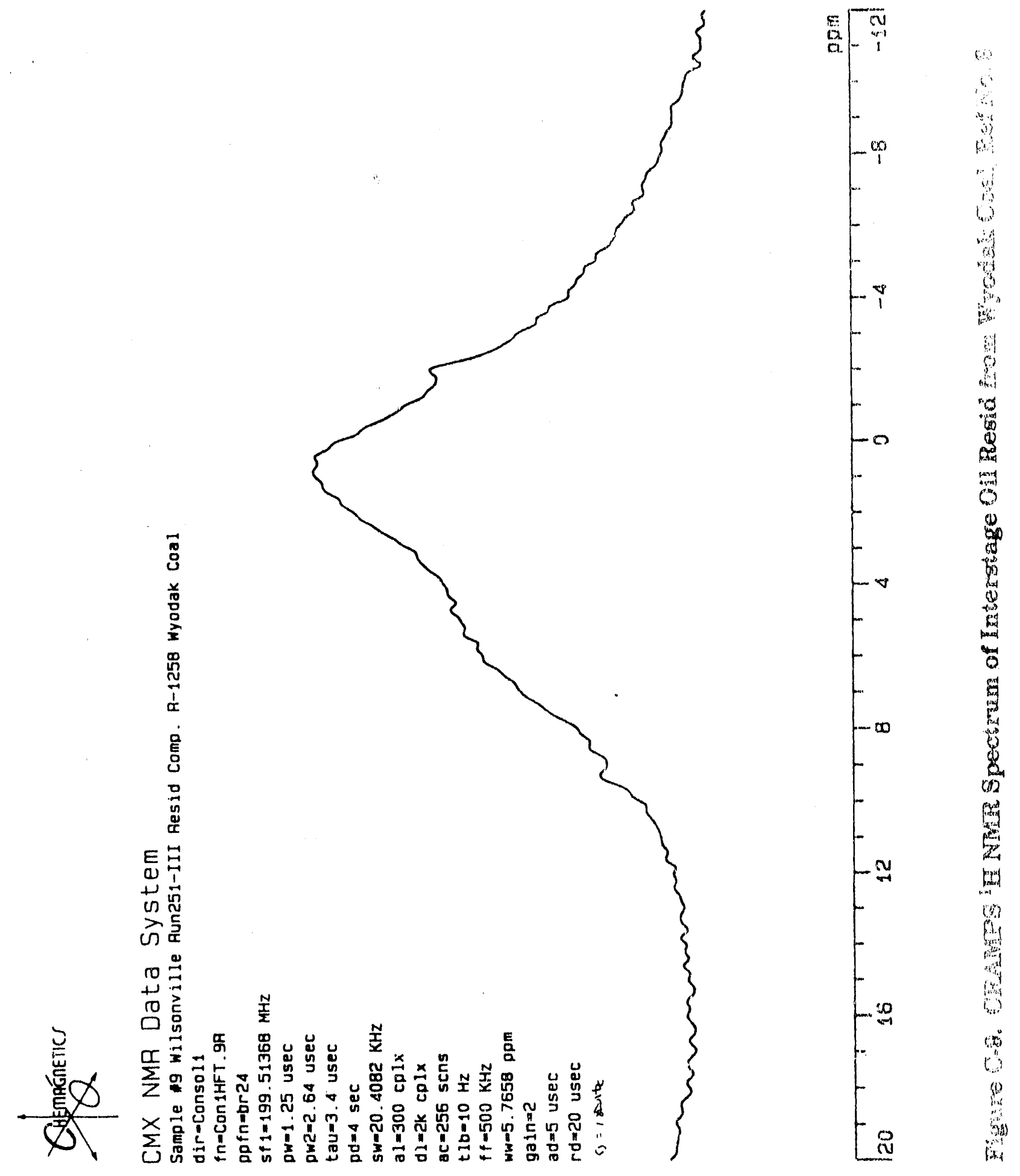




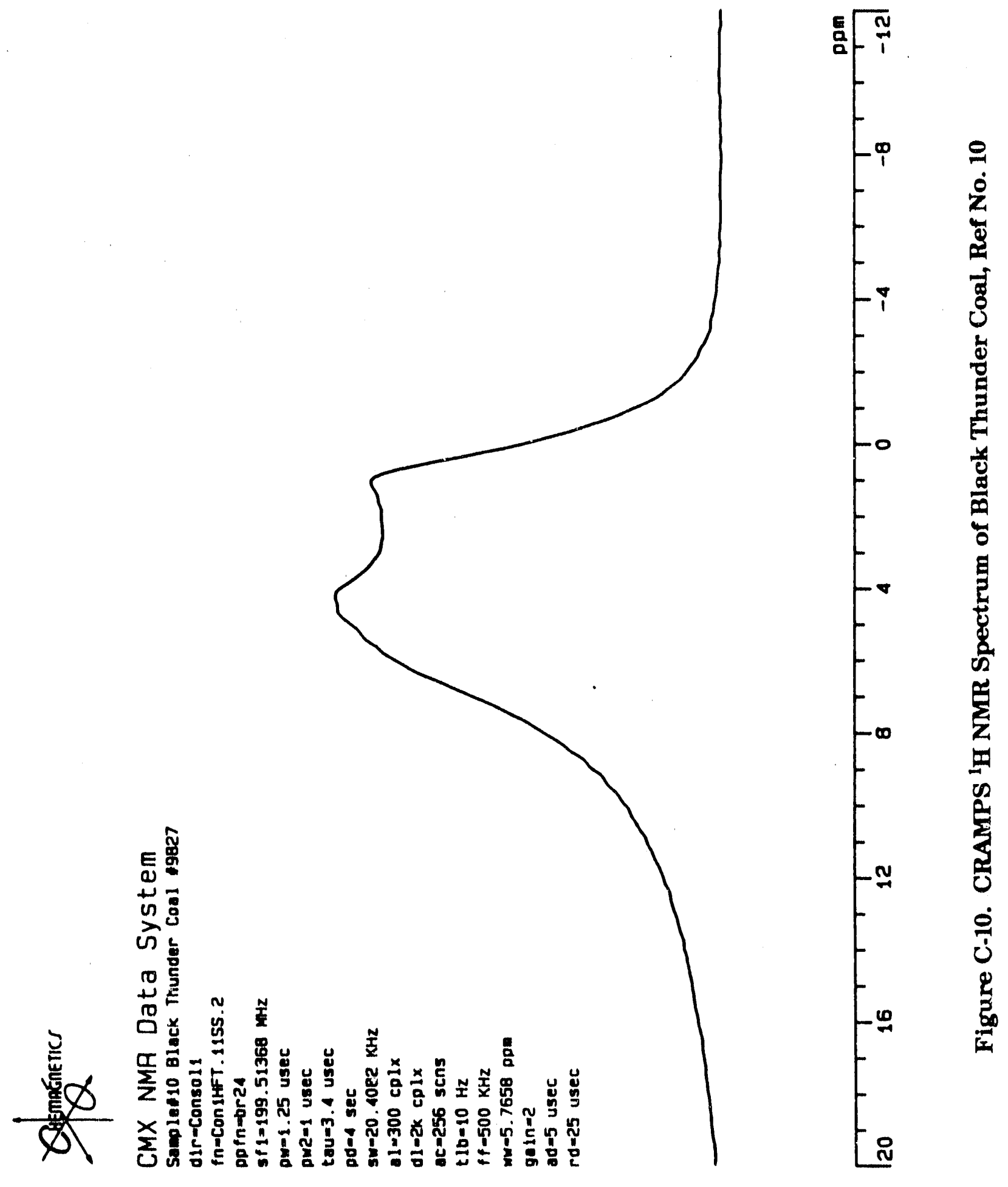




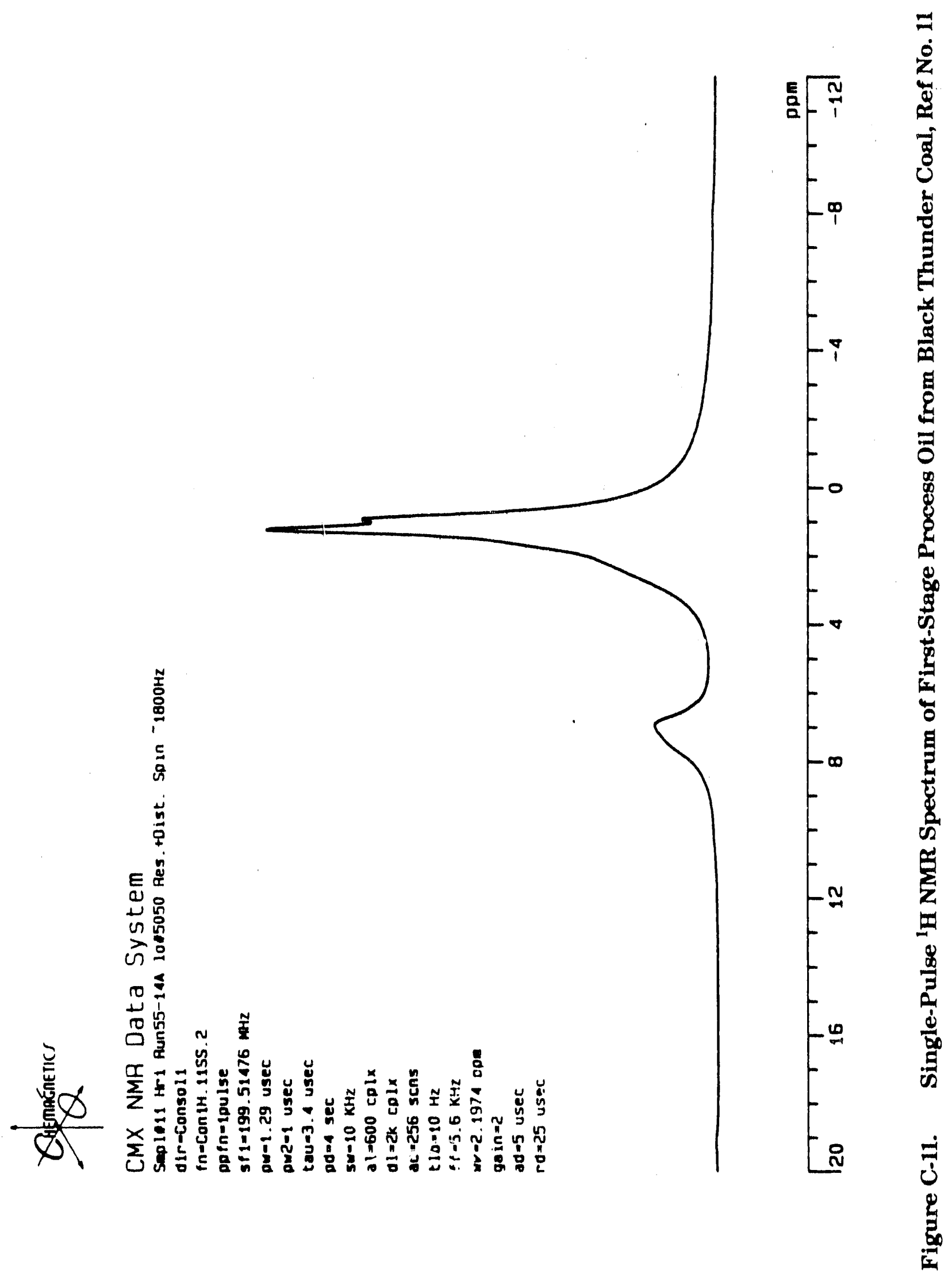




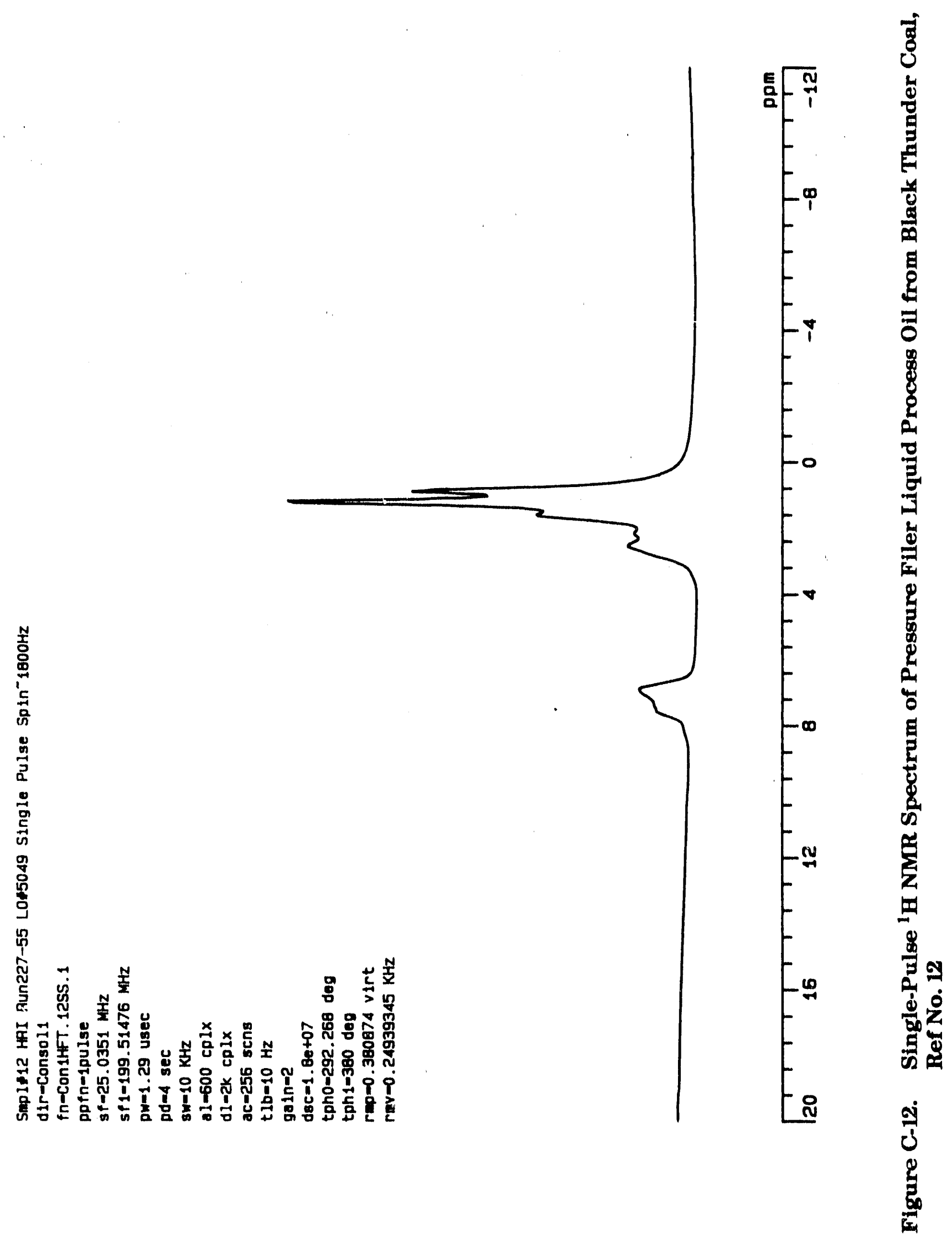




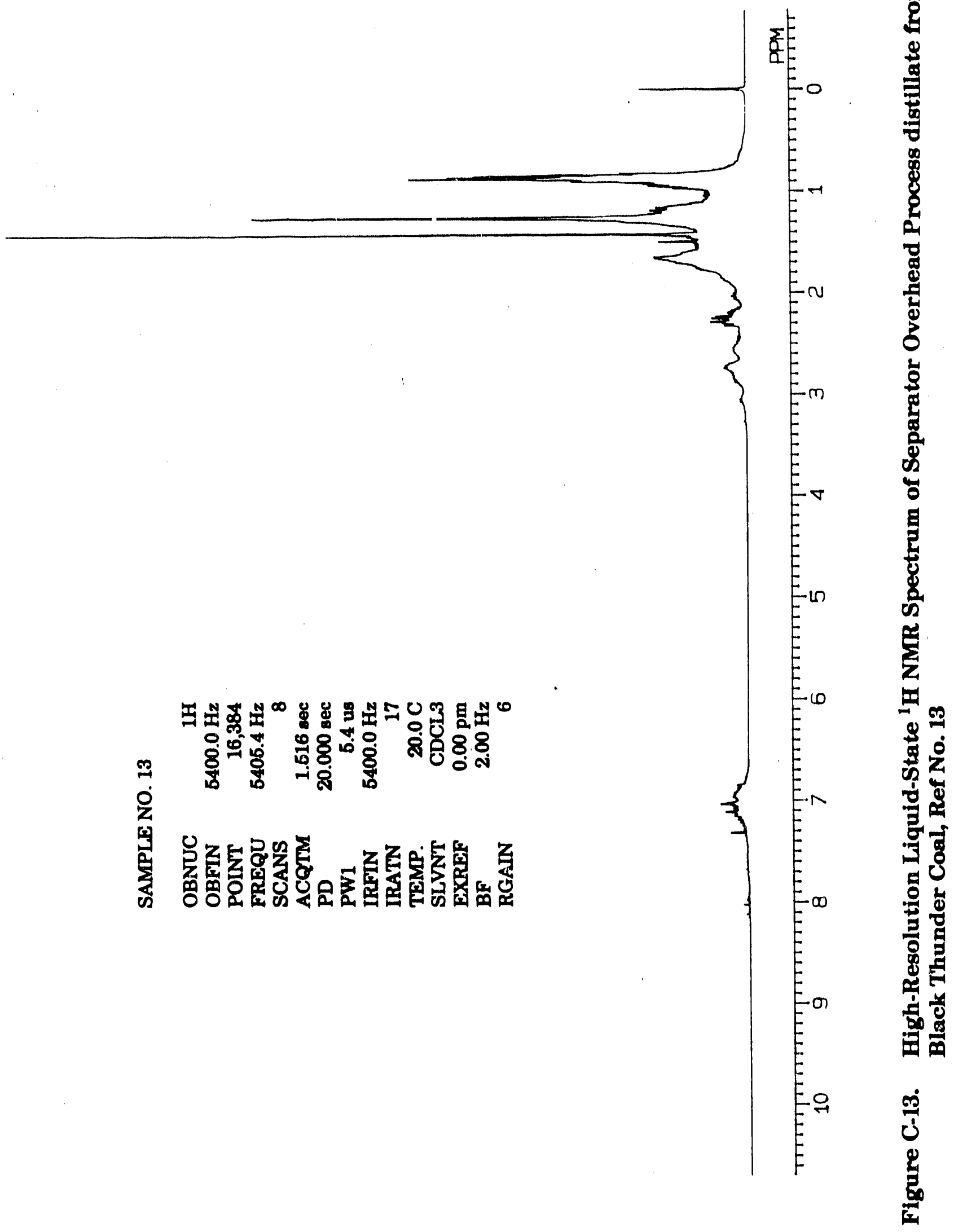




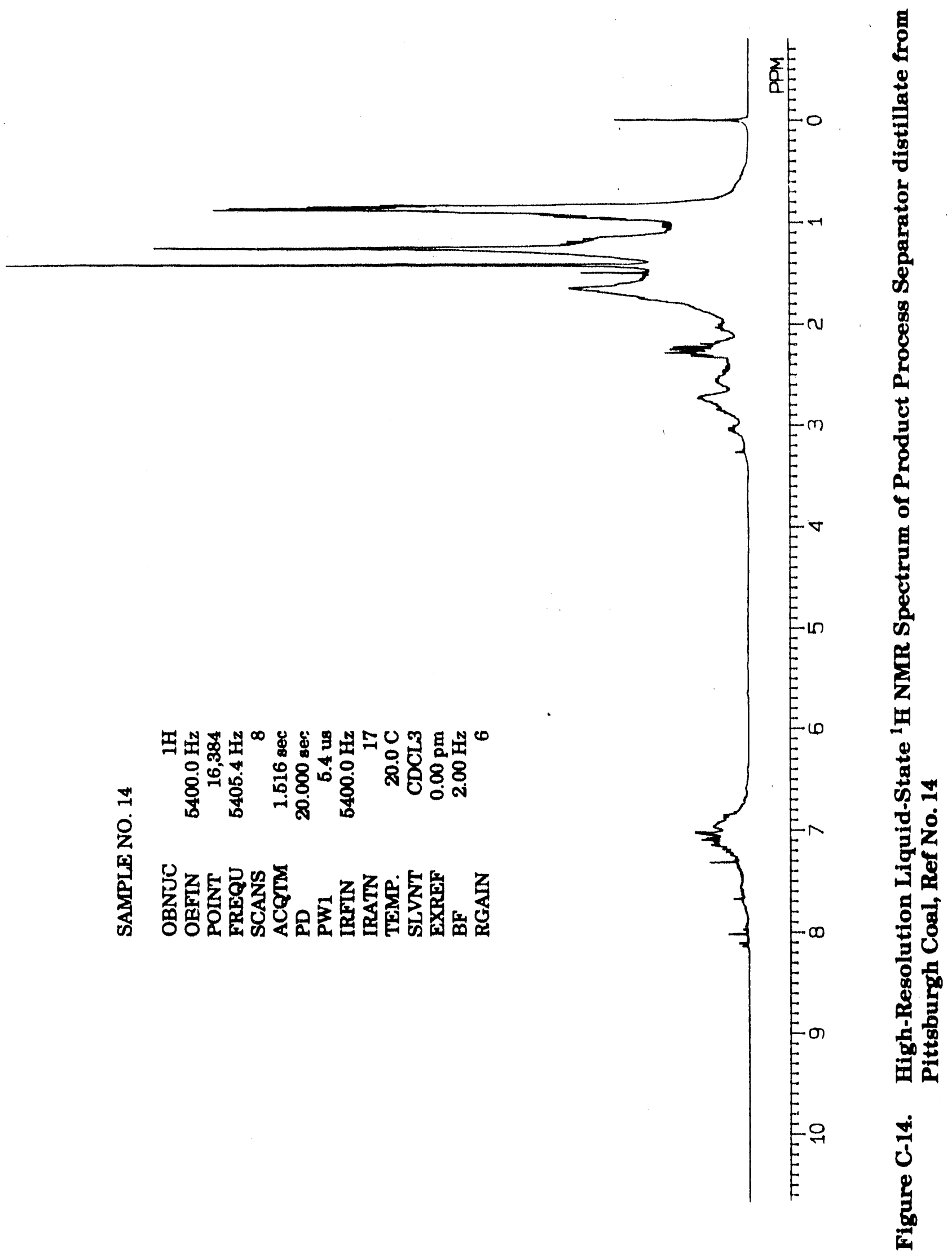




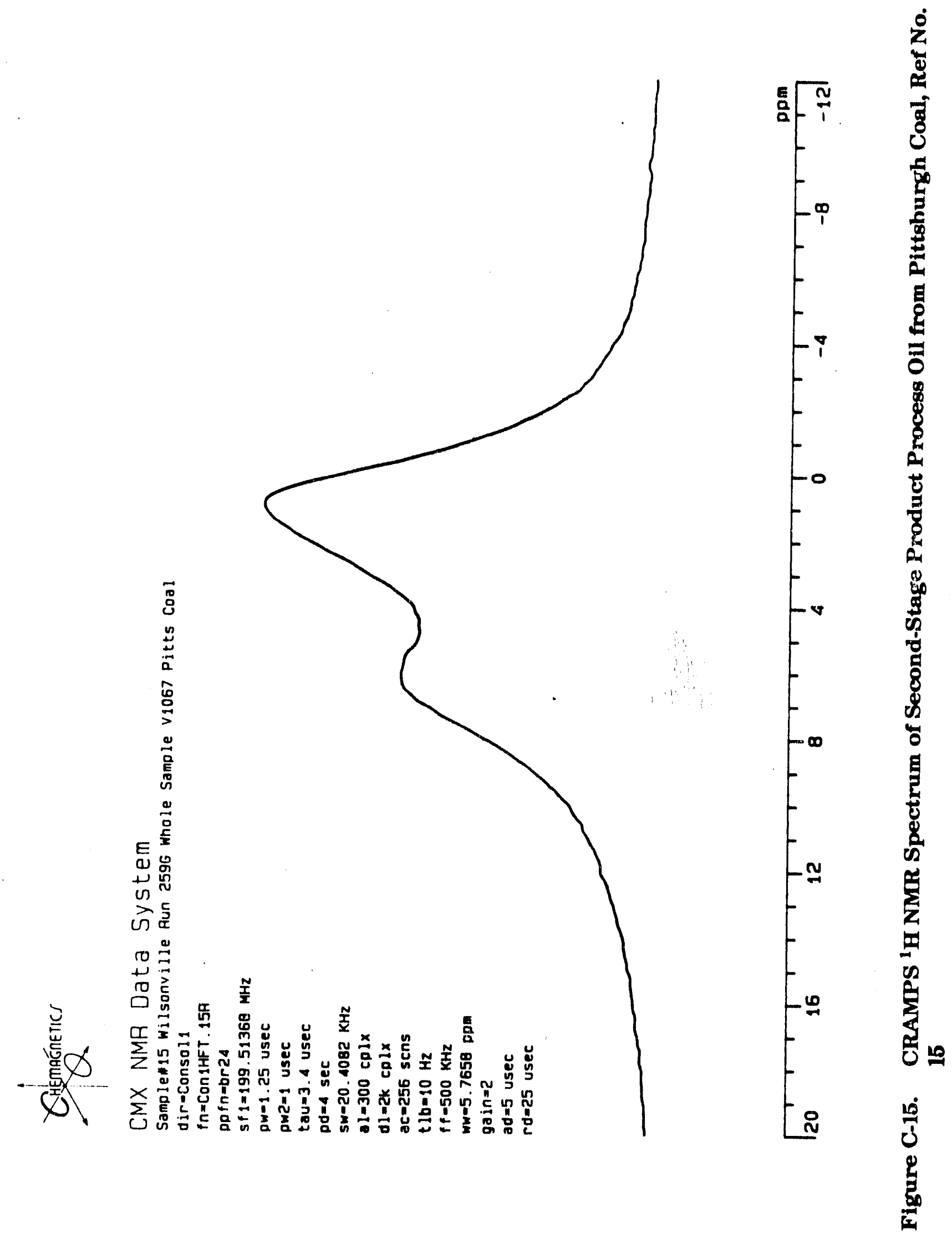




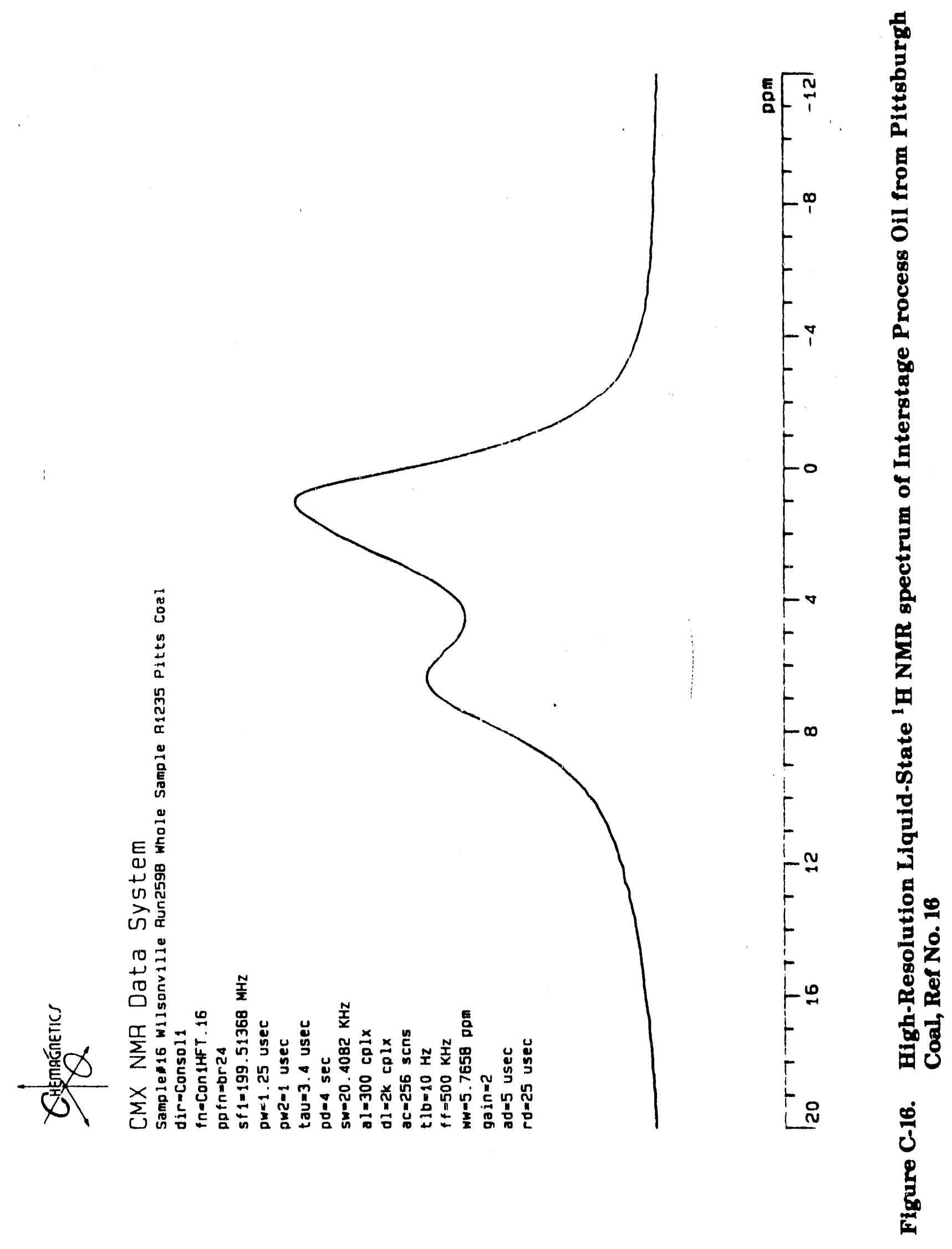




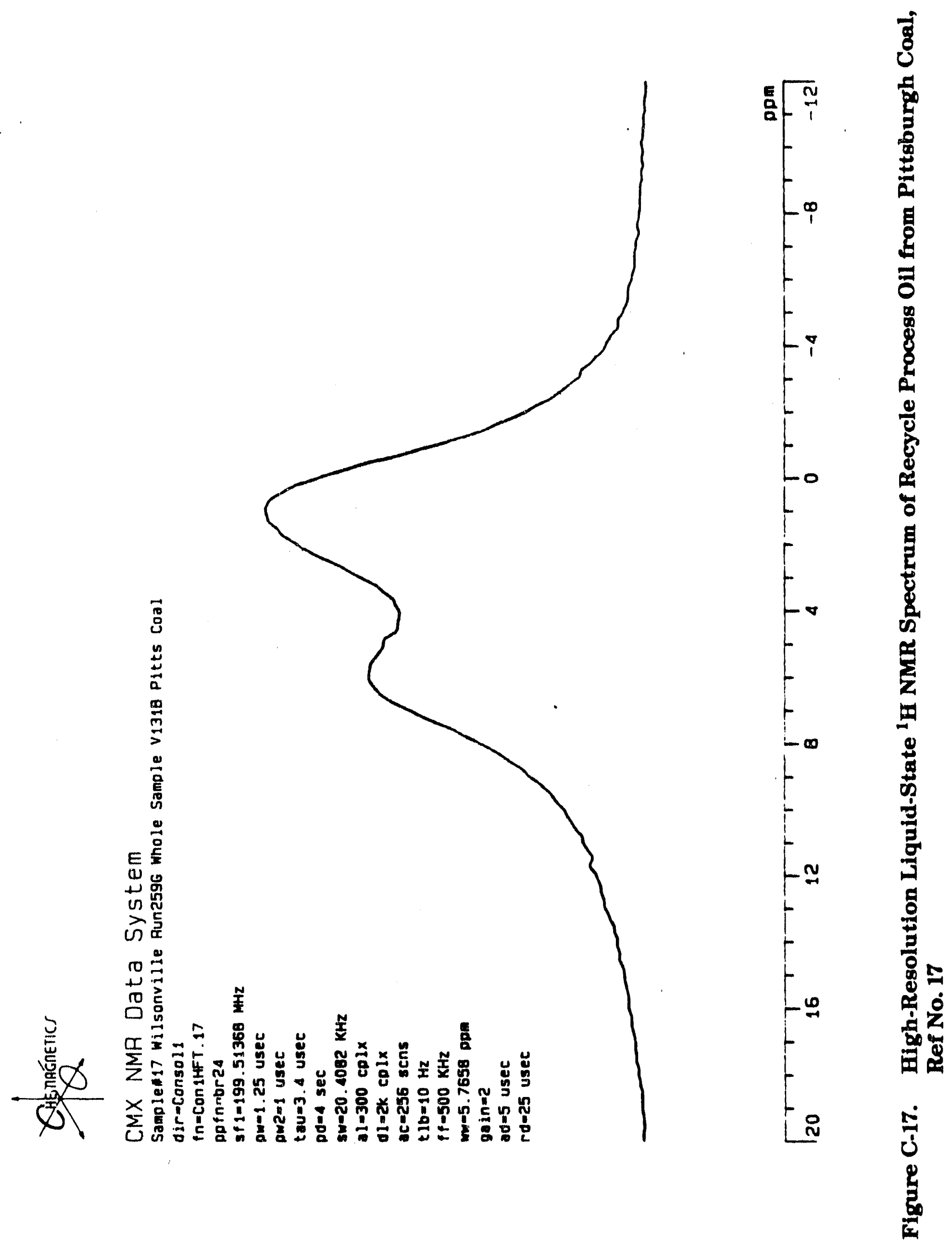




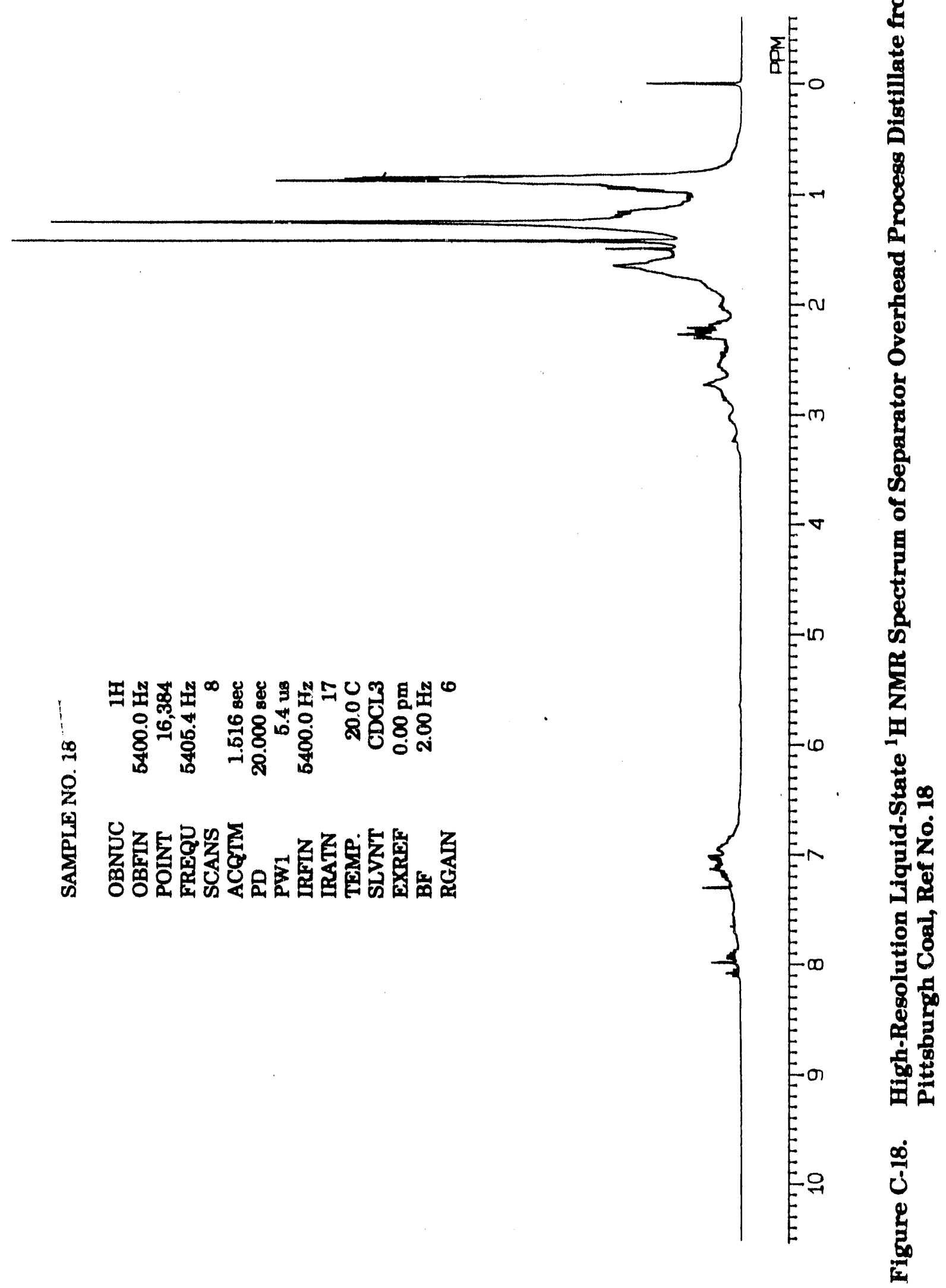



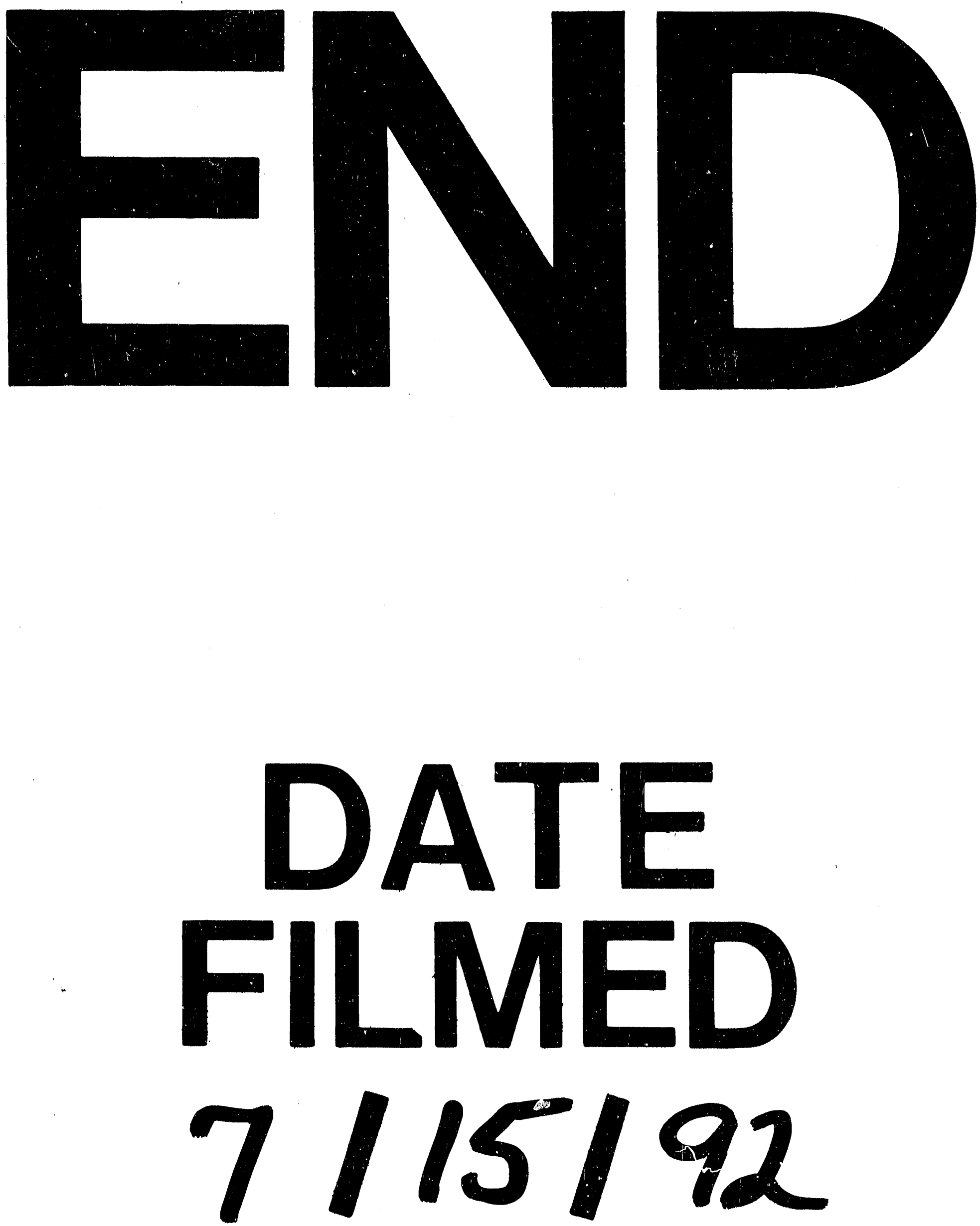
